\title{
SIMULAÇÃO BIDIMENSIONAL DA DINÂMICA DA ÁGUA EM UM SULCO DE IRRIGAÇÃO
}

\author{
EDUARDO PINHEIRO DE FREITAS
}

Engenheiro Agrônomo

Orientador: Prof. Dr. TARLEI ARRIEL BOTREL

Tese apresentada à Escola Superior de Agricultura "Luiz de Queiroz", da Universidade de São Paulo, para obtenção do título de Doutor em Agronomia, área de concentração: Irrigação e Drenagem.

PIR A C I C A B A

Estado de São Paulo - Brasil

Abril - 1996 
Freitas, Eduardo Pinheiro de

Simulação bidimensional da dinâmica da água em um sulco de irrigação / Eduardo Pinheiro de Freitas. Piracicaba, 1996.

109p. : il

Tese (doutorado) Escola Superior de Agricultura Luiz de Queiroz, 1996. Bibliografia.

1. Água no solo - Dinâmica - Simulação automatizada 2. Irrigação por sulco 3. Modelo matemático I. Título

CDD 631.7 


\title{
SIMULAÇÃO BIDIMENSIONAL DA DINÂMICA DA ÁGUA EM UM SULCO DE IRRIGAÇÃO
}

\author{
EDUARDO PINHEIRO DE FREITAS
}

Aprovada em: 19.04.1996

Comissão julgadora:

Prof. Dr. Tarlei Arriel Botrel

ESALQ/USP

Prof, Dr. José Antônio Frizzone

ESALQ/USP

Prof. Dr. Márcio Mota Ramos

UFV

Prof. Dr. Carlos Alberto Vieira de Azevedo

UFPB

Prof. Dr. Vital Pedro da Silva Paz

UFPB

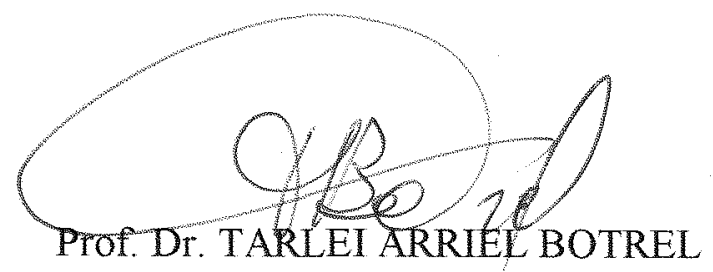

Orientador 
Aos meus pais

Levítico e Tereza

pelo que com sacrificio proporcionaram

Dedico este Trabalbo!

À minha esposa e à minha filha

Cilay e Daniela

significado superlativo 


\section{AGRADECIMENTOS}

Ao Prof. Dr. Tarlei Arriel Botrel, pela confiança, companheirismo, ensinamentos e orientação recebidos na estada como aluno do curso de pós-graduação.

Aos funcionários do Departamento de Engenharia Rural, cujos préstimos foram fundamentais nos trabalhos de campo e de laboratório.

Aos colegas de curso, alunos e professores, cujo dia-a-dia compartilhado inspirou idéias que resultaram em enobrecimento social e intelectual.

Ao Conselho Nacional de Desenvolvimento Científico e Tecnológico (CNPq) e à Coordenação de Aperfeiçoamento de Pessoal de Ensino Superior (CAPES), pela contribuição na forma de bolsa de estudos.

A todos outros, que de alguma forma particular garantiram o sucesso deste trabalho. 


\section{SUMÁRIO}

Página

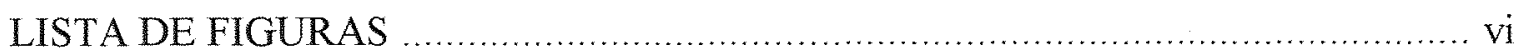

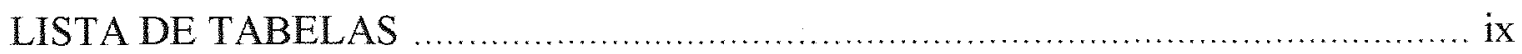

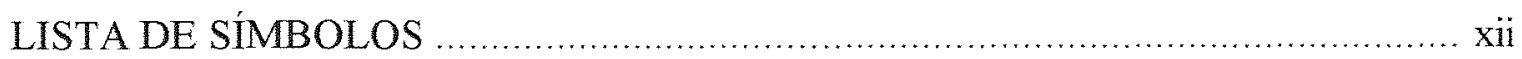

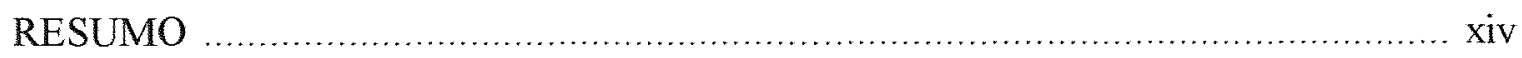

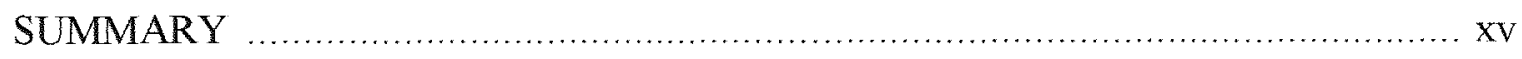

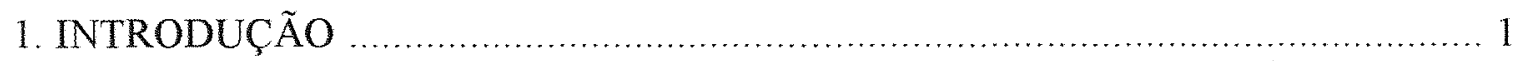

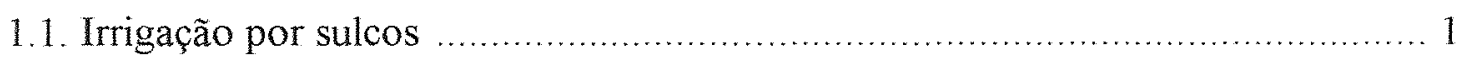

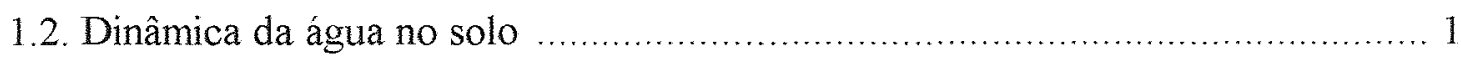

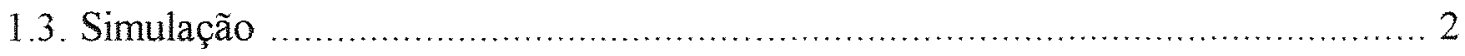

1.4. A união irrigação por sulcos - dinâmica da água no solo - simulação ……....... 3

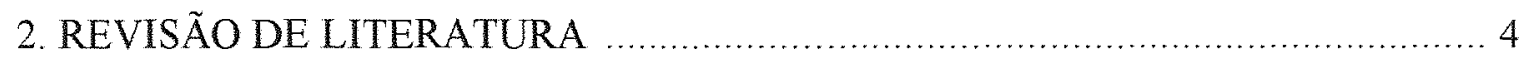

2.1. O método de irrigação por sulcos ……..................................................... 4

2.2. Primeiros estudos quanto à dinâmica da água em solos não saturados .............. 6

2.3. Considerações quanto à condutividade hidráulica do solo …........................ 7

2.4. Considerações quanto ao potencial total da água no solo ............................ 10

2.5. Limitações à validade da equação de Buckingham-Darcy ............................ 11

2.6. Modelagem do fluxo de água em solos não saturados ……......................... 12

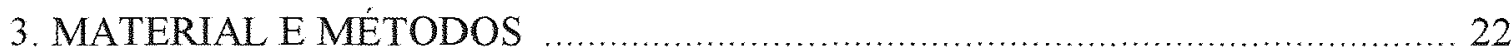

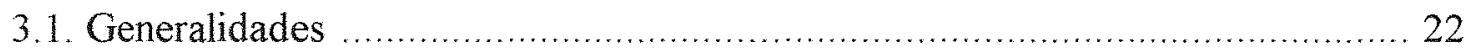

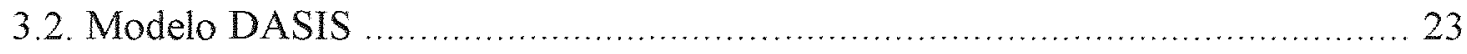

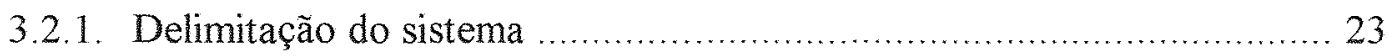

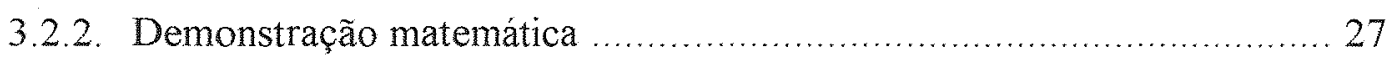

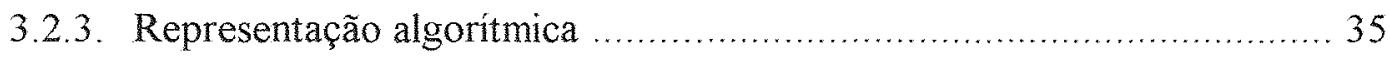


Página

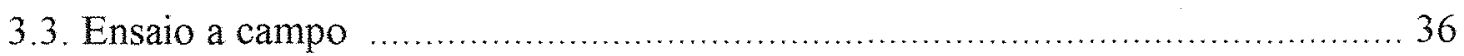

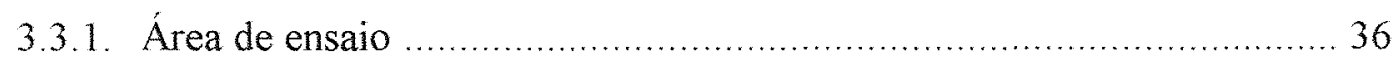

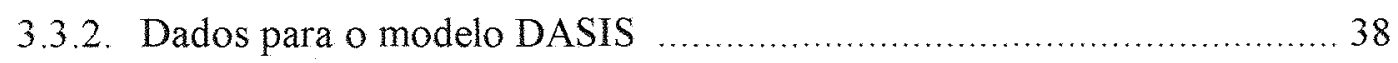

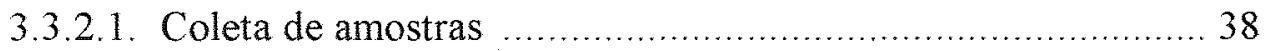

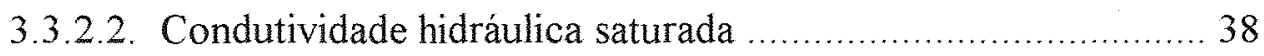

3.3.2.3. Massa específica do solo e curva de retenção ....................... 39

3.3.2.4. Teor de água inicial no solo ............................................. 42

3.3.2.5. Perfil transversal do sulco ............................................. 43

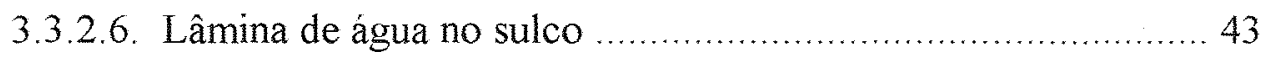

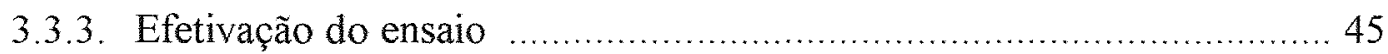

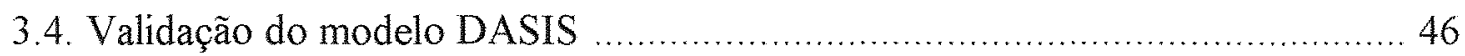

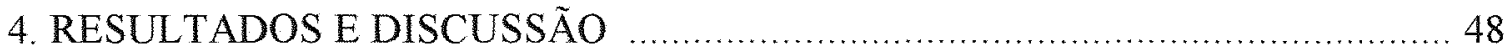

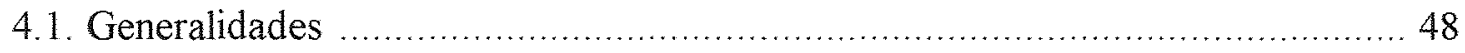

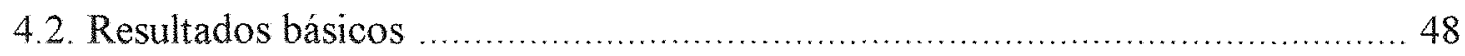

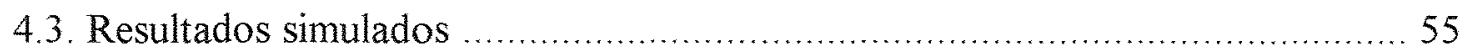

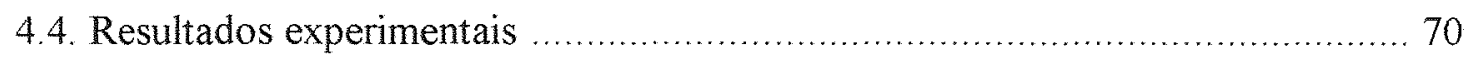

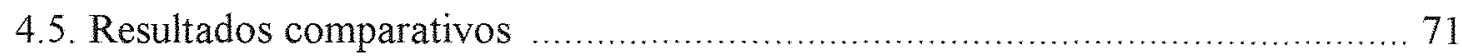

5. CONCLUSÕES E RECOMENDAÇÕES …............................................... 74

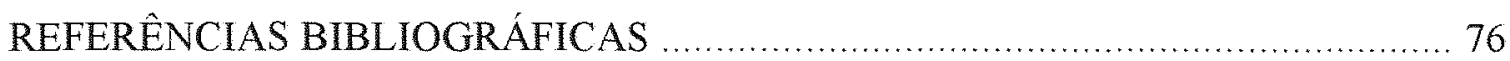

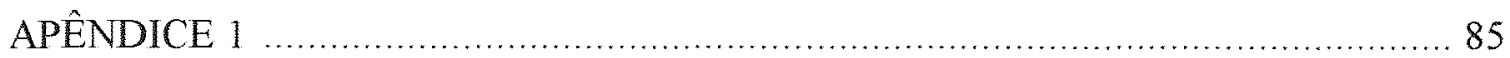

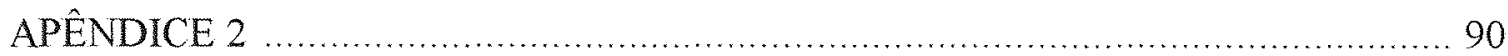




\section{LISTA DE FIGURAS}

Página

Figura 1. Esquema da compartimentação utilizada na definição do perfil computacional, com posicionamento das linhas de contomo e radiais, e orientação quanto aos eixos cartesianos, com origem à superficie do perfil no ponto médio da largura de topo do sulco.

Figura 2. Relacionamento entre o contorno original e o contorno ajustado do sulco, originando a base para a definição das demais linhas de contorno.

Figura 3. Comvenção adotada para o posicionamento dos limites dos compartimentos, apresentando também a forma pela qual obtém-se as distâncias, a partir do baricentro, até tais limites, exemplificando para um compartimento $C$ qualquer.

Figura 4. Esquema da estrutura utilizada no ensaio a campo.

Figura 5. Comportamento dos valores de condutividade hidráulica saturada em função da profundidade no perfil ensaiado.

Figura 6. Comportamento dos valores de massa especifica do solo em função da profundidade no perfil ensaiado.

Figura 7. Curvas de retenção de água no solo do perfil ensaiado.

Figura 8. Perfis transversais do sulco ao inicio de cada um dos ensaios realizados.

Figura 9. Comportamento da altura da lamina de água dentro do sulco em função tempo após início de aplicação de água, para cada um dos ensaios.

Figura 10a. Algoritmo simplificado do modelo DASIS (corpo principal). 
Página

Figura 10b. Algoritmo simplificado do modelo DASIS (procedimento LIMITE_ 2). ... 52 Figura 10c. Algoritmo simplificado do modelo DASIS (procedimento LIMITE_1) ... 53

Figura 11. Padrão de distribuição de água no perfil computacional para o Ensaio I (volume de água aplicado simulado igual a $0,0707 \mathrm{~m}^{3} \cdot \mathrm{m}^{-1}$ ).

Figura 12. Padrão de distribuição de água no perfil computacional para o Ensaio II (volume de água aplicado simulado igual a $0,0279 \mathrm{~m}^{3} \cdot \mathrm{m}^{-1}$ ).

Figura 13. Padrão de distribuição de água no perfil computacional para o Ensaio III (volume de água aplicado simulado igual a $0,0181 \mathrm{~m}^{3} \cdot \mathrm{m}^{-1}$ ).

Figura 14. Padrão de distribuição de água no perfil computacional para o Ensaio IV (volume de água aplicado simulado igual a $0,0222 \mathrm{~m}^{3} \cdot \mathrm{m}^{-1}$ ). 64

Figura 15. Padrão de distribuição de água no perfil computacional para o Ensaio $\mathrm{V}$ (volume de água aplicado simulado igual a $0,0269 \mathrm{~m}^{3} \cdot \mathrm{m}^{-1}$ ).

Figura 16. Comportamento do volume de água infiltrado no solo por anidade de comprimento de sulco e da velocidade de infiltração, em função do tempo após inicio de aplicação de água ao sulco, para a simulação referente ao Ensaio I (volume de água aplicado simulado igual a $\left.0,0707 \mathrm{~m}^{3} \cdot \mathrm{m}^{-1}\right)$

Figura 17. Comportamento do volume de água infiltrado no solo por unidade de comprimento de sulco e da velocidade de infiltração, em função do tempo após início de aplicação de água ao sulco, para a simulação referente ao Ensaio II (vohme de água aplicado simulado igual a $\left.0,0279 \mathrm{~m}^{3} \cdot \mathrm{m}^{-1}\right)$ 
Página

Figura 18. Comportamento do volume de água infiltrado no solo por unidade de comprimento de sulco e da velocidade de infiltração, em função do tempo após início de aplicação de água ao sulco, para a simulação referente ao Ensaio III (volume de água aplicado simulado igual a $\left.0,0181 \mathrm{~m}^{3} \cdot \mathrm{m}^{-1}\right)$.

Figura 19. Comportamento do volume de água infiltrado no solo por unidade de comprimento de sulco e da velocidade de infiltração, em função do tempo após início de aplicação de água ao sulco, para a simulação referente ao Ensaio IV (volume de água aplicado simulado igual a $\left.0,0222 \mathrm{~m}^{3} \cdot \mathrm{m}^{-1}\right)$. 68

Figura 20. Comportamento do volume de água infiltrado no solo por unidade de comprimento de sulco e da velocidade de infiltração, em função do tempo após início de aplicação de água ao sulco, para a simulação referente ao Ensaio V (volume de água aplicado simulado igual a $\left.0,0269 \mathrm{~m}^{3} \cdot \mathrm{m}^{-1}\right)$.

Figura 21. Comparação entre teores de água no solo com base em volume observados a campo e simulados, correspondentes aos três pontos amostrados dos cinco ensaios realizados. 


\section{LISTA DE TABELAS}

Página

Tabela 1. Informações referentes ao perfil de solo ensaiado, com respectivas características fisicas e químicas. 36

Tabela 2. Coeficientes das curvas de retenção de água, referentes aos pares de dados de potencial matricial versus teor de água no solo em base de volume, em função da profundidade, para o perfil ensaiado.

Tabela 3. Teores de água iniciais no solo em função da profundidade, referente a cada um dos ensaios realizados.

Tabela 4. Tempo consumido em processamento, volume simulado de água infiltrado por unidade de comprimento de sulco e variação entre volume simulado de água infiltrado e volume aplicado a campo, em função do múmero de linhas radiais, de linhas de contorno, e da variação permitida no teor de água dentro de um laço de simulação, referente ao Ensaio I (volume de água aplicado igual a $0,060 \mathrm{~m}^{3} \cdot \mathrm{m}^{-1}$ ),

Tabela 5. Tempo consumido em processamento, volume simulado de água infiltrado por unidade de comprimento de sulco e variação entre volume simulado de água infiltrado e volume aplicado a campo, em função do mimero de linhas radiais, de linhas de contorno, e da variação permitida no teor de água dentro de um laço de simulação, referente ao Ensaio II (volume de água aplicado igual a $0,030 \mathrm{~m}^{3} \cdot \mathrm{m}^{-1}$ ). 
Página

Tabela 6. Tempo consumido em processamento, volume simulado de água infiltrado por unidade de comprimento de sulco e variação entre volume simulado de água infiltrado e volume aplicado a campo, em função do mimero de linhas radiais, de linhas de contorno, e da variação permitida no teor de água dentro de um laço de simulação, referente ao Ensaio III (volume de água aplicado igual a $\left.0,020 \mathrm{~m}^{3} \cdot \mathrm{m}^{-1}\right)$

Tabela 7. Tempo consumido em processamento, volume simulado de água infiltrado por unidade de comprimento de sulco e variação entre volume simulado de água infiltrado e volume aplicado a campo, em função do múmero de linhas radiais, de linhas de contorno, $e$ da variação permitida no teor de água dentro de um laço de simulação, referente ao Ensaio IV (volume de água aplicado igual a $\left.0,024 \mathrm{~m}^{3} \cdot \mathrm{m}^{-1}\right)$

Tabela 8. Tempo consumido em processamento, volume simulado de água infiltrado por unidade de comprimento de sulco e variação entre volume simulado de água infiltrado e volume aplicado a campo, em função do mumero de linhas radiais, de linhas de contorno, e da variação permitida no teor de água dentro de um laço de simulação, referente ao Ensaio V (volume de água aplicado igual a $\left.0,026 \mathrm{~m}^{3} \cdot \mathrm{m}^{-1}\right)$. 
Página

Tabela 9. Teores de água com base em volume no perfil computacional, correspondentes a cada ponto de amostragem. 66

Tabela 10. Teores de água com base em volume no perfil de solo, para cada ponto de amostragem.

Tabela 11. Resumo estatistico das comparações entre valores experimentais $e$ simulados para os perfis de teor de água no solo, referente aos cinco ensaios realizados. 


\section{LISTA DE SIMBOLOS}

$A_{n} \quad$ área disponível ao fluxo no limite $n$

$c \quad$ índice para o número de ordem da camada no perfil computacional

C número de camadas no perfil computacional

DI distância da linha de contorno de ordem 1 à de ordem $I$ sobre a linha radial

$d_{n}$ distância entre baricentros de um compartimento e seu conexo quanto ao limite $n$

$d_{n^{\prime}} \quad$ distância entre o baricentro do compartimento e o ponto médio da face no limite $n$

$d_{n}{ }^{\prime \prime} \quad$ distância entre a face no limite $n$ e o baricentro do compartimento conexo

$f \quad$ índice para o número de ordem da fatia

F número total de fatias no perfil computacional

i indice para o número de ordem da linha de contorno

I número de ordem da linha de contorno

$K \quad$ condutividade hidráulica no compartimento $\quad$ L.T $T^{-1}$

$K_{n} \quad$ condutividade hidráulica no compartimento conexo quanto ao limite $n \quad$ L.T ${ }^{-1}$

$\bar{K}_{n} \quad$ condutividade hidráulica média entre um compartimento e seu conexo quanto ao limite $n$

$\begin{array}{lll}K_{S} & \text { condutividade hidráulica em condição de solo saturado } & \text { L. T } \\ & -1\end{array}$

$m \quad$ coeficiente de ajuste da equação de van Genuchten

$n \quad$ indice para os limites de um compartimento

PP profundidade do perfil computacional

Q quantidade de água infiltrada no intervalo de tempo 
$q_{n} \quad$ densidade de fluxo através do limite $n \quad$ L.T ${ }^{-1}$

$T$ tempo transcorrido a partir do início da simulação $\quad$ T

$V \quad$ volume do compartimento $\quad \mathrm{L}^{3}$

$V I \quad$ velocidade de infiltração $\quad$ L. T ${ }^{-1}$

$\alpha \quad$ coeficiente de ajuste da equação de van Genuchten $\quad L^{-1}$

$\begin{array}{ll}\Delta t \quad \text { intervalo de tempo } & \mathrm{T}\end{array}$

$\Delta \Phi_{n}$ diferença de potencial total entre um compartimento e seu conexo quanto ao limite $n$

$\Delta \theta \quad$ variação permitida no teor de água dentro de um laço de simulação

$\Phi m$ potencial matricial no compartimento $\quad$ L

$\Phi m_{n}$ potencial matricial no compartimento conexo quanto ao limite $n \quad \mathrm{~L}$

$\Phi p_{1}$ potencial de pressão à superfície do sulco $\quad \mathrm{L}$

$\Phi z \quad$ potencial gravitacional no baricentro do compartimento L

$\Phi z_{n}$ potencial gravitacional no baricentro do compartimento conexo quanto ao limite $n$

$\eta \quad$ coeficiente de ajuste da equação de van Genuchten

$\Theta \quad$ teor de água adimensional

$\theta$ teor de água com base em volume para confecção da curva de retenção

$\theta_{f}$ teor de água final com base em volume no compartimento após um intervalo de tempo

$\theta_{i} \quad$ teor de água inicial com base em volume no compartimento

$\theta_{r} \quad$ teor de água residual com base em volume

$\theta_{S} \quad$ teor de água no solo saturado com base em volume 


\title{
SIMULAÇÃO BIDIMENSIONAL DA DINÂMICA DA ÁGUA EM UM SULCO DE IRRIGAÇÃO
}

\author{
Autor: EDUARDO PINHEIRO DE FREITAS \\ Orientador: Prof. Dr. TARLEI ARRIEL BOTREL
}

\section{RESUMO}

Condensando conhecimentos quanto à irrigação por sulcos, à dinâmica da água no solo e à simulação, confeccionou-se um modelo computacional que torna possível a estimativa dos padrões de distribuição de teor de água em solos irrigados por sulcos, quantificando o volume infiltrado e definindo a lei de infiltração.

Consistindo basicamente da aplicação das equações de BuckinghamDarcy e da Continuidade em uma representação computacional do perfil de solo, utilizando um procedimento explícito de linearização, e aliadas a condições iniciais e de contorno, o modelo identificado como DASIS (Dinâmica da Água em Solo Irrigado por Sulco) foi compilado em linguagem de programação Pascal e aplicado às condições referentes a cinco ensaios realizados a campo.

As comparações entre resultados experimentais e simulados mostram que o modelo DASIS, para as condições estudadas, simula os perfis de teor de água no solo de forma aceitável à utilização prática, podendo ser utilizado no dimensionamento e manejo de sistemas de irrigação por sulcos. 


\title{
BIDIMENTIONAL SIMULATION OF THE WATER DYNAMIC IN A FURROW OF IRRIGATION
}

\author{
Author: EDUARDO PINHEIRO DE FREITAS \\ Adviser: Prof. Dr. TARLEI ARRIEL BOTREL
}

\section{SUMMARY}

Condensing knowledges about furrow irrigation, water dynamic and simulation, was made a computational model which allows estimation of moisture distribution patterns, estimated in furrow irrigated soils, water volume infiltrated and the assessment of an infiltration law.

Consisting mainly in the Buckingham-Darcy and Continuity equations application in a soil profile computational representation, using an explicit procedure of linearization, and allied to initial and boundary conditions, the model identifyed as DASIS (Water Dynamic in Furrow Irrigated Soil) was compiled in Pascal language and applied to conditions concerning five tests achieved in tag field.

The comparisons between experimental and simulated results show that the DASIS model, for the studied conditions, simulate fair well the soil moisture profiles to practical use, and that it can be used in design and handling of the furrow irrigation systems. 


\section{INTRODUÇÃO}

\subsection{Irrigação por sulcos}

O método de irrigação por sulcos, quando comparado a outros, ocupa área relativamente grande a nível mundial, adaptando-se bem às culturas plantadas em linha, contudo Kay (1989) o considera pouco pesquisado.

A infiltração da água no solo representa o principal processo envolvido no dimensionamento, operação, manejo e avaliação da irrigação por sulcos, controlando a quantidade de água que penetra no perfil e o avanço da água sobre o sulco. Frizzone (1993) comenta ainda que este processo afeta o desempenho do sistema, pois influencia todas as fases da irrigação, porém, juntamente com a rugosidade da superficie de escoamento, constituem os fatores mais dificeis de serem determinados com precisão. Uma análise mostra que a declividade, a resistência ao escoamento e a altura da lâmina de água sobre a superficie do solo influenciam a infiltração.

\subsection{Dinâmica da água no solo}

Objetivando evitar interpretações ambíguas no que se refere ao assunto abordado, assume-se que a palavra água deve ser entendida como sinônimo de solução do solo, e não unicamente como o componente água presente nesta solução. 
Neste tópico, assume-se que a dinâmica da água no solo contempla, em seus devidos momentos, os fenômenos da infiltração e da redistribuição. Tais fenômenos, como citados por Campbell (1985), afetam profundamente o balanço de água no solo, sendo governados principalmente pelas propriedades hidráulicas do solo, com a condutividade hidráulica e o potencial total representando, respectivamente, a habilidade na transmissão de água no material poroso e a força responsável pelo movimento.

Considera-se que o movimento da água ocorre em condições de temperatura constante, a uma pressão, na fração gasosa do meio poroso, constante e igual à atmosférica e com a fração sólida rígida, não havendo gradientes outros que não devido às forças matriciais, gravitacionais e de pressão da coluna líquida. Além disso, as propriedades hidráulicas do solo, condutividade hidráulica e potencial matricial, são assumidas univocas, não dependendo do histórico de molhamento e secagem ocorrido.

\subsection{Simulação}

Um significado para a palavra simular, apresentado por Naylor et al. (1971), é "... a ação de transformar e manipular simples informações acerca de um determinado sistema, resultando em algo de relativa equivalência a este, mas de caráter geralmente matemático, formando o que se conhece por modelo de simulação ...". Desta forma, pode-se deduzir conseqüências quanto às hipóteses elaboradas sobre tal sistema, o que poderia ser dificil de realizar, ou pela impraticabilidade ou impossibilidade de uma verificação experimental.

É prática um tanto comum trabalhar-se com modelos de simulação nos vários campos da ciência, impulsionada pela extrema rapidez no desenvolvimento de ferramentas computacionais, que por muito limitou o uso prático dos modelos até então 
existentes. Aliado a isto, o surgimento de novos métodos numéricos tem facilitado o tratamento matemático de equações complexas, sendo um dos campos da Matemática que mais se desenvolve atualmente.

\subsection{A união irrigação por sulcos - dinâmica da água no solo - simulação}

A simulação do movimento da água em solos irrigados por sulcos, torna possível estimativas mais consistentes do comportamento que um solo venha a apresentar quando irrigado por este método, mesmo na fase de planejamento, resultando em subsídios para um dimensionamento melhor elaborado.

Tendo em mente tais considerações, confeccionou-se um modelo de simulação para computador que facilita o entendimento da dinâmica da água em solos irrigados por sulcos, envolvendo infiltração e redistribuição, tratando condições de fronteira de seção transversal irregular e altura variável da lâmina de água sobre o sulco, confecção esta viabilizada pela já existência de certos modelos de aplicação geral, alguns poucos relacionados com o presente problema, ou para outras situações que não esta.

Esse modelo foi analisado quanto aos erros sistemáticos existentes, definindo as condições iniciais e de contorno mais adequadas à simulação quanto à exatidão e requerimento de tempo de processamento. Os termos de comparação utilizados foram obtidos em ensaios a campo, de onde coletaram-se os dados de alimentação do modelo.

Os artificios utilizados na diminuição do tempo de processamento, caso da compartimentação crescente com o distanciamento a partir do sulco de irrigação, intervalo de tempo variável em cada laço de simulação e contorno inferior móvel, foram bastante eficientes, garantindo tempos de simulação adequados à utilização prática. 


\section{REVISÃO DE LITERATURA}

\subsection{O método de irrigação por sulcos}

Distribuindo água à área a ser irrigada através de pequenos canais não revestidos, o método de irrigação por sulcos tem tradição de uso em vários países. De boa adaptabilidade ao relevo suave, ao tipo de solo e às culturas, em especial às cultivadas em linha, apresenta variações de tipos, sendo os sulcos em gradiente com drenagem livre os mais utilizados.

Comentando custos dos sistemas de irrigação, Frizzone (1993) cita que, geralmente, os sistemas de irrigação por superficie têm menores custos anuais de operação, incluindo custos fixos e variáveis. Alia-se a isto a simplicidade operacional, facilitando a assimilação das técnicas de manejo pelos irrigantes, a não dependência ao porte da cultura e à ocorrência de ventos, e o fato da água de baixa qualidade física, química ou biológica não impor severas restrições à utilização destes sistemas, em especial quanto à qualidade biológica, uma vez que, em geral, a água não entra em contato direto com as partes vegetais consumidas in natura.

Avanço, alimentação, depleção e recessão, bem como redistribuição, são fases da irrigação por sulcos, definidas por:

a) fase de avanço: tempo transcorrido do início do fornecimento de água ao sulco até o momento em que a frente de avanço atinja sua extremidade de jusante; 
b) fase de alimentação: tempo transcorrido do final da fase de avanço até a paralisação no fornecimento de água ao sulco;

c) fase de depleção: tempo transcorrido do final da fase de alimentação até que a água desapareça da superficie do solo na extremidade de montante do sulco;

d) fase de recessão: tempo transcorrido do final da fase de depleção até que a água desapareça da superficie do solo na extremidade de jusante do sulco;

e) fase de redistribuição: inicia, em uma seção transversal qualquer do sulco, no momento em que a água desaparece da superficie, cessando a partir da próxima irrigação, quando a frente de avanço atinge tal seção.

Considerado por Walker \& Skogerboe (1987), a infiltração é um dos parâmetros mais importantes na irrigação por sulcos, porém de dificil obtenção no campo com acurácia. Os autores discutiram a utilização de sulcos fechados para sua medição, embora reconheçam que a menor velocidade facilite a decantação das partículas, provocando maior selamento superficial. Essa descaracterização, em principio, ocorre também em sulcos abertos. Segeren \& Trout (1991) comentam que em sulcos abertos a turbulência da água causa o colapso dos agregados do solo e mantém em suspensão as particulas, que podem sedimentar formando uma camada na superficie do sulco de baixa condutividade hidráulica, comumente denominada de selamento superficial. Sua extensão depende da textura do solo, podendo reduzir a infiltração unidimensional em até $50 \%$. Observações e estudos conduzidos por Brown et al. (1988) resultaram na constatação de que uma grande parte do solo em suspensão é gerada pela ação da turbulência da água, pelo colapso de agregados de solo ou pelas forças cisalhantes.

A infiltração é inversamente relacionada com a velocidade da água no sulco, sendo que Trout (1992) justifica a conclusão quanto ao transporte e deposição de sedimentos. Comenta, também, que o efeito da velocidade da água mascara a influência 
do perimetro molhado na infiltração.

Outro fator influindo na infiltração é a temperatura da água. Obtendo variações de temperatura na água entre os extremos de um sulco, Duke (1992) comenta o efeito disto na viscosidade, sendo que para tal situação resultaria em variação na condutividade hidráulica ao longo do sulco.

As propriedades fisicas do solo, práticas culturais, condição hídrica do solo, qualidade fisica e química da água, e número de irrigações realizadas no mesmo sulco, exercem influência na infiltração (U. S. Department of Agriculture, Soil Conservation Service, 1967). Citam, "também, que o conhecimento do padrão de molhamento, ou seja, o formato do bulbo molhado no perfil, é necessário para o dimensionamento do sistema, sendo dependente da uniformidade e textura do solo.

\subsection{Primeiros estudos quanto à dinâmica da água em solos não saturados}

O estudo do movimento da água no solo, como uma especialidade da Física de Solos, pode ser considerado iniciar em 1905, quando Edgar Buckingham completou sua primeira e única pesquisa publicada sobre o comportamento estático e dinâmico da água no solo. A publicação de Buckingham¹, citado por Sposito (1986), promoveu a base física conceitual dos processos isotérmicos da água no solo. Foi ele quem definiu o que se conhece atualmente por potencial matricial, obtido em função do teor de água no solo a temperatura e pressão constantes. Além disso, inspirado nas leis de fluxo de Ohm e Fourier, postulou uma relação para o fluxo de água no solo em meio não saturado, mas em nenhum ponto de sua discussão mencionou a lei de fluxo de água, em

\footnotetext{
1BUCKINGHAM, E. Studies on the movement of soil moisture. Bur. of Soil Bull. 38, U.S. Dep. of Agric., Washington, D.C. 1907.
} 
meio poroso saturado, postulada pelo engenheiro civil Henry Darcy ${ }^{2}$. A semelhança entre as equações obtidas por Buckingham e por Darcy foi constatada posteriormente, quando esta equação de fluxo de água em solo não saturado foi denominada equação de Buckingham-Darcy. Tal equação resulta no valor da densidade de fluxo, ou seja, no volume de água que passa por unidade de área da seção transversal de um solo, por unidade de tempo, dada pelo produto do valor da função condutividade hidráulica do solo pelo seu gradiente de potencial total.

A verificação experimental da equação de Buckingham-Darcy foi realizada por Richards ${ }^{3}$. Também foi ele que obteve a equação fundamental que governa o fluxo de água, isotermicamente e isobaricamente, através do solo não saturado, resultante da incorporação da equação da Continuidade na equação de BuckinghamDarcy, conhecida hoje como equação de Richards.

A estimativa da densidade de fluxo de água, em um dado solo, ocorre sob certas considerações, a principal sendo que o sistema seja isotérmico e isobárico. Além disto, os parâmetros condutividade hidráulica e gradiente de potencial total da água revestem-se de implicações, algumas das quais são discutidas a seguir.

\subsection{Considerações quanto à condutividade hidráulica do solo}

Com o reconhecimento de que os poros ocupados por ar reduzem a área efetiva ao fluxo, com conseqüente aumento da tortuosidade do fluxo remanescente, Buckingham ${ }^{1}$ obteve que a condutividade hidráulica em solo não saturado é menor que em solo sob condição de saturação, bem como depende do teor de água ou do potencial

\footnotetext{
${ }^{2}$ DARCY, H. Les Fontaines Publiques de la Ville de Dijon. Dalmont, Paris, 1856.

${ }^{3}$ RICHARDS, L.A. Capillary conduction of liquids through porous mediums. Physics, v. 1, p.318-333, 1931.
} 
matricial do meio. Philip (1969) comenta que o valor da condutividade hidráulica decresce muito rapidamente com o decréscimo do teor de água no solo, a partir de seu valor à saturação, pelas seguintes razões: a seção transversal total disponivel ao fluxo decresce; os poros maiores são esvaziados primeiro; a probabilidade de que a água esteja em poros e fendas isoladas aumenta, havendo falta de contato hidráulico e ausência de fluxo na fase líquida.

Objetivando determinar a condutividade hidráulica, quer seja em meios porosos saturados ou não saturados, vários métodos de campo, de laboratório e que utilizam dados da curva de retenção de água no solo foram desenvolvidos. Poulovassilis et al (1988) compararam quatro modelos para a dedução da relação entre condutividade hidráulica e teor de água no solo, a partir da curva de retenção, dentre eles o de Childs \& Collis-George ${ }^{4,5}$, que foram os primeiros a explorarem tal recurso, e o de Mualem (1976), semelhante ao primeiro, mostrando uma melhor aderência aos dados experimentais. Outros trabalhos utilizando a curva de retenção de água no solo, para a obtenção da função condutividade hidráulica, estão presentes na literatura mundial, dentre eles van Genuchten (1980), que baseado no descrito por Mualem (1976) adaptou uma equação de ajuste da curva de retenção de água no solo, ao modelo de determinação da condutividade hidráulica relativa, no teor de água considerado.

Comparando a função condutividade hidráulica, obtida pela adaptação de van Genuchten (1980) ao modelo de Mualem (1976), com a função obtida pelo método do perfil instantâneo, para dois solos, um de textura média e outro arenoso, Paige \& Hillel (1993) obtiveram boa aderência. Contudo, a análise dos valores de condutividade hidráulica saturada mostraram que, com a utilização do permeâmetro de

\footnotetext{
${ }^{4}$ CHILDS, E.C. \& COLLIS-GEORGE, N. The permeability of porous materials. Proc. Roy. Soc. v.A201, p.392-405, 1950 .

${ }^{5}$ CHILDS, E.C. \& COLLIS-GEORGE, N. Movement of moisture in unsaturated soils. Trans. Int. Congr. Soil Sci., v.1, p. $1-4,1950$.
} 
Guelph, os valores obtidos foram até três vezes menores do que aqueles obtidos pelos dois outros métodos. O método do perfil instantâneo foi considerado o mais efetivo para determinar as propriedades hidráulicas do solo.

Buscando selecionar um modelo apropriado para descrever as propriedades hidráulicas do solo, Russo (1988) trabalhou com três diferentes modelos, os quais foram Mualem (1976) adaptado por van Genuchten (1980), Brooks \& Corey ${ }^{6}$, e uma adaptação de Gardner (1958), obtendo resultados bastante acurados e consistentes com os dados experimentais quando da utilização do primeiro.

Assumindo ser necessário o conhecimento da função condutividade hidráulica, dois fatores são considerados por Alexander \& Skaggs (1986) importantes na escolha do método de estimativa, o primeiro sendo qual parte da curva é mais importante ter valores acurados na modelagem do fenômeno de interesse, e a segunda baseia-se na não exatidão dos métodos de estimativa, onde pergunta-se se é melhor subestimar ou superestimar os valores de condutividade hidráulica em uma dada aplicação. Os autores chegaram à conclusão de que a adaptação de van Genuchten (1980) ao modelo de Mualem (1976) tende a subestimar os valores em toda a curva, para a maioria dos solos estudados

Afetando a condutividade hidráulica, a histerese foi tema para Poulovassilis $(1969,1970)$, que obteve resultados experimentais com diferenças acima de 100\% entre valores de condutividade hidráulica, para um mesmo teor de água no solo, mas produto de diferentes históricos de molhamento e secagem. A uma constatação semelhante chegaram Poulovassilis \& Tzimas (1975).

Acerca da possibilidade de histerese na função condutividade hidráulica em relação ao teor de água no solo, alguns autores, como Nielsen \& Biggar (1961) e

${ }^{6}$ BROOKS, R.H. \& COREY, A.T. Hydraulic properties of porous media. Hydrol. Pap. 3, Colo. State Univ, Fort Collins, 1964. 
Topp \& Miller (1966), consideraram-na relativamente de pouca importância. Contudo, Philip (1969) afirma que tal função não pode, em qualquer caso, fazer parte da classe dos fenômenos não histeréticos da água no solo.

Outro método de estimativa da função condutividade hidráulica do solo é com a utilização de relacionamento com propriedades do solo, como distribuição dos tamanhos das partículas, densidade do solo, porosidade efetiva, quantidade de matéria orgânica, sendo que Wösten \& van Genuchten (1988) e Jabro (1992) obtiveram resultados promissores trabalhando com este método.

\subsection{Considerações quanto ao potencial total da água no solo}

A água, em solos não saturados, não está "livre" no sentido termodinâmico, devido à capilaridade e à adsorção, sendo a última significante em solos com baixos teores de água. Philip (1969) considera também que, para meios não saturados, o potencial total pode ser reconhecido, de uma maneira simplista, como compreendendo o potencial matricial e o potencial gravitacional.

A água flui em resposta aos gradientes de potencial total, definido como a energia potencial, por unidade de massa, de volume ou de peso, da água em um sistema, comparada à da água pura e livre. Quanto expresso por unidade de peso, o potencial total da água possui dimensões de comprimento (L).

O potencial matricial é um dos componentes mais importantes do potencial total, principalmente devido à faixa de variação possível, relativamente grande quando comparada à dos demais, nos problemas corriqueiros. Além disto, ele é importante como força impulsionadora para o fluxo de água em solos não saturados. Dependente do teor de água no solo, esta relação é denominada curva característica de 
retenção de água no solo ou simplesmente curva de retenção.

A histerese na função potencial matricial, em relação ao teor de água no solo, é um fator que interfere no estudo da dinâmica da água sob condição de solo não saturado. Royer \& Vachaud (1975) mostram que a histerese nesta função é muito importante para ser desprezada; caso contrário, erros consideráveis podem ocorrer com os resultados da determinação do teor de água ou do potencial matricial no solo. Contudo, Philip (1957a) afirma que a histerese, na curva de retenção, não apresenta dificuldades se a relação usada na análise é apropriada ao fenômeno e se o fenômeno é livre de histerese, como infiltração, absorção ou secagem.

\subsection{Limitações à validade da equação de Buckingham-Darcy}

Há, certamente, uma pequena faixa de tempo, partindo do início da infiltração, que Philip (1957a) afirma que a equação de Buckingham-Darcy não funciona, apresentando duas razões para isto. Primeiro, parte do trabalho devido ao gradiente de potencial no movimento da água no meio, provém da energia cinética do sistema, portanto nem todo o trabalho estará disponível para a dissipação de energia pela lei de Darcy. Segundo, em tempos muito pequenos o número de Reynolds do sistema excede o valor crítico, acima do qual a equação de Buckingham-Darcy falha.

Uma discussão acerca das limitações à aplicabilidade da equação de Fokker-Planck, obtida a partir da equação de Buckingham-Darcy, na solução de processos de infiltração é apresentada por Philip (1969), sendo algumas delas listadas a seguir:

a) a representatividade das características do solo, como o potencial matricial e a condutividade hidráulica, ou seja, características baseadas em grandes elementos de 
volume, quando comparado com o volume do poro individual, podem não ser adequadas;

b) efeitos inerciais, tirando a linearidade da equação de Navier-Stokes, juntamente com o comportamento não-newtoniano da solução;

c) comportamento coloidal, referente a solos expansivos ou de caráter vértico acentuado;

d) efeito da concentração eletrolitica sobre a estrutura do solo e na condutividade hidráulica;

e) possíveis complicações devida às diferenças de pressão no ar do solo, como no caso do impedimento à saída do ar do solo no processo de infiltração, ou ar originalmente dissolvido na solução, que com sua liberação pode preencher o poro, afetando a estabilidade das funções condutividade hidráulica e potencial matricial, em relação ao teor de água no meio;

f) efeitos térmicos, com a equação de Buckingham-Darcy exigindo sistemas isotérmicos. Tais limitações podem ocorrer ao mesmo tempo ou individualizadas.

\subsection{Modelagem do fluxo de água em solos não saturados}

Um dos primeiros trabalhos procurando analisar a distribuição da água no solo sob sulcos de irrigação, onde observou-se o desenvolvimento da frente de molhamento em relação ao tempo após aplicação de água, foi o de Loughridge ${ }^{7}$, citado por Browning \& Milam (1940).

$\mathrm{Na}$ busca de uma metodologia adaptada à obtenção de um modelo para a simulação da distribuição da água no solo, dispensando-se com isto uma análise a campo, como no trabalho citado acima, é conveniente ter-se a idéia do que vem a ser um

${ }^{7}$ LOUGHRIDGE, R.H. Distribution of water in the soil in furrow irrigation. U.S. Department of Agriculture, Office of Exp. Sta., 1908. (Bul. 203) 
modelo.

Um modelo pode ser definido como uma abstração de um sistema real, que possa ser utilizada com os propósitos de predição e controle. Naylor et al. (1971), tratando da importância dos modelos e de sua construção, como parte integrante da pesquisa cientifica, cita Rosemblueth \& Wiener ${ }^{8}$, os quais consideraram que nenhuma parte substancial do universo é tão simples que possa ser compreendida e controlada sem abstração, sendo que a abstração consiste em substituir a parte do universo em estudo por um modelo semelhante, porém de estrutura mais simples, modelo este constituindo, portanto, uma necessidade primordial de qualquer procedimento científico.

Com esta visão superficial quanto à modelagem, pode-se compreender melhor as discussões seguintes a respeito da simulação do fluxo de água em solos não saturados.

Trabalhos como os de Youngs (1958a,1958b), citando a aceitação da equação de Buckingham-Darcy para descrever o fluxo de água em materiais porosos não saturados, são de grande importância quando se pensa em modelagem da dinâmica da água em meios porosos, sendo que o autor considera ser possivel, com o conhecimento prévio da distribuição inicial do teor de água no corpo poroso e como este foi obtido, predizer perfis futuros de teor de água no solo, se o comportamento da condutividade hidráulica, em relação ao teor de água, e a curva de retenção forem conhecidas. Nestes dois trabalhos, realizaram-se simulações da redistribuição da água infiltrada em corpos de material poroso inerte, para fluxo na direção horizontal e na direção vertical, respectivamente.

O teor de água inicial tem sido estudado quanto à influência no movimento da água no meio poroso há muito, como no trabalho de Karraker (1920), que

\footnotetext{
${ }^{8}$ ROSEMBLUETH, A. \& WIENER, N. The role of models in science. Philosophy of Science, v. 12, n. 4 , p.316-321, October 1945 .
} 
não observou influência para pequenas diferenças no teor de água inicial. Contudo, Philip (1957b) comenta que há tempo conhece-se tal influência, em especial na infiltração, mas até então os estudos realizados teriam sido em grande parte empíricos. Este autor, através de exemplos numéricos, considera o efeito do teor de água inicial na sortividade, na taxa de infiltração, na infiltração acumulada, no perfil de teor de água e no avanço da frente de molhamento, obtendo que para pouco tempo após o início da infiltração, para valores crescentes de teor de água inicial reduz-se a taxa de infiltração, mas aumenta a velocidade de avanço da frente de molhamento. Obteve ainda que, com o passar do tempo, a influência na infiltração torna-se menor até tornar-se negligivel, mas a influência no avanço da frente de molhamento persiste e, de fato, torna-se mais marcada.

Quanto à utilização do solo como material poroso, o trabalho de Hanks \& Bowers (1962) inova pelo método de estimativa da solução da equação do fluxo de água, para a infiltração em solos estratificados. Partiu-se, desta forma, para o estudo de sistemas não necessariamente homogêneos, incluindo, além disto, a não necessidade de uma relação matemática específica entre difusividade hidráulica e teor de água no solo. Os autores, ao compararem o método proposto a dois outros métodos quanto à infiltração horizontal de água, obtiveram razoável concordância, mas não houve evidência experimental. Outra constatação foi que a infiltração é governada pelo fluxo através da camada menos permeável, citando também que o método requer, em adição ao conhecimento das condições inicial e de contorno, uma relação conhecida entre teor de água e difusividade hidráulica no solo, e um computador de alta velocidade para os cálculos, sendo que entre as vantagens do método tem-se que o solo pode ser estratificado, não precisa ser semi-infinito, o efeito gravitacional pode ser considerado, e que o teor inicial de água no solo não precisa ser uniforme.

Entre outros trabalhos relacionados ao estudo do fluxo de água em 
solos estratificados tem-se os de Philip (1972) e Philip \& Forrester (1975), o primeiro desenvolvendo uma equação semi-linearizada para o fluxo de água nesta condição e em regime permanente, e o segundo apresentando soluções com detalhes e discussão de algumas implicações da utilização do método. Tal equação aplica-se bem quando a fonte de água é do tipo sulco ou canal, entre outras.

Um teorema geral, possibilitando a solução da equação semi-linearizada da infiltração permanente, redutiveis para o caso de canais e bacias de configurações apropriadas, foi estabelecido por Philip (1971), concluindo que o teorema é primariamente matemático que físico. Neste trabalho o autor cita Raats (1970), que apresenta uma solução analítica para a infiltração em regime permanente, usando fontes lineares ou sulcos. Raats (1970) expressou sua expectativa de que grandes computadores e métodos numéricos aperfeiçoados, pudessem habilitar o desenvolvimento de soluções numéricas para problemas de fluxo transiente de tamanhos práticos, citando como vantagens esperadas que as propriedades reais do solo, condições de contorno e sistemas de geometrias complexas pudessem ser tratados. Contudo, o autor considera que estudos numéricos e analíticos são desejáveis de serem realizados concomitantemente, mesmo tendo-se que soluções analíticas são baseadas em hipóteses simplificadoras.

Ainda no estudo da infiltração permanente, Zachmann \& Thomas (1973) descreveram o processo de fluxo de água para métodos de irrigação subsuperficial. Neste caso, os autores basearam-se na forma semi-linearizada da equação da infiltração permanente, bem como em uma relação exponencial entre condutividade hidráulica e potencial matricial. Tal relação reveste-se de uma importância fundamental quando se pretende trabalhar com a modelagem da dinâmica da água no solo.

Uma equação comumente utilizada no estudo do fluxo de água em solos não saturados, sob condição isotérmica, é a de Fokker-Planck. Uma solução 
alternativa para o cálculo de tal equação foi apresentada por van der Ploeg \& Benecke (1974), que utilizaram-na para a confecção de um modelo matemático, visando o tratamento do fluxo de água no solo. Este modelo foi ilustrado na forma de um programa computacional, considerado simples em relação aos modelos existentes até então, sendo que as comparações com dados obtidos por outros trabalhos foram satisfatórias.

Partindo da premissa de que um modelo, a ser utilizado para estimar padrões molhados em solos estratificados, deve ser capaz de aceitar caracteristicas de solo que mudem com a profundidade através do perfil, Armstrong \& Wilson (1983) modificaram o modelo de van der Ploeg \& Benecke (1974), considerado não requerer grande conhecimento matemático. As modificações foram:

a) o solo foi dividido em uma série de camadas, cada uma tendo uma única série de propriedades relacionadas ao teor de água;

b) a maneira de determinar a condutividade hidráulica média, ponderando-a;

c) o método de integração numérica, que utilizava um intervalo de tempo fixo, passou a utilizar um intervalo variável ao longo da simulação, menor quando o teor de água muda rapidamente e maior quando o movimento da água é mais lento, com conseqüente uso mais eficiente do tempo de computador.

Uma particularidade deste trabalho é a utilização do método da sonda de nêutrons para obtenção do teor de água no solo e, com isto, o acompanhamento da distribuição de água no solo.

Um trabalho que veio confirmar o modelo de van der Ploeg \& Benecke (1974) foi realizado por Botrel (1988). Neste, trabalhando com fonte puntiforme sobre solo de textura média, o autor utilizou o conceito de estratificação e a adaptação de van Genuchten (1980) ao modelo de Mualem (1976), para representação das características hidráulicas do solo, obtendo uma boa aderência dos dados simulados aos dados obtidos 
experimentalmente.

Trabalhos como os de Botrel (1988), Armstrong \& Wilson (1983) e van der Ploeg \& Benecke (1974) utilizam como método para a solução da equação do fluxo de água em solos não saturados, o das diferenças finitas. Entretanto, alguns modelos matemáticos com esta finalidade baseiam-se no método dos elementos finitos. Neuman (1973), utilizando o método dos elementos finitos, foi o primeiro a utilizá-lo em problemas envolvendo o fluxo de água em meios porosos, sendo que Neuman et al. (1975) descreveram como este método pode ser utilizado para simular o fluxo bidimensional de água em um solo incompressivel, não saturado ou parcialmente saturado, com ênfase especial para o tratamento das condições atmosféricas e para a absorção de água pelas raízes das plantas. Tal método foi verificado em relação a dados de campo por Feddes et al. (1975), havendo discrepância entre a comparação do método em questão com o da diferença finita, cujas prováveis causas foram citadas, sendo uma delas a histerese, não considerada no modelo.

Um problema comum ao modelo de Hillel et al. (1975) e a muitos outros trabalhos referentes ao estudo da água no solo, a histerese foi tratada por Whisler \& Klute (1965) na análise da infiltração em colunas verticais, citando que ao ignorá-la, a posição da frente de molhamento pode ser subestimada ou superestimada, dependendo do uso da curva de retenção de água no solo obtida por molhamento ou secagem, respectivamente. Tal assunto pode ser encontrado também no trabalho de Staple (1969), onde mediu-se a redistribuição da água após duas quantidades iniciais infiltradas. Os perfis de redistribuição medidos foram comparados com aqueles calculados pela equação do fluxo, levando-se em consideração a histerese na curva de retenção. A concordância entre perfis de teor de água no solo medido e calculado foi considerada satisfatória. Pôde-se observar, também, que a taxa de molhamento ocasionou influência na histerese. 
No trabalho de Bresler et al. (1969), o qual estudou a redistribuição de água em colunas de solo, levando-se em consideração a histerese na relação entre potencial matricial e teor de água no solo, constatou que a superfície manteve-se mais úmida quando a histerese foi considerada.

Trabalho mais recente tratando da simulação da infiltração de água em sulcos de irrigação é o de Samani et al. (1985), o qual descreveu um modelo computacional aplicável a sulcos de seção transversal irregular, com altura da lâmina de água sobre o sulco variável. Tal modelo simula o processo de infiltração em uma ou duas dimensões, prevendo o volume infiltrado e a posição da frente de molhamento no solo. Buscando minimizar o número de equações a serem solucionadas em cada intervalo de tempo, um contorno móvel foi estimado, sendo ajustado com o avanço da frente de molhamento. O intervalo de tempo utilizado foi variável. O autor considerou que, pela simulação em diferentes seções ao longo do sulco, pode-se chegar a uma avaliação mais acurada da uniformidade e eficiência da irrigação. Este trabalho foi utilizado por Segeren \& Trout (1991), que o utilizaram na determinação da resistência hidráulica da superficie do sulco de irrigação, visando a análise do selamento ocasionado pela deposição de partículas de solo trazidas pela água, promovendo uma diminuição na densidade de infiltração. O selamento é um parâmetro de difícil modelagem, pois é variável em função de vários fatores, como tempo, vazão no sulco, qualidade da água, entre outros.

Tratando, entre outros assuntos, da modelagem da infiltração e redistribuição em sistemas bidimensionais, fazendo-se menção também a sulcos de irrigação, a publicação de Campbell (1985) inova pela utilização de analogia a circuitos elétricos como forma de simular as propriedades do perfil de solo, tornando possivel, desta maneira, o tratamento de sistemas não homogêneos. É um trabalho de caráter didático muito interessante quando se pensa em modelagem de processos ocorrendo no 
sistema solo-planta-atmosfera.

Atual e abrangente quanto ao assunto da modelagem bidimensional e tridimensional da dinâmica da água em solos irrigados por sulcos, Tabuada (1989) aplicou a equação de Richards na simulação de sistemas compostos por sulcos de diferentes tipos, entre eles sulcos longos, sendo que nestes associou-se as equações que regem o escoamento superficial. $\mathrm{O}$ autor utilizou o método das diferenças finitas para a solução da equação de fluxo, e métodos de campo para a determinação das propriedades hidráulicas do solo que foram utilizadas no modelo. Considerando sulcos de seção transversal trapezoidal, compartimentos de formato regular e constante, não considerando o processo evaporativo, constatou-se que as observações de campo não mostraram-se satisfatórias para uma completa calibração do modelo proposto, citando que uma reformulação dos métodos de campo pode solucionar o problema.

A simulação da infiltração em sulcos de irrigação, em solo com lençol freático a pouca profundidade, foi realizada por Vogel \& Hopmans (1992), utilizando um modelo para fluxo transiente bidimensional, solucionado por um esquema de elementos finitos com compartimentos de tamanho variável. Estudou-se a influência de um sulco adjacente seco comparado com este contendo água; o efeito de um decréscimo na condutividade hidráulica à superficie do solo sobre a infiltração acumulada; a influência da altura da lâmina de água sobre o sulco na infiltração; e diferenças entre perfis de solo homogêneos e heterogêneos. O modelo utilizado considera uma situação envolvendo sistema isotérmico em um meio poroso rígido parcialmente saturado, assumindo que o papel do ar no solo é insignificante no fluxo da água, este descrito por uma forma modificada da equação de Richards.

Os sulcos de irrigação tiveram também a atenção de Schmitz (1993), que apresentou um método para descrever a infiltração ai ocorrida quando da aplicação 
de uma quantidade de água. Considerando a solução da equação de Richards, em condição de fluxo bidimensional, dificil quando do uso de métodos numéricos clássicos, justificando quanto ao contorno do sulco e quanto ao complexo padrão de molhamento, aliando a isto a quantidade de memória de computador e tempo de uso requerido, apresenta uma aproximação alternativa desta equação, onde o fenômeno bidimensional da infiltração é decomposto e, então, tratado como uma série de processos unidimensionais. A idéia básica é considerar a infiltração bidimensional, a partir de um sulco, como um tipo de soma ponderada de processos unidimensionais de infiltração em colunas de solo separadas. A modificação introduzida na equação de Richards refere-se ao peso do termo gravidade, o qual varia com o ângulo entre a vertical e a ortogonal ao perímetro do sulco.

Buscando aglutinar as principais idéias lançadas em todo o texto, temse que a modelagem do processo de irrigação por sulcos, envolvendo infiltração, redistribuição e evaporação, é complexa e de dificil solução. A utilização da equação de Richards ou da equação de Fokker-Planck, apesar de todas as limitações físicas conhecidas, não tem solução exata neste caso, exigindo uma aproximação por métodos numéricos, como o das diferenças finitas ou dos elementos finitos, onde as funções condutividade hidráulica e potencial matricial necessitam ser linearizadas, geralmente de forma explícita. Além disto, a condição de contorno referente à superficie de infiltração é dinâmica quanto ao tempo, tanto em relação à geometria quanto à permeabilidade, e conclui-se que não chegou-se a um método apropriado de considerá-la.

Todos os agravantes considerados somam-se e resultam em modelos pesados, consumindo máquina e tempo de computação, resultando em soluções apenas aproximadas e específicas. Buscando minimizar o problema de tempo, os artificios de utilização de compartimentos de tamanho variável, intervalos de tempo variáveis e o contorno móvel relacionado à frente de molhamento são muito úteis. No que se refere às 
propriedades hidráulicas do solo, parece clara uma certa aceitação, com algumas exceções, da adaptação de van Genuchten ao modelo de Mualem. Em relação ao tratamento do processo evaporativo ocorrendo à superfície do solo, são trabalhosos e exigem um número de parâmetros de dificil obtenção, em especial na determinação da evaporação potencial, o que dificulta quanto à aplicabilidade dos modelos. 


\section{MATERIAL E MÉTODOS}

\subsection{Generalidades}

O estudo de simulação da dinâmica da água em solo irrigado por sulco consistiu de três etapas. Na primeira desenvolveu-se um modelo computacional que permite a estimativa dos perfis de teor de água no solo, a partir de dados relativamente fáceis de serem obtidos, com ênfase em ser simples o suficiente para facilidade de utilização prática.

Tal modelo é identificado como DASIS (Dinâmica da Água em Solo Irrigado por Sulco). Ele permite simular condições de presença de sulco com seção transversal de formato não necessariamente regular, e capaz de quantificar o volume de água infiltrado e definir a lei de infiltração do solo para utilização em irrigação por sulcos. O modelo DASIS foi interpretado em linguagem de programação Pascal.

A segunda etapa consistiu na condução de um ensaio a campo, para o acompanhamento do desenvolvimento dos perfis de teor de água e aquisição de dados para alimentação do modelo DASIS. Estes dados referem-se às características hidráulicas do solo (retenção e condutividade), ao teor de água inicial no perfil, ao formato do perfil transversal do sulco e ao comportamento da altura da lâmina de água sobre o sulco.

$\mathrm{Na}$ terceira e última etapa foi realizada a simulação com o modelo, utilizando os dados obtidos na segunda etapa do estudo. Buscou-se verificar a influência 
de fatores intrínsecos ao modelo, elegendo as condições iniciais e de contorno mais apropriadas, utilizadas em um segundo instante na análise de acuracidade.

\subsection{Modelo DASIS}

\subsubsection{Delimitação do sistema}

Preliminarmente, procurou-se definir qual o sistema estudado, ou seja, o sistema água-solo-atmosfera. A propriedade analisada foi a transferência de água no interior deste, considerada dedutível pelas leis da conservação de energia e de massa, representadas pelas equações de Buckingham-Darcy e da Continuidade, respectivamente, sendo necessárias as seguintes características:

a) forma e dimensões dos compartimentos que constituem o perfil computacional a ser estudado;

b) funções potencial matricial e condutividade hidráulica, em relação ao teor de água no solo em base de volume, de cada compartimento; associadas ao conhecimento do teor de água no solo ao início do estudo.

Enfatiza-se que tal estudo assume um sistema isotérmico, com solo de estrutura perfeitamente rígida, e os únicos potenciais influindo no movimento de água são o matricial, gravitacional e de pressão (este apenas para pontos à superficie do perfil computacional sob uma coluna líquida); e as funções potencial matricial e condutividade hidráulica, em relação ao teor de água no solo, são assumidas singulares.

Conhecidos o sistema e a propriedade estudados, bem como as caracteristicas e condições iniciais necessárias, existiu a necessidade de adaptar o sistema à presença de um sulco de irrigação, como fonte de água. Para tal, necessitou-se 
conhecer as dimensões do sulco, no caso seu contorno quanto à seção transversal, e o comportamento temporal da altura da lâmina de água.

Quanto à forma e dimensões dos compartimentos, estas dependem diretamente do formato da seção transversal do sulco. A Figura 1 apresenta um esquema de compartimentação do perfil computacional e a localização de cada compartimento, para uma dada seção hipotética.

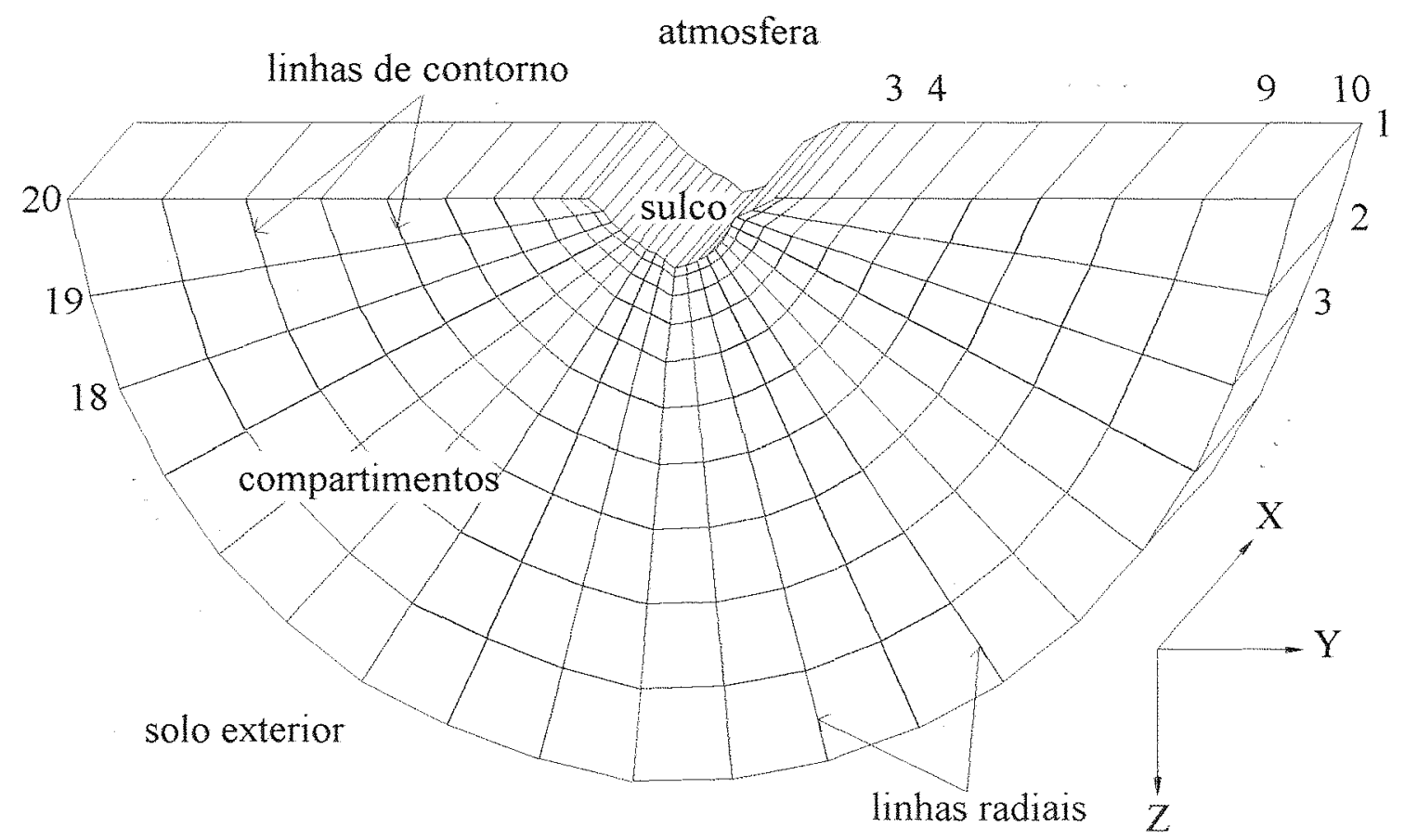

Figura 1. Esquema da compartimentação utilizada na definição do perfil computacional, com posicionamento das linhas de contorno e radiais, $e$ orientação quanto aos eixos cartesianos, com origem à superficie do perfil no ponto médio da largura de topo do sulco.

Necessitando um procedimento em separado no modelo, tal compartimentação baseia-se no traçado de algumas linhas radiais, com origem no ponto localizado ao nivel da superficie do solo e à metade da largura de topo do sulco, com 
ângulos de abertura iguais entre linhas consecutivas, e de forma que a primeira e a última radial formem um ângulo de $180^{\circ}$. Tais linhas formarão fatias com largura variável ao longo de sua extensão, em um total de $F$ fatias. Resultará, então, que tais linhas interceptarão a superficie do sulco, possibilitando o traçado de um contorno dito ajustado, pela ligação dos pontos de intercepto, conforme pode ser visualizado na Figura 2. Este será, doravante, o limite do perfil quanto ao sulco.

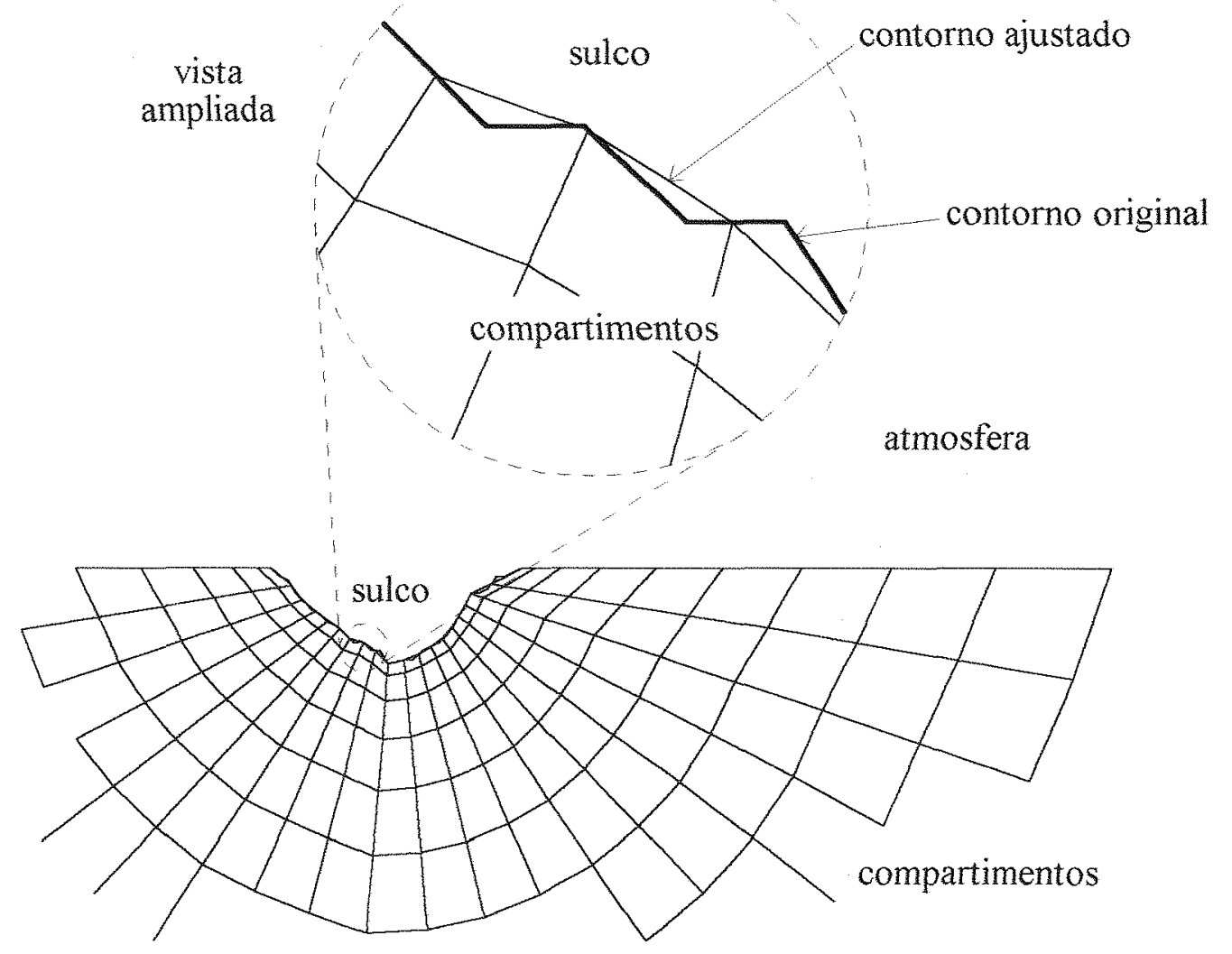

Figura 2. Relacionamento entre o contorno original e o contorno ajustado do sulco, originando a base para a definição das demais linhas de contorno.

Para o traçado dos demais contornos, o primeiro passo foi definir a distância $D_{I}(\mathrm{~L})$, sobre as radiais, que separa o contorno de ordem $I$ do primeiro, dada 
pela expressão

$$
D_{I}=P P \cdot \frac{\sum_{i=1}^{I-1} i}{\sum_{c=1}^{C} c}
$$

com $I$ representando o número de ordem do contorno (valores inteiros de 2 ao total de contornos); $P P$ a profundidade desejada para o perfil computacional (L) a partir da superficie; $C$ o número de camadas do perfil, formadas entre dois contornos consecutivos e igual ao total destes menos um; e $i$ e $c$ os índices do somatório. Obtidas as distâncias e conhecendo-se as coordenadas dos interceptos, formados pelas linhas radiais e contornos, calculam-se as coordenadas de interesse, definindo, desta forma, os limites de cada compartimento.

Com esse procedimento, os compartimentos puderam ser posicionados espacialmente no plano vertical que contém o contorno conhecido do sulco, assumida uma espessura unitária considerada quanto ao eixo X. O passo seguinte é definir outros parâmetros referentes a cada compartimento, ou seja: volume por unidade de comprimento; coordenadas $(\mathrm{Y}, \mathrm{Z})$ do baricentro; menor distância entre o baricentro e cada face limite do compartimento; área de contato por unidade de comprimento com os compartimentos conexos, ou área das faces limites.

Pela maneira como definiu-se a compartimentação do perfil computacional, esse resulta em domínio com fronteira fechada móvel, ampliada conforme o avanço da frente de molhamento, com subdomínios crescentes a partir do sulco, proporcionando um maior detalhamento da dinâmica da água, em especial durante a 
infiltração, quando os gradientes de potencial são grandes, ao mesmo tempo otimizando a velocidade de simulação.

\subsubsection{Demonstração matemática}

A dinâmica da água, em solo não saturado, é caracterizada pelas equações diferenciais parabólicas de Richards e/ou de Fokker-Planck. Contudo, não se aplicam às condições encontradas no domínio do método de irrigação por sulcos, admitindo apenas uma solução aproximada, via análise numérica, como o método das diferenças finitas.

A complexidade na compartimentação do perfil computacional, juntamente com a irregularidade permissivel no contorno do sulco, inviabilizam a utilização destas equações no modelo DASIS, mas é possível trabalhar-se com as equações de Buckingham-Darcy e da Continuidade, que combinadas e organizadas na forma de interesse resulta em

$$
\frac{\theta_{f}-\theta_{i}}{\Delta t}=\frac{1}{V} \cdot \sum_{n=1}^{4}\left(q_{n} \cdot A_{n}\right)
$$

sendo $\theta_{f}$ e $\theta_{i}$ os teores de água final e inicial com base em volume, respectivamente, no compartimento em análise, em relação ao intervalo de tempo $\Delta t(\mathrm{~T}) ; V$ o volume deste compartimento $\left(\mathrm{L}^{3}\right) ; n$ o índice referente aos quatro limites existentes $(n=1,2,3,4) ; q_{n}$ a densidade de fluxo através do limite de índice $n\left(\mathrm{~L} . T^{-1}\right)$; e $A_{n}$ a área disponível ao fluxo no limite $n\left(\mathrm{~L}^{2}\right)$.

Convencionou-se adotar a seguinte seqüência em relação ao índice $n$ : 
a) $n$ igual a 1 - limite posicionado entre duas linhas radiais, sobre a linha de contorno de menor ordem, estando mais próximo ao sulco;

b) $n$ igual a 2 - limite posicionado sobre a linha radial de menor ordem;

c) $n$ igual a 3 - limite posicionado entre duas linhas radiais, sobre a linha de contorno de maior ordem, estando mais distante ao sulco;

d) $n$ igual a 4 - limite posicionado sobre a linha radial de maior ordem; sendo que a Figura 3 ilustra esta convenção.

A eq. (2), aplicada no domínio do perfil computacional, tem solução por aproximação explícita, com linearização explícita e ponderação por média aritmética, estando sujeita a três condições de contorno, relacionadas ao contato com a atmosfera, com o sulco e com o solo além da última camada. Fora destas condições, $q_{n}$ é obtido por:

$$
q_{n}=-\bar{K}_{n} \cdot \frac{\Delta \Phi_{n}}{d_{n}}
$$

que é a equação de Buckingham-Darcy, com $\bar{K}_{n}$ representando a condutividade hidráulica média, ocorrendo entre o compartimento em análise e seu conexo, quanto ao limite $n\left(\mathrm{~L} . \mathrm{T}^{-1}\right) ; \Delta \Phi_{n}$ a diferença de potencial total entre tais compartimentos $(\mathrm{L})$; e $d_{n}$ a distância entre os baricentros destes (L). O valor de $d_{n}$ é obtido somando-se as distâncias dos baricentros até a face limite comum aos compartimentos (Figura 3), ou seja,

$$
d_{n}=d_{n^{\prime}}+d_{n^{\prime \prime}}
$$

sendo $d_{n^{\prime}}$ e $d_{n}{ }^{\prime \prime}$ as distâncias entre os baricentros do compartimento considerado e de seu conexo, respectivamente, à face limite comum (L). 


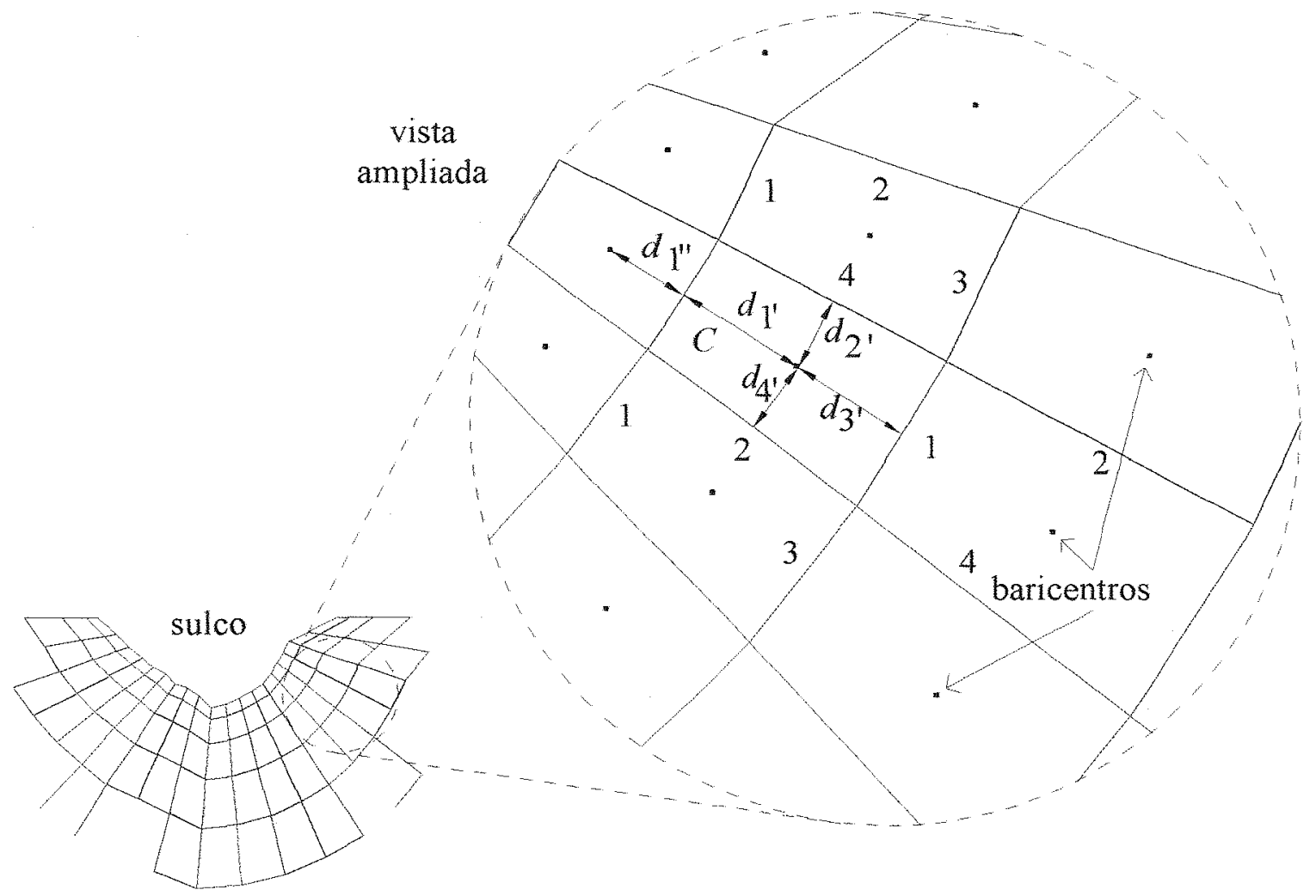

Figura 3. Convenção adotada para o posicionamento dos limites dos compartimentos, apresentando também a forma pela qual obtém-se as distâncias, a partir do baricentro, até tais limites, exemplificando para um compartimento $C$ qualquer.

A condutividade hidráulica média, ponderada quanto às distâncias $d_{n^{\prime}} \mathrm{e}$ $d_{n^{\prime \prime}}$, é expressa por

$$
\bar{K}_{n}=\frac{K \cdot d_{n^{\prime}}+K_{n} \cdot d_{n^{\prime \prime}}}{d_{n}}
$$

com $K$ representando a condutividade hidráulica no compartimento em análise (L.T $\left.{ }^{-1}\right)$, e $K_{n}$ a condutividade hidráulica no compartimento conexo (L.T-1 $)$, quanto ao limite $n$. A utilização da linearização explícita deixa claro que os valores de condutividade hidráulica, 
dados em função do teor de água no solo dos compartimentos envolvidos, são aqueles ao início do intervalo de tempo, ou seja, aqueles referentes aos valores de teor de água inicial.

Quanto à diferença de potencial total, os potenciais influindo no movimento da água são o matricial, o gravitacional e o de pressão, este considerado apenas à superficie do sulco sob a lâmina de água. Portanto, para os limites fora das condições de contorno, tal diferença é dada por

$$
\Delta \Phi_{n}=(\Phi m+\Phi z)-\left(\Phi m_{n}+\Phi z_{n}\right)
$$

com $\Phi m$ e $\Phi m_{n}$ os potenciais matriciais no compartimento em análise e em seu conexo quanto ao limite $n(\mathrm{~L})$, respectivamente; e sendo $\Phi z$ e $\Phi z_{n}$ os potenciais gravitacionais nestes (L). Os valores de potencial matricial, linearizados de modo explícito, segue $o$ mesmo raciocínio exposto quanto à condutividade hidráulica, ou seja, são obtidos a partir do valor de teor de água inicial. Quanto à medição do potencial gravitacional, considerase como referência a superficie do perfil computacional, tendo seu valor igual à coordenada $\mathrm{Z}$ do baricentro do compartimento, sempre negativo.

O valor do potencial matricial é estimado com o auxílio da equação desenvolvida por van Genuchten (1980), aplicada a dados experimentais de retenção de água no solo, que se escreve

$$
\Phi m=\frac{\left(\Theta^{-\frac{1}{m}-1}\right)^{\frac{1}{\eta}}}{\alpha}
$$

sendo $m$ e $\eta$ coeficientes de ajuste adimensionais, $\alpha$ outro coeficiente de ajuste $\left(L^{-1}\right)$, e $\Theta$ 
representa o teor de água adimensional no solo do compartimento, dado por

$$
\Theta=\frac{\theta_{i}-\theta_{r}}{\theta_{s}-\theta_{r}}
$$

$\operatorname{com} \theta_{r}$ e $\theta_{S}$ representando os teores de água residual (teor de água referente a um valor de potencial matricial igual a $-150 \mathrm{~m}$ ) e saturado, em base de volume, respectivamente, obtidos experimentalmente. Todas as variáveis envolvidas nas eq. (7) e (8) são específicas do subdomínio considerado, podendo diferir entre compartimentos. Estas equações são válidas apenas para teores de água na faixa entre condições saturada e residual, sendo que para aqueles abaixo desta faixa, considera-se que variam linearmente com os valores de potencial matricial, com limite superior igual a $-150 \mathrm{~m}$ e limite inferior $-100000 \mathrm{~m}$, condição esta representando um teor de água zero (Ross et al., 1991).

O comportamento da condutividade hidráulica é expressa por

$$
K=K_{S} \cdot \sqrt{\Theta} \cdot\left[1-\left(1-\frac{1}{\Theta m}\right)^{m}\right]^{2}
$$

sendo $K_{S}$ o valor da condutividade hidráulica em condição de solo saturado, obtido experimentalmente (L. $\left.T^{-1}\right)$. Tal equação foi obtida por van Genuchten (1980), resultante de um tratamento matemático aplicado à equação definida por Mualem (1976), para a condutividade hidráulica relativa.

A eq. (9) é válida para a mesma faixa de teor de água referente às eq. (7) e (8), sendo que para teores menores considera-se que a condutividade hidráulica é igual a zero.

Definidas as densidades de fluxo ocorrendo fora das condições de 
contorno, o passo seguinte é obter aquelas para tais condições, iniciando pelo contorno com o solo além da última camada. Assume-se que não há fluxo nesta condição, ou seja,

$$
q_{3}=0
$$

com $q_{3}$ representando a densidade de fluxo ocorrendo através do limite de índice 3, convencionado anteriormente e apresentado na Figura 3, dos compartimentos localizados na camada mais distante do sulco.

A segunda condição de contorno, ou o limite entre a superficie do perfil de solo e a atmosfera, tratando do processo evaporativo e da infiltração de água, proveniente de chuva ou irrigação que não via sulco, considera fluxo nulo, semelhante à condição anterior, ou seja,

$$
q_{n}=0
$$

Para os compartimentos superficiais posicionados entre as linhas radiais 1 e 2, o índice do limite $n$ é 4; para aqueles na fatia $F$, entre as duas últimas linhas radiais, $n$ é igual a 2; e para os posicionados no contorno do sulco, $n$ é igual a 1 . A análise da Figura 3 permite uma correta identificação do índice $n$.

A terceira e última de contorno refere-se à aplicação de água ao solo, via sulco. Para esta, a densidade de fluxo, ou densidade de infiltração, é expressa na forma

$$
q_{1}=-\overline{K_{1}} \cdot \frac{\Delta \Phi_{1}}{d_{1}}
$$


que é a eq. (3) aplicada ao limite 1 dos compartimentos em contato com a água no sulco. Neste caso, $\bar{K}_{1}$ é obtido por

$$
\bar{K}_{1}=\frac{K \cdot d_{1}+K_{S}, 0,001}{d_{1}+0,001}
$$

semelhante à eq. (5), porém, o valor de $d_{1}$ ' é definido como a distância entre o baricentro do compartimento em análise e o ponto médio da região molhada da face limite 1 , que pode estar totalmente ou parcialmente em contato com a lâmina de água sobre o sulco. $\mathrm{O}$ valor 0,001 é utilizado para inserir o efeito de uma interface de contato água-solo, representando um percurso de $0,001 \mathrm{~m}$ onde a condutividade hidráulica é saturada.

Outra diferença referente à eq. (3) e eq. (12) é que nesta, o valor da diferença de potencial total é obtido por

$$
\Delta \Phi_{1}=(\Phi m+\Phi z)-\left(\Phi_{p_{1}}+\Phi_{z_{1}}\right)
$$

sendo $\Phi p_{1}$ o potencial de pressão à superficie do sulco $(L)$, no ponto médio da região molhada da face limite 1 , igual à altura da lâmina de água sobre este, e $\Phi z_{1}$ o potencial gravitacional referente a tal ponto. $\mathrm{O}$ valor de $\Phi p_{1}$ é variável durante a aplicação de água.

Obtidas as densidades de infiltração, pode-se calcular a quantidade de água infiltrada por unidade de comprimento de sulco, durante o intervalo de tempo $\Delta t$, expressa por

$$
Q=\Delta t \cdot \sum_{f=1}^{F}\left(q_{1}^{f} \cdot A_{1}^{f}\right)
$$


com $Q$ representando o volume de água infiltrado $\left(L^{3}\right)$, no intervalo de tempo, por unidade de comprimento de sulco; e $q_{1}^{f}$ a densidade de infiltração, referente à área de contato $A_{1}^{f}$ do compartimento da fatia $f$ com a água do sulco. A densidade de infiltração média no perímetro molhado, ocorrendo no tempo simulado $T$, definindo o que convencionou-se chamar de velocidade de infiltração, é obtido dividindo-se o volume de água infiltrado pelo intervalo de tempo e pela área molhada por unidade de comprimento de sulco, ou seja,

$$
V I=\frac{Q}{\Delta t . \sum_{f=1}^{F} A_{1}^{f}}
$$

sendo $V I$ a velocidade de infiltração $\left(\right.$ L.T $\left.T^{-1}\right)$.

Definido o intervalo de tempo $\Delta t$ e com as eq. (2) a (14), torna-se possível obter o valor de $\theta_{f}$, para cada um dos compartimentos que constituem o perfil computacional, que será o novo valor de $\theta_{i}$ para o tempo simulado $T+\Delta t$. Este é o novo valor do tempo $T$, transcorrido a partir do início da simulação, repetindo-se o laço até que tal tempo seja igual àquele desejado, resultando em uma nova distribuição de teor de água no perfil.

O intervalo de tempo é variável, de forma que a variação permitida no teor de água dentro de um laço de simulação, ou a diferença máxima entre $\theta_{f}$ e $\theta_{i}$, para todos os compartimentos, limite-se a um valor arbitrário $\Delta \theta$, garantindo uma condição de simulação mais próxima da linearidade e, ao mesmo tempo, um melhor aproveitamento do tempo de computação, sendo expresso por 


$$
\Delta t=\frac{\Delta \theta}{4} \cdot \frac{V}{q_{n} \cdot A_{n}}
$$

Esta equação, aplicada em todo o domínio do perfil computacional, resultará em valores para $\Delta t$, adotando o menor intervalo de tempo, contudo limitando a valores inferiores a 60 segundos, pré-definido. Como a eq. (17) aplica-se a cada limite $n$, assume-se que o valor de $\Delta t$ representa $25 \%$ da variação $\Delta \theta$ em um compartimento qualquer, justificando o denominador 4 presente na equação.

O domínio do modelo inicialmente é constituído por duas camadas de compartimentos junto ao sulco, ampliando-se gradualmente até atingir um número $C$ de camadas pré-definido. Para ampliação do domínio, a condição é que o valor de $\theta_{f}$, de qualquer um dos compartimentos da camada ativa mais distante do sulco, ao final do laço seja superior ao valor de $\theta_{j}$ ao início da simulação, mais 0,01 , ou seja,

$$
\theta_{f}>\theta_{i}+0,01
$$

Quanto às eq. (15) e (16), pela primeira, acumulando-se valores de $Q$ obtém-se, no final da simulação, a quantidade total de água infiltrada pelo sulco, por unidade de comprimento deste. Com a segunda, relacionando-se cada valor de $V I \mathrm{com}$ seu respectivo valor de $T$, define-se a lei da infiltração, referente às condições simuladas.

\subsubsection{Representação algorítmica}

Demonstrado matematicamente, o modelo DASIS foi representado na forma de um algoritmo simplificado que permitiu confeccionar um programa computacional, escrito em linguagem Pascal. 


\subsection{Ensaio a campo}

\subsection{1. Área de ensaio}

A área escolhida para a condução do ensaio a campo, com o propósito de verificação da acurácia do modelo ora desenvolvido, localiza-se na Escola Superior de Agricultura "Luiz de Queiroz", campus da Universidade de São Paulo, no município de Piracicaba - SP. O solo é um Podzólico Vermelho Escuro Latossólico Álico (PEL), com horizonte A moderado e textura argilosa a muito argilosa, posicionado quanto ao relevo próximo ao divisor de águas, apresentando boa drenagem natural. Algumas informações referentes aos horizontes deste solo são apresentadas na Tabela 1, extraídas em Vidal Torrado \& Sparovek (1993).

Tabela 1. Informações referentes ao perfil de solo ensaiado, com respectivas caracteristicas fisicas e quimicas.

\begin{tabular}{|c|c|c|c|c|}
\hline Horkomte & Ap & $\mathrm{AB}$ & Bt & B1 \\
\hline profindidade (m) & $0-0,08$ & $0,08-0,2$ & $0,2-0,6$ & $0,6-1,1$ \\
\hline 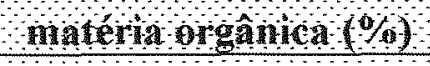 & 4,1 & 3,1 & 2,6 & 2,1 \\
\hline $\mathrm{pu} \mathrm{Hel}_{2} \mathrm{O}$ & 5,1 & 5,2 & 4,9 & 5,0 \\
\hline $\mathrm{ClCl}(\mathrm{meg} 100 \mathrm{~cm} / \mathrm{s}$ & 9,81 & 8,66 & 10,07 & 9,59 \\
\hline argla $(\%)$ & 47,2 & 51,7 & 57,8 & 56,4 \\
\hline sile $(\%)$ & 20,8 & 14,8 & 16,1 & 16,6 \\
\hline ara $(\%)$ & 32,0 & 33,5 & 26,1 & 27,0 \\
\hline cor (Muluse) & 2,5 YR $3 / 4$ & 2,5 YR $3 / 4$ & 2,5 YR $3 / 4$ & 2,5 YR $3 / 4$ \\
\hline
\end{tabular}

Quanto ao preparo da área para a realização dos ensaios, esta foi trabalhada realizando-se uma limpeza e um nivelamento da superficie manualmente. A 
área útil teve as dimensões de $5,0 \mathrm{~m}$ por $3,0 \mathrm{~m}$, a qual recebeu uma estrutura de aplicação de água, consistindo de um sulco e um reservatório, sendo mantida sem vegetação. $\mathrm{O}$ sulco foi construído no sentido do maior comprimento da área útil, posicionado à metade da largura e com declividade zero, tendo suas extremidades fechadas. A seção transversal foi definida pela utilização de um molde de madeira, forçosamente irregular, obtendo-se um formato assimétrico.

A estrutura utilizada no ensaio pode ser vista, de forma esquemática, na Figura 4.

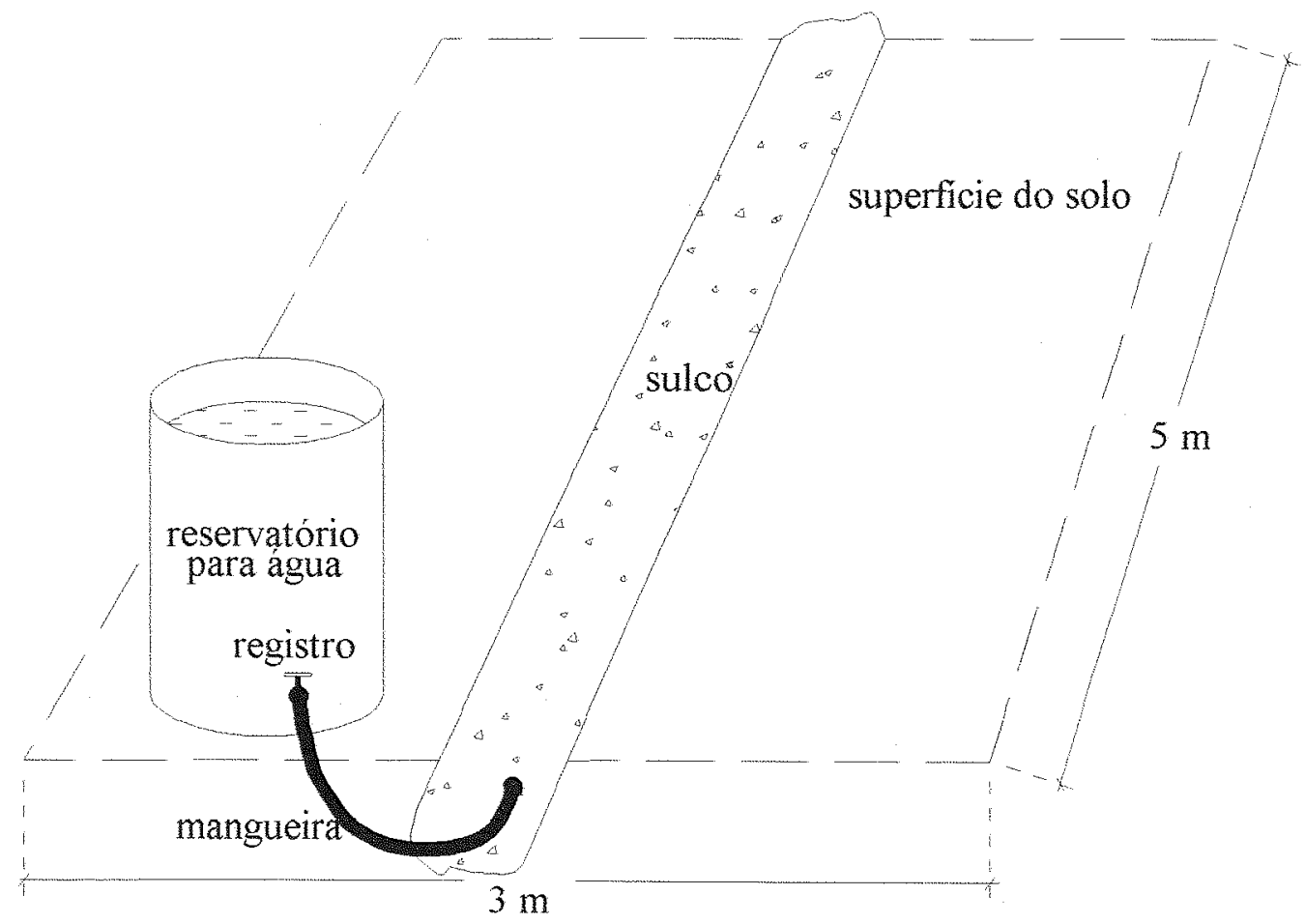

Figura 4. Esquema da estrutura utilizada no ensaio a campo.

Embora a configuração do sulco não represente o que é normalmente encontrado a nivel de lavoura irrigada, buscou-se com a utilização de sulco fechado com declividade zero evitar que aplicações sucessivas provocassem selamento da superficie de 
infiltração, bem como modificação da seção transversal, o que foi necessário, a princípio, para uma calibração do modelo, tornando-se possivel, após, evoluções no tratamento das condições de fronteira para usos futuros.

\subsubsection{Dados para o modelo DASIS}

\subsubsection{Coleta de amostras}

Com o intuito de se determinar alguns parâmetros para simulação com o modelo DASIS, abriu-se uma trincheira na área, onde foram coletadas amostras representativas de camadas de $0,2 \mathrm{~m}$ de espessura, até a profundidade de $1 \mathrm{~m}$, totalizando

cinco camadas. Em cada uma destas foram coletadas amostras em cilindros de Uhland, utilizadas na determinação da condutividade hidráulica saturada; e em cilindros amostradores de Kopecky, utilizadas na determinação da massa específica do solo e da curva de retenção, em um total de três repetições para cada tipo de cilindro.

\subsubsection{Condutividade hidráulica saturada}

Com as amostras de solo coletadas através da utilização do cilindro de Uhland, após prévia saturação, determinou-se a condutividade hidráulica saturada do solo pela utilização do método do permeâmetro de carga constante, para uma coluna de água sobre a amostra igual a $0,03 \mathrm{~m}$.

O comportamento assumido pelos valores de condutividade hidráulica saturada do solo em função da profundidade pode ser visualizado na Figura 5.

Os dados de condutividade hidráulica saturada foram válidos para todos 
os ensaios realizados, sendo que quando da aplicação destes dados ao modelo, assumiuse que todos os compartimentos com baricentro compreendido dentro de uma dada camada amostrada eram representados pelo mesmo valor de condutividade.

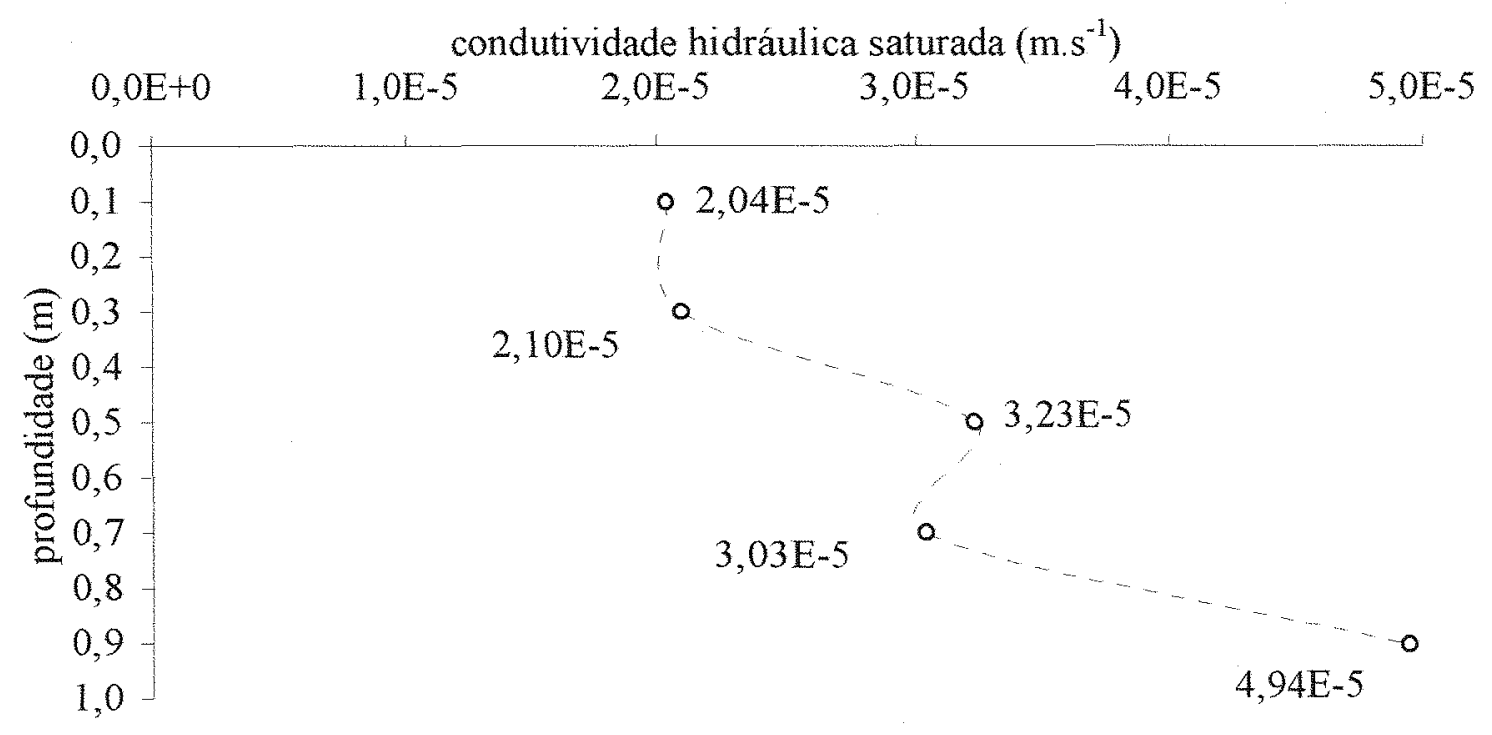

Figura 5. Comportamento dos valores de condutividade hidráulica saturada em função da profundidade no perfil ensaiado.

\subsubsection{Massa específica do solo e curva de retenção}

Trabalhando-se com as amostras coletadas nos cilindros de Kopecky, após a saturação destas, determinaram-se pares de dados de potencial matricial versus teor de água em base de massa, pelo método da "mesa de tensão" para as tensões representando potenciais de $-0,01 \mathrm{~m},-0,1 \mathrm{~m},-0,2 \mathrm{~m},-0,4 \mathrm{~m}$ e $-0,7 \mathrm{~m}$, e pelo método da câmara de Richards para as pressões representando os potenciais de $-1 \mathrm{~m},-2 \mathrm{~m},-3 \mathrm{~m},-5$ $m,-10 m,-50 m$ e $-150 m$. Tais determinações foram realizadas pelo processo de secagem. O teor de água residual, utilizado na equação de ajuste da curva de retenção, 
foi considerado igual ao teor de água referente ao potencial matricial de $-150 \mathrm{~m}$.

Obtidos os pares de dados citados, utilizou-se as amostras para determinação da massa específica do solo, assumindo a média em cada camada como seu valor representativo. Teve utilidade na estimativa do teor de água em base de volume, a partir dos valores de teor de água em base de massa seca, sendo que a Figura 6 apresenta seu comportamento em função da profundidade no perfil de solo.

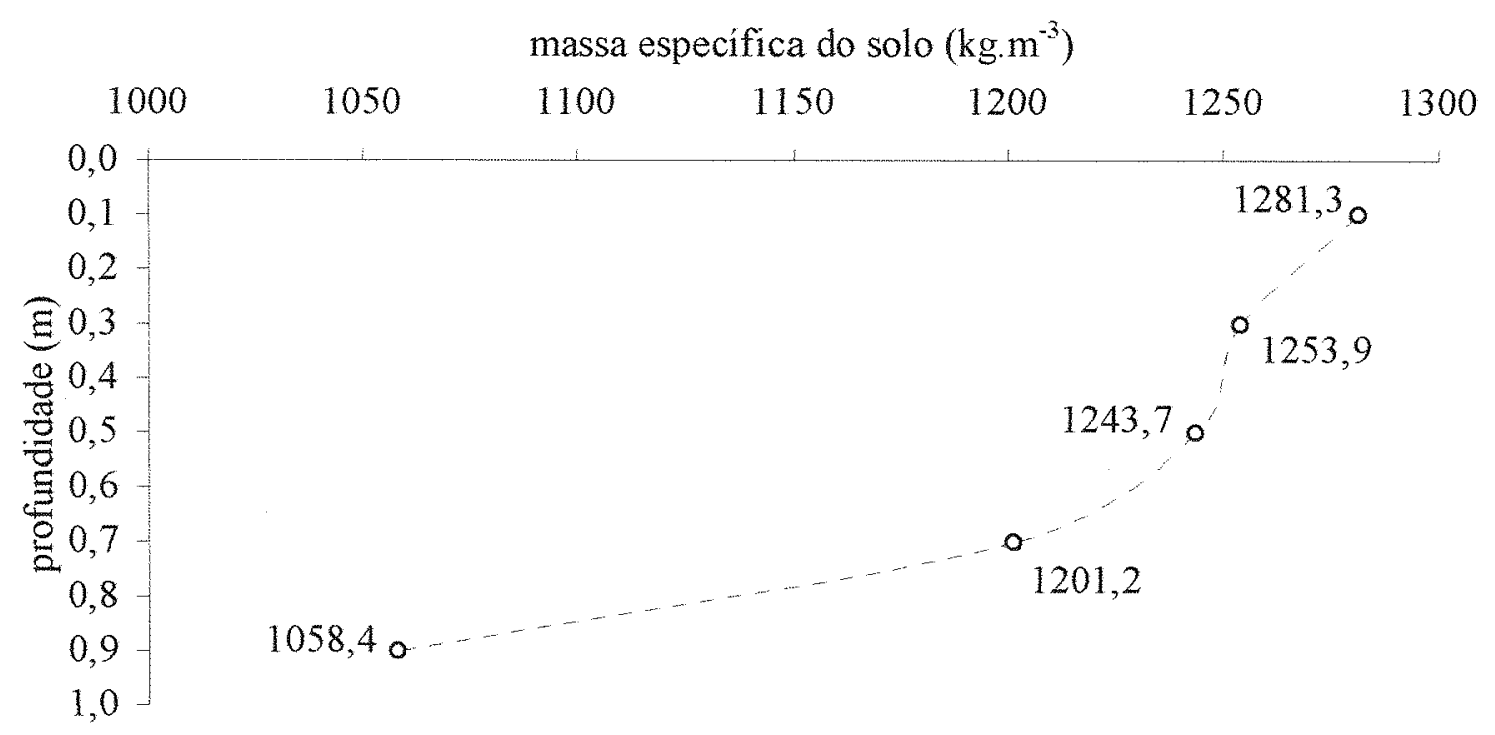

Figura 6. Comportamento dos valores de massa especifica do solo em função da profundidade no perfil ensaiado.

Com isto tornou-se possivel calcular os teores de água em base de volume que, com os respectivos valores de potencial matricial, foram ajustados à eq. (7), que reorganizada pode ser escrita como

$$
\theta=\theta_{r}+\frac{\theta_{s}-\theta_{r}}{\left[1+\left(\alpha \cdot \Phi_{m}\right)^{\eta}\right]^{m}}
$$


sendo $\theta$ o teor de água na amostra com base em volume e $\Phi_{m}$ o respectivo potencial matricial, representado pela tensão à qual esta foi submetida $(L)$, com sinal negativo.

Os pares de dados supracitados são mostrados no Apêndice 1, referentes a cada uma das cinco camadas do perfil, conforme intervalos de profundidade de amostragem. Ratifica-se a não consideração do fenômeno da histerese no processo de molhamento e secagem do solo, sendo estes dados obtidos em condição exclusiva de secagem, ainda que ciente da infiltração ser um processo apenas de molhamento e determinar o volume de água que entra no sistema.

Os coeficientes de ajuste da eq. (19) são apresentados na Tabela 2, e as curvas de retenção de água no solo são apresentadas na Figura 7.

Tabela 2. Coeficientes das curvas de retenção de água, referentes aos pares de dados de potencial matricial versus teor de água no solo em base de volume, em função da profundidade, para o perfil ensaiado.

\begin{tabular}{|c|c|c|c|c|c|}
\hline \multirow{2}{*}{ coefretts } & \multicolumn{5}{|c|}{ 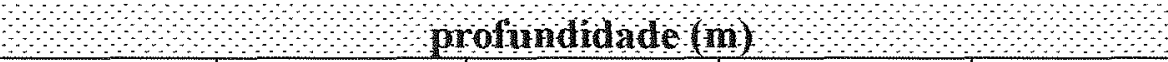 } \\
\hline & $0,0 \because 0,2$ & $0,2-0,4$ & $0,4<0,6$ & $0,6 \Leftrightarrow 0, \mathrm{~g}$ & $\mathrm{og} \mathrm{s}, \mathrm{O}$ \\
\hline$\alpha\left(\mathrm{m}^{-1}\right)$ & $-2,9484$ & $-2,5962$ & $-7,6387$ & $-3,5955$ & $-5,5825$ \\
\hline$\eta$ & 1,5147 & 1,4885 & 1,4519 & 1,4726 & 1,6032 \\
\hline$m$ & 0,3398 & 0,3282 & 0,3113 & 0,3209 & 0,3762 \\
\hline$\theta_{S}\left(\mathrm{~m}^{3} \cdot \mathrm{m}^{-3}\right)$ & 0,5847 & 0,5394 & 0,5521 & 0,5309 & 0,5318 \\
\hline$\theta_{r}\left(\mathrm{~m}^{3} \cdot \mathrm{m}^{-3}\right)$ & 0,2976 & 0,3020 & 0,3238 & 0,3114 & 0,2776 \\
\hline
\end{tabular}

As curvas de retenção obtidas serviram para todos os ensaios realizados, e semelhante ao tratamento dado aos valores de condutividade hidráulica saturada, os compartimentos com baricentro dentro de uma das camadas amostradas são representados por uma única curva. 


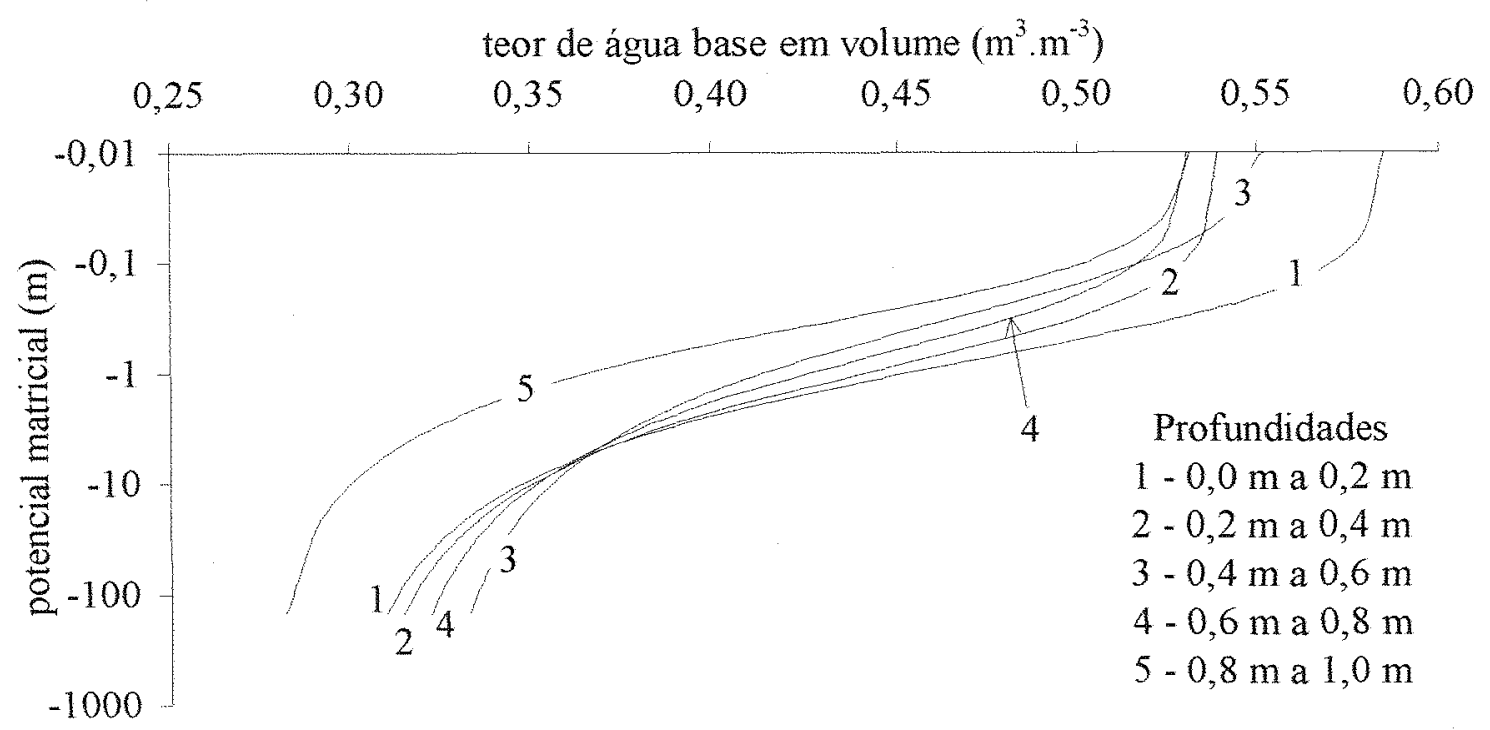

Figura 7. Curvas de retenção de água no solo do perfil ensaiado.

\subsubsection{Teor de água inicial no solo}

Antes da efetivação de cada um dos cinco ensaios foram feitas amostragens com trado, visando obter o teor de água inicial no solo, na profundidade média de cada uma das cinco camadas de $0,2 \mathrm{~m}$ de espessura, ou seja, às profundidades de $0,1 \mathrm{~m}, 0,3 \mathrm{~m}, 0,5 \mathrm{~m}, 0,7 \mathrm{~m}, \mathrm{e} 0,9 \mathrm{~m}$, a uma distância lateral de $1 \mathrm{~m}$ do sulco e a cerca de $1 \mathrm{~m}$ do local onde foram realizadas as amostragens de acompanhamento do perfil de teor de água no solo, após aplicação de água.

Todos os compartimentos com baricentro compreendido dentro de uma dada camada amostrada são representados pelo mesmo teor de água inicial, a esta atribuída, semelhante ao tratamento dado à condutividade hidráulica saturada e à retenção de água.

Os valores de teor de água no solo, obtidos antes de cada um dos ensaios, estão apresentados na Tabela 3. 
Tabela 3. Teores de água iniciais no solo em função da profundidade, referente a cada um dos ensaios realizados.

\begin{tabular}{|c|c|c|c|c|c|}
\hline \multirow{2}{*}{ (n) } & \multicolumn{5}{|c|}{ profundrade (m) } \\
\hline & $0,0-0,2$ & $0,2<0_{4}$ & $0,40,6$ & $0,6,0$ & $0, \mathrm{O} \quad 0$ \\
\hline I & 0,2515 & 0,3267 & 0,3280 & 0,3158 & 0,2987 \\
\hline II & 0,2384 & 0,3312 & 0,3259 & 0,3266 & 0,3000 \\
\hline III & 0,2594 & 0,3294 & 0,3306 & 0,3101 & 0,3017 \\
\hline IV & 0,2564 & 0,3214 & 0,3381 & 0,3274 & 0,2974 \\
\hline $\mathrm{V}$ & 0,2271 & 0,3189 & 0,3423 & 0,3345 & 0,2834 \\
\hline
\end{tabular}

\subsubsection{Perfil transversal do sulco}

O contorno original do sulco quanto ao perfil transversal foi obtido com a utilização de perfilômetro de varetas, escolhendo-se três posições espaçadas de 0,5 m para leitura e centralizadas ao longo do comprimento do sulco. O perfil utilizado na simulação no modelo DASIS foi aquele resultante da média entre as três determinações.

Cada um dos ensaios realizados foi caracterizado por um perfil transversal do sulco, determinado minutos antes da aplicação de água a este. Cinco perfís foram definidos, referentes aos cinco ensaios realizados, sendo apresentados na Figura 8 , cujos valores utilizados em sua confecção encontram-se no Apêndice 1.

\subsubsection{Lâmina de água no sulco}

A lâmina de água no sulco foi caracterizada quanto a sua altura, desde o início da aplicação até seu completo desaparecimento da superficie, em intervalos de 30 segundos. 


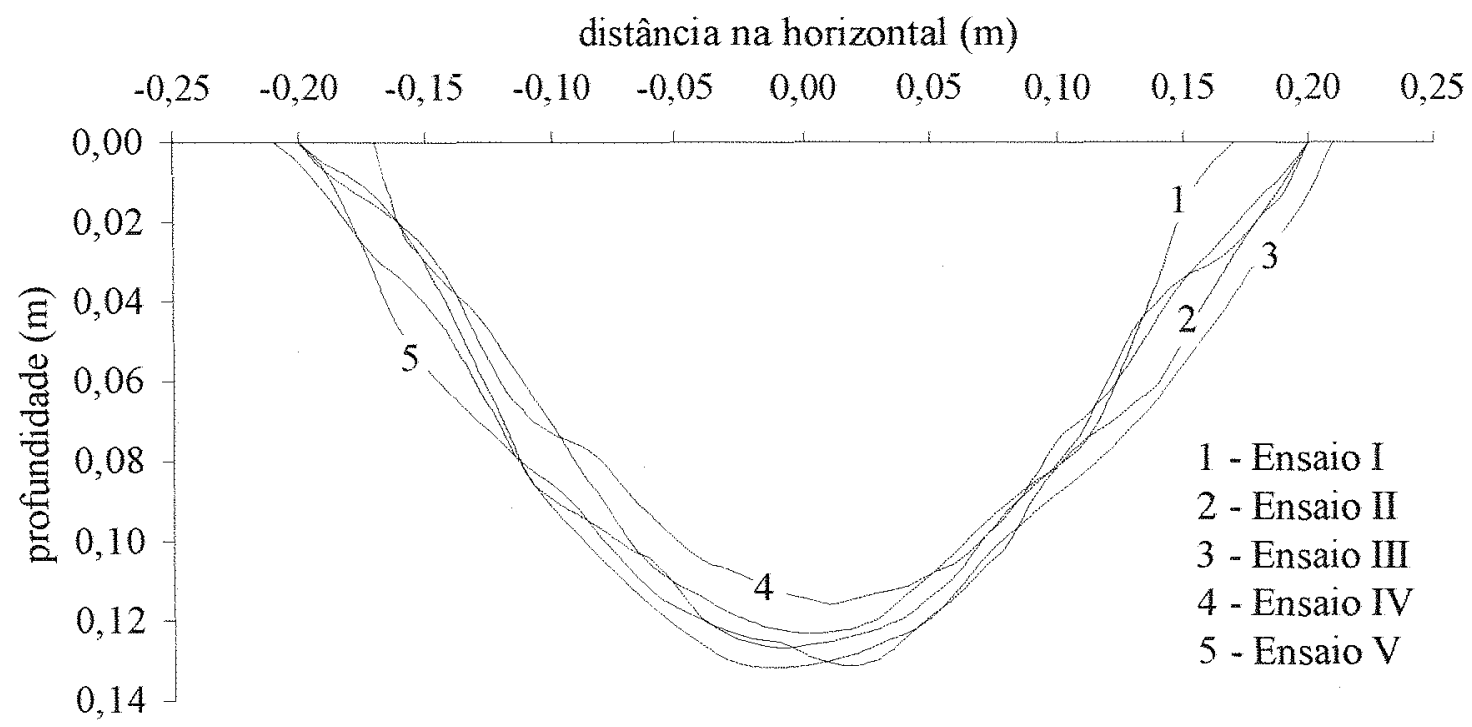

Figura 8. Perfis transversais do sulco ao inicio de cada um dos ensaios realizados.

As medições foram feitas utilizando-se uma régua posicionada na parte mais profunda do sulco, de forma a permitir o registro da altura da lâmina de água durante todo o tempo de molhamento.

O comportamento da altura da lâmina de água no sulco foi registrado para cada um dos ensaios realizados e está apresentado na Figura 9, cujos dados utilizados em sua confecção estão apresentados no Apêndice 1.

No Ensaio I foram aplicados $0,30 \mathrm{~m}^{3}$ de água, com o reservatório posicionado $1,0 \mathrm{~m}$ acima do terreno. Nos demais ensaios manteve-se o reservatório ao nível do terreno, consumindo $0,15 \mathrm{~m}^{3}$ de água no Ensaio $I I, 0,10 \mathrm{~m}^{3}$ de água no Ensaio III, $0,12 \mathrm{~m}^{3}$ de água no Ensaio IV, e $0,13 \mathrm{~m}^{3}$ de água no Ensaio V. Tais valores, convertidos para metro cúbico de água consumido por metro de sulco, resultam em $0,060 \mathrm{~m}^{3} \cdot \mathrm{m}^{-1}, \quad 0,030 \mathrm{~m}^{3} \cdot \mathrm{m}^{-1}, \quad 0,020 \mathrm{~m}^{3} \cdot \mathrm{m}^{-1}, \quad 0,024 \mathrm{~m}^{3} \cdot \mathrm{m}^{-1}$, e $0,026 \mathrm{~m}^{3} \cdot \mathrm{m}^{-1}$, respectivamente. 


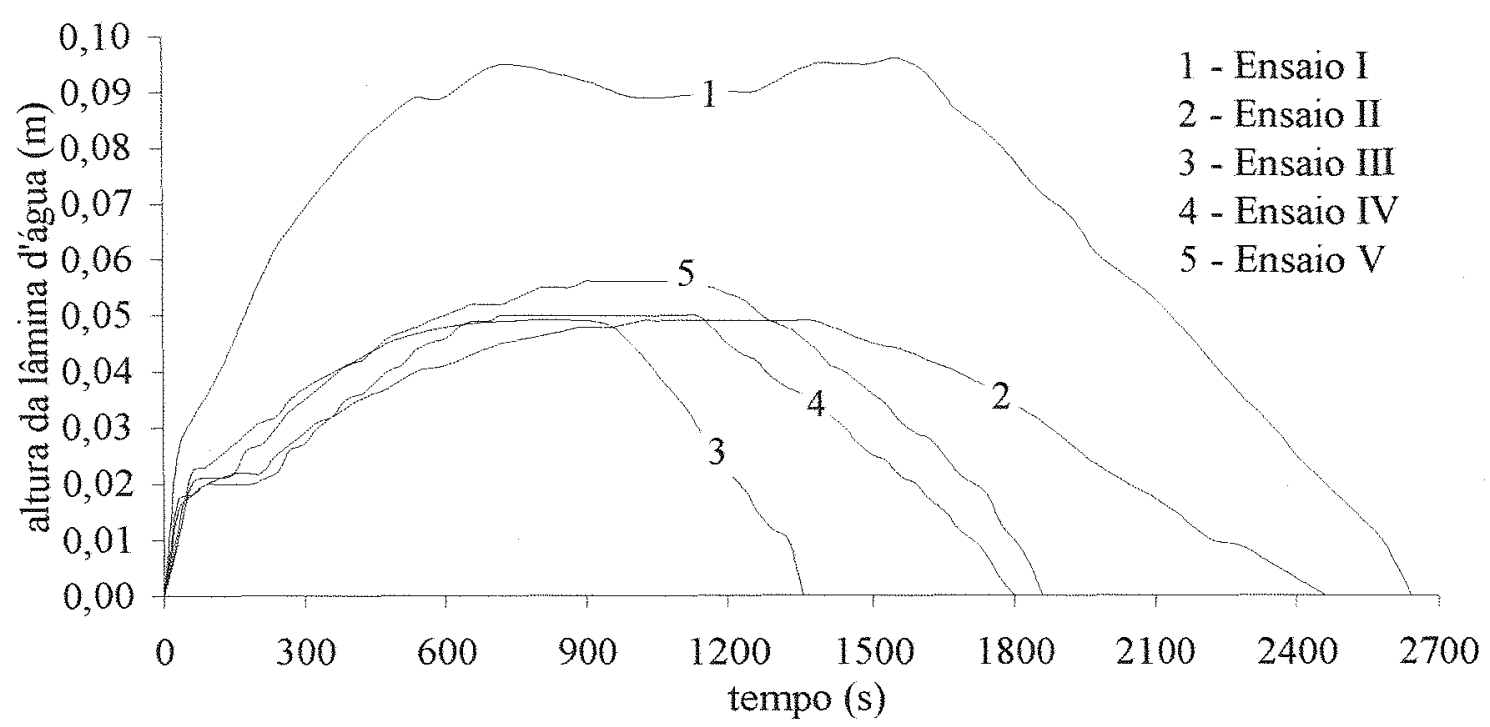

Figura 9. Comportamento da altura da lâmina de água dentro do sulco em função tempo após inicio de aplicação de água, para cada um dos ensaios.

\subsubsection{Efetivação do ensaio}

Com a estrutura da área instalada, efetivaram-se os ensaios a campo em número de 5, identificados por Ensaio I até Ensaio V, sendo condição necessária para a realização destes a manutenção de no mínimo duas semanas consecutivas com tempo sem chuva, o que foi respeitado. Esta condição possibilita realizar os ensaios em solo com gradientes de potencial total praticamente inexpressivos para o propósito do estudo.

Passadas 24 horas após o início da aplicação de água, foram feitas tradagens para determinação do teor de água no solo, nas profundidades de $0,1 \mathrm{~m}, 0,3 \mathrm{~m}$ $0,5 \mathrm{~m}, 0,7 \mathrm{~m}$ e $0,9 \mathrm{~m}$ a partir da superficie do solo, e em três locais, um sendo no centro do sulco e os outros dois afastados lateralmente deste de $0,5 \mathrm{~m}$, um à direita e outro à esquerda do primeiro. Na determinação do teor de água no solo ao centro do sulco, a referência de nivel foi seu leito, ou seja, considerou-se a profundidade a partir do fundo 
do sulco.

Os dados obtidos permitiram confeccionar perfis de teor de água referentes a cada um dos três pontos de tradagem, para cada um dos cinco ensaios.

\subsection{Validação do modelo DASIS}

No processo de validação do modelo, buscou-se identificar sua acurácia utilizando o programa computacional, aplicado aos dados coletados a campo em cada um dos cinco ensaios realizados.

A existência de fontes de erros sistemáticos, inerentes a condições iniciais e de contorno do modelo, implica na necessidade de se identificar como estes erros ocorrem, sendo que para isto realizaram-se simulações, correspondentes a cada um dos ensaios a campo, fazendo variar três parâmetros:

a) número de linhas radiais - 10, 20 e 30 linhas radiais;

b) número de linhas de contorno - 5, 10 e 15 linhas de contorno;

c) variação permitida no teor de água dentro de um laço de simulação - 0,001,0,005 e $0,01 \mathrm{~m}^{3} \cdot \mathrm{m}^{-3}$

Todas as simulações foram realizadas para um total de 24 horas $(86400$ segundos), das quais selecionou-se a combinação dos três parâmetros citados que resultaram, para os cinco ensaios realizados, em valores de volume de água infiltrado mais próximos dos volumes de água aplicados a campo. Esta combinação foi utilizada na análise de acurácia do modelo. Para isto, os padrões de distribuição do teor de água nos perfis computacionais foram comparados aos perfis de teor de água obtidos a campo, buscando identificar o quanto os dados simulados foram condizentes com aqueles obtidos experimentalmente nas áreas ensaiadas, ou seja, acurados. Uma análise referente ao 
tempo consumido em processamento também foi realizada.

A análise estatística de dados emparelhados, aplicando o teste " $\mathrm{t} " \mathrm{e}$ determinando o coeficiente de correlação de Pearson, foi a ferramenta utilizada para maiores inferências quanto à acurácia.

O equipamento utilizado nas simulações foi um micro-computador padrão IBM-PC, com CPU 80486 DX2-S, e clock de $66 \mathrm{MHz}$. 


\section{RESULTADOS E DISCUSSÃO}

\subsection{Generalidades}

Os resultados obtidos durante a realização deste trabalho podem ser divididos em quatro categorias, ou seja: resultados básicos, referentes à confecção do programa computacional e à obtenção de dados para sua alimentação; resultados simulados, obtidos com o uso do modelo; resultados experimentais, obtidos ao final dos ensaios a campo; e resultados comparativos, referentes à análise de acurácia do modelo.

\subsection{Resultados básicos}

Como resultados básicos têm-se o algorítmo desenvolvido para confecção do programa computacional; os dados obtidos a partir de amostras de solo coletadas a campo e processadas em laboratório; e dados obtidos durante a realização dos ensaios a campo. Estes dados dispensam discussão por apenas caracterizar uma condição inerente ao local ensaiado, pelo qual foram apresentados no capítulo referente a material e métodos

Os dados obtidos a partir de amostras de solo, coletadas a campo, são referentes à condutividade hidráulica saturada e à curva de retenção, estando também presente a determinação da massa específica do solo. Quanto aos dados obtidos no ensaio 
a campo, estes referem-se ao teor de água inicial no solo, ao perfil transversal do sulco e ao comportamento da altura da lâmina no sulco.

A análise do modelo DASIS permitu desenvolver um algoritmo simplificado, apresentado nas Figuras 10a,b,c. Este algoritmo não abrange todas as rotinas e estruturas envolvidas no modelo, mas contém suas partes fundamentais.

\begin{tabular}{|c|c|}
\hline 00 & INICIO algoritmo DASIS \\
\hline & $\sqrt{2}$ \\
\hline 01 & LER \\
\hline & número de linhas radiais \\
\hline & número de linhas de contorno \\
\hline & profundidade do perfil computacional \\
\hline & coordenadas $(Y, Z)$ ao longo do contorno original do sulco \\
\hline & $\sqrt{3}$ \\
\hline 02 & para cada um dos compartimentos do perfil computacional CALCULAR \\
\hline & volume para um comprimento unitário \\
\hline & coordenada $(Y, Z)$ do baricentro \\
\hline 16 & distâncias do baricentro até as quatro faces limites \\
\hline$\because$ & áreas das quatro faces limites para um comprimento unitário \\
\hline & $\sqrt{3}$ \\
\hline 03 & para cada um dos compartimentos do perfil computacional LER \\
\hline & teor de água inicial \\
\hline & teor de água à saturação \\
\hline & teor de água residual \\
\hline & coeficientes $\alpha$ e $m$ da curva de retenção de água \\
\hline$\because$ & condutividade hidráulica saturada \\
\hline & 8 \\
\hline 04 & para cada um dos compartimentos do perfil computacional CALCULAR \\
\hline$\because$ & potencial matricial para o teor de água inicial \\
\hline & condutividade hidráulica para o teor de água inicial \\
\hline & I \\
\hline 05 & LER \\
\hline & tempo total a simular \\
\hline$\because$ & variação permitida no teor de água dentro de um laço de simulação \\
\hline & tempo de aplicação de água ao sulco \\
\hline & alturas da lâmina d'água sobre o sulco ao longo do tempo de aplicação \\
\hline
\end{tabular}


$\sqrt{3}$

06
$0 \rightarrow$ ATtervalo de tempo
$0 \rightarrow$ tempo simulado
$0 \rightarrow$ número de laços efetuados
$0 \rightarrow$ volume de água infiltrado por unidade de comprimento de sulco
$0 \rightarrow$ área molhada média por unidade de comprimento de sulco
$2 \rightarrow$ número de ordem da camada limite

\begin{tabular}{cc}
\hline 7 & ATRIBUIR \\
$60.4 \rightarrow$ intervalo de tempo calculado
\end{tabular}

08 VERIFICAR

tempo simulado < tempo de aplicação de água ao sulco ?

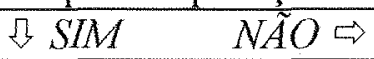

IR PARA campo 14

ATRIBUIR
número de laços efetuados $+1 \rightarrow$ número de laços efetuados

$10 \quad$ REALIZAR PROCEDIMENTO LIMITE 2

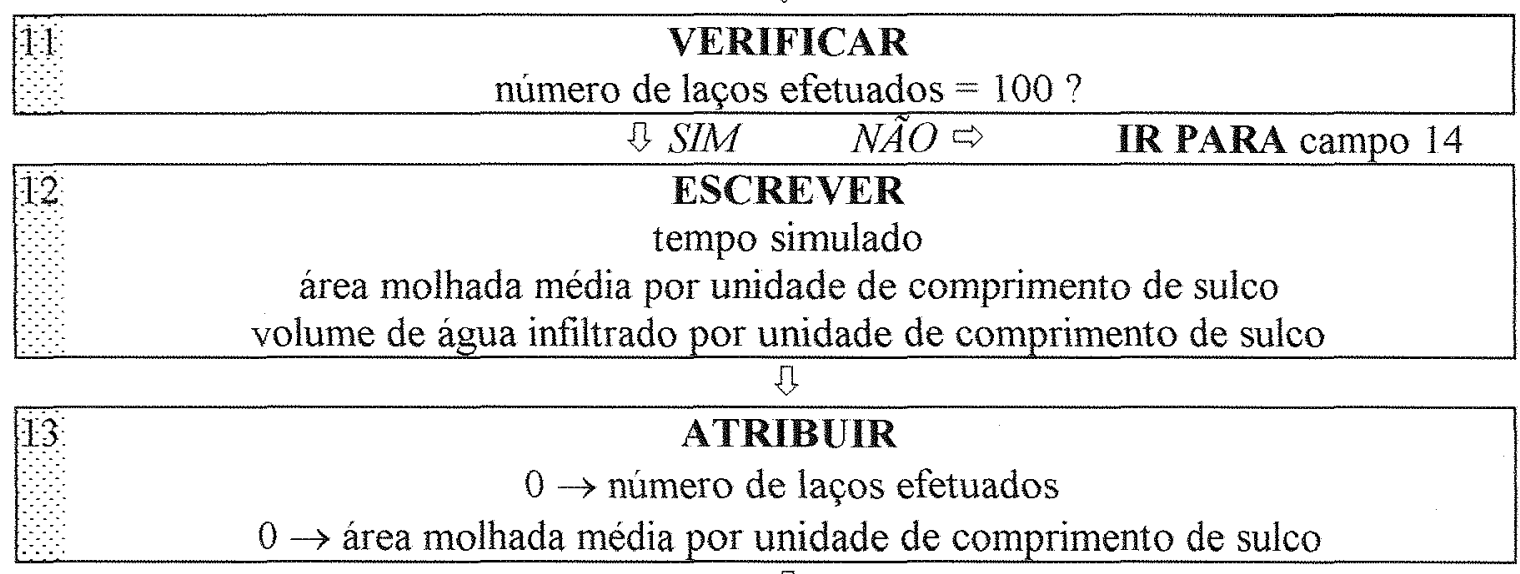
$\sqrt{3}$

14: REALIZAR PROCEDIMENTO LIMITE 1 $\sqrt{3}$

ATRIBUIR
tempo simulado + intervalo de tempo $\rightarrow$ tempo simulado
intervalo de tempo calculado $\rightarrow$ intervalo de tempo

$$
\text { n }
$$

16. para cada um dos compartimentos do perfil computacional VERIFICAR teor de água no compartimento > teor de água à saturação ?

$$
\text { ?ु } S I M \quad N \tilde{A} O \Rightarrow \quad \text { IR PARA campo } 18
$$


ת) SIM

\begin{tabular}{|c|c|}
\hline 17 & $\begin{array}{l}\text { ATRIBUIR } \\
\text { teor de água no compartimento }- \text { teor de água à saturação } \rightarrow \text { excedente } \\
\text { teor de água à saturação } \rightarrow \text { teor de água no compartimento } \\
\text { cor de água compartim. inferior }+ \text { excedente } \rightarrow \text { teor de água compartimento inferior }\end{array}$ \\
\hline & $\sqrt{3}$ \\
\hline 18 & $\begin{array}{c}\text { para cada um dos compartimentos do perfil computacional CALCULAR } \\
\text { potencial matricial para o teor de água no compartimento } \\
\text { condutividade hidráulica para o teor de água no compartimento }\end{array}$ \\
\hline & $\sqrt{3}$ \\
\hline 19 & $\begin{array}{c}\text { para cada um dos compartimentos da última camada ativa VERIFICAR } \\
\text { teor de água - teor de água inicial }>0,01 \text { ? }\end{array}$ \\
\hline & IR PARA campo 21 \\
\hline 20 & $\begin{array}{c}\text { ATRIBUIR } \\
\text { contorno limite }+1 \rightarrow \text { contorno limite }\end{array}$ \\
\hline & 乃 \\
\hline 21 & $\begin{array}{c}\text { VERIFICAR } \\
\text { tempo simulado }>\text { tempo total a simular? }\end{array}$ \\
\hline & $\sqrt{3 S I M} \quad N \tilde{A} O \Rightarrow \quad$ IR PARA campo 07 \\
\hline 22 & $\begin{array}{c}\text { para cada um dos compartimentos do perfil computacional ESCREVER } \\
\text { coordenada }(\mathrm{Y}, \mathrm{Z}) \text { do baricentro } \\
\text { teor de água no compartimento }\end{array}$ \\
\hline & $\sqrt{3}$ \\
\hline
\end{tabular}

Figura 10a. Algoritmo simplificado do modelo DASIS (corpo principal).

\begin{tabular}{|c|c|}
\hline 00 & INÍCIO procedimento LIMITE 2 \\
\hline & तु \\
\hline 0 & $\begin{array}{c}\text { CALCULAR } \\
\text { coordenada }(\mathrm{Z}) \text { da superficie da lâmina de água no sulco }\end{array}$ \\
\hline
\end{tabular}
3 02 para cada um dos compartimentos da camada jumto ao sulco VERIFICAR coordenada $(Z)$ da superfície da lâmina de água no sulco $>$ coordenada $(Z)$ do(s) vértice(s) da face limite 1 ?

$$
\text { ת } S I M N A \hat{O} \Rightarrow \text { IR PARA campo } 08
$$


$\sqrt{3}$

\begin{tabular}{|c|c|}
\hline \multicolumn{2}{|r|}{ VERIFICAR } \\
\hline & IR PARA campo 04 \\
\hline 83 & $\begin{array}{l}\text { ATRIBUIR } \\
\text { ariação permitida no teor de água dentro de um laço de simulação / taxa de variação } \\
\text { de teor de água em relação ao compartimento à esquerda } \rightarrow \text { intervalo de tempo } \\
\text { calculado }\end{array}$ \\
\hline & $\pi$ \\
\hline & $\begin{array}{c}\text { para cada um dos compartimentos do perfil computacional CALCULAR } \\
\text { variação de teor de água no intervalo de tempo } \\
\text { novo teor de água no compartimento à esquerda } \\
\text { novo teor de água no compartimento considerado }\end{array}$ \\
\hline
\end{tabular}

तु

\begin{tabular}{|c|c|}
\hline 05 & para cada um dos compartimentos do perfil computacional CALCULAR \\
condutividade hidráulica média em relação ao compartimento inferior \\
gradiente de potencial total em relação ao compartimento inferior \\
taxa de variação de teor de água em relação ao compartimento inferior \\
variação de teor de água no intervalo de tempo calculado
\end{tabular}

\begin{tabular}{cc|}
\hline 06 & VERIFICAR \\
zariação de teor de água no intervalo de tempo calculado > variação permitida no \\
teor de água dentro de um laço de simulação ?
\end{tabular}
teor de água dentro de um laço de simulação ?

\begin{tabular}{c} 
S. SIM NAO $\Rightarrow$ IR PARA campo 08 \\
ATRIBUIR \\
$\begin{array}{c}\text { variação permitida no teor de água dentro de um laço de simulação / taxa de variação } \\
\text { de teor de água em relação ao compartimento inferior } \rightarrow \text { intervalo de tempo } \\
\text { calculado }\end{array}$ \\
\hline
\end{tabular}

\begin{tabular}{|c|c|}
\hline 08 & $\begin{array}{c}\text { para cada um dos compartimentos do perfil computacional CALCULAR } \\
\text { variação de teor de água no intervalo de tempo } \\
\text { novo teor de água no compartimento inferior } \\
\text { novo teor de água no compartimento considerado }\end{array}$ \\
\hline
\end{tabular}

Q9: FINAL procedimento LIMITE 1

Figura 10c. Algoritmo simplificado do modelo DASIS (procedimento LIMITE_1).

A estrutura do algorítmo é composta basicamente de três partes, sendo um corpo principal e dois procedimentos específicos. O corpo principal trata da entrada 
de dados, da definição do perfil computacional, do controle da simulação, e da apresentação dos resultados simulados. No controle da simulação são acionados os procedimentos especificos.

O primeiro procedimento específico, denominado LIMITE_2, trata do processo de transferência de água junto ao sulco de irrigação, quantificando o volume infiltrado no perfil computacional. Este procedimento é acionado enquanto o tempo simulado for menor que o tempo de aplicação de água ao sulco.

O segundo procedimento específico é denominado. LIMITE_1. É acionado durante tôda a simulação, envolvendo as trocas de água entre os compartimentos do perfil computacional.

O programa computacional foi escrito em linguagem Pascal (Turbo Pascal 6.0 Copyright ${ }^{(} 1990$ Borland International, Inc.). Este programa, denominado DASIS, é apresentado no Apêndice 2 e permite obter os padrões de distribuição de teor de água no perfil de solo, facilitado por uma estrutura existente para criação de script files, de manipulação direta pelo programa AutoCAD (AutoCAD Release 12 Copyright $\left.^{(}\right)$ 1982-92 Autodesk, Inc), que desenha o perfil computacional e lança os pontos representando os baricentros, cuja coordenada $(Z)$ é igual ao teor de água no compartimento ao final da simulação. Pela utilização de um aplicativo específico para AutoCAD, denominado QuickSurf (QuickSurf Version 2.92 Copyright ${ }^{\circledR} 1991$ Schreiber Instruments, Inc), é feita a interpolação das coordenadas $(Z)$ de cada compartimento, desenhando o padrão de distribuição.

Os dados de entrada e os resultados da simulação são manipulados na forma de arquivos tipo texto, podendo-se observar um exemplo no Apêndice 2. Os arquivos de dados de entrada utilizam o mesmo nome, diferindo apenas em suas extensões. Os arquivos de resultados são criados também com o nome base e diferentes 
quanto às extensões.

\subsection{Resultados simulados}

Os resultados simulados foram gerados a partir do processamento dos resultados básicos pelo programa DASIS. Esses resultados compreendem padrões de distribuição de água no perfil computacional, representados por linhas de mesmo teor, sendo também registrado o comportamento do volume de água infiltrado e da velocidade de infiltração ao longo do tempo, referentes a cada um dos cinco ensaios realizados.

O tratamento das fontes de erros sistemáticos, inerentes a condições iniciais e de contorno do modelo e correspondentes a cada um dos ensaios a campo, tem por base os resultados apresentados nas Tabelas 4 até 8 . Tais dados referem-se ao tempo consumido em processamento (s), volume simulado de água infiltrado por unidade de comprimento de sulco $\left(\mathrm{m}^{3} \cdot \mathrm{m}^{-1}\right)$, e variação percentual do volume simulado em relação ao volume aplicado a campo (\%), estes em função do número de linhas radiais, número de linhas de contorno, e variação permitida no teor de água dentro de um laço de simulação. 
Tabela 4. Tempo consumido em processamento, volume simulado de água infiltrado por unidade de comprimento de sulco e variação entre volume simulado de água infiltrado e volume aplicado a campo, em função do número de linhas radiais, de linhas de contorno, e da variação permitida no teor de água dentro de um laço de simulação, referente ao Ensaio I (volume de água aplicado igual a $0,060 \mathrm{~m}^{3} \cdot \mathrm{m}^{-1}$ ).

\begin{tabular}{|c|c|c|c|}
\hline \multirow{2}{*}{ 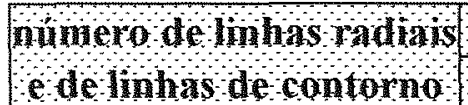 } & \multicolumn{3}{|c|}{ 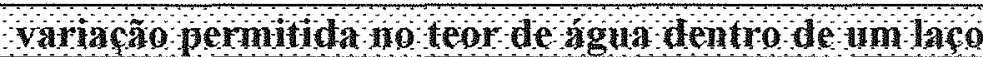 } \\
\hline & $0,001 \mathrm{~m}^{3} \mathrm{~cm}^{-3}$ & $0,005 \mathrm{~m}^{3} \mathrm{~m}^{-3}$ & $0,01 \mathrm{~m}^{3} \mathrm{im}^{-3}$ \\
\hline 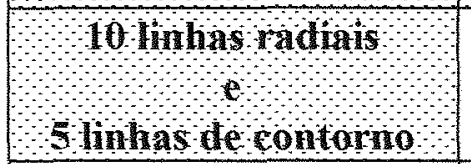 & $\begin{array}{c}37,02 \mathrm{~s} \\
0,0171 \mathrm{~m}^{3} \cdot \mathrm{m}^{-1} \\
-71,50 \%\end{array}$ & $\begin{array}{c}16,86 \mathrm{~s} \\
0,0172 \mathrm{~m}^{3} \cdot \mathrm{m}^{-1} \\
-71,33 \%\end{array}$ & $\begin{array}{c}14,28 \mathrm{~s} \\
0,0172 \mathrm{~m}^{3} \cdot \mathrm{m}^{-1} \\
-71,33 \%\end{array}$ \\
\hline 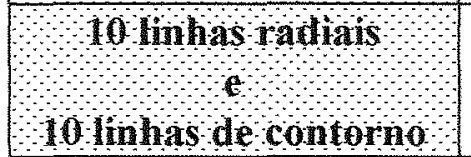 & $\begin{array}{c}583,55 \mathrm{~s} \\
0,0707 \mathrm{~m}^{3} \cdot \mathrm{m}^{-1} \\
+17,83 \%\end{array}$ & $\begin{array}{c}138,30 \mathrm{~s} \\
0,0676 \mathrm{~m}^{3} \cdot \mathrm{m}^{-1} \\
+12,67 \%\end{array}$ & $\begin{array}{c}84,64 \mathrm{~s} \\
0,0662 \mathrm{~m}^{3} \cdot \mathrm{m}^{-1} \\
+10,33 \%\end{array}$ \\
\hline 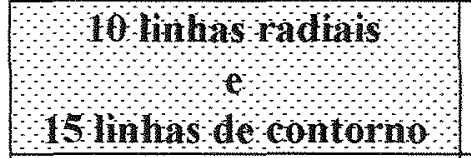 & $\begin{array}{c}2093,60 \mathrm{~s} \\
0,1673 \mathrm{~m}^{3} \cdot \mathrm{m}^{-1} \\
+178,83 \% \\
\end{array}$ & $\begin{array}{c}459,73 \mathrm{~s} \\
0,1624 \mathrm{~m}^{3} \cdot \mathrm{m}^{-1} \\
+170,67 \% \\
\end{array}$ & $\begin{array}{c}261,17 \mathrm{~s} \\
0,1603 \mathrm{~m}^{3} \cdot \mathrm{m}^{-1} \\
+167,17 \% \\
\end{array}$ \\
\hline $\begin{array}{ll}b_{1} & \end{array}$ & $\begin{array}{c}103,98 \mathrm{~s} \\
0,0162 \mathrm{~m}^{3} \cdot \mathrm{m}^{-1} \\
-73,00 \% \\
\end{array}$ & $\begin{array}{c}39,99 \mathrm{~s} \\
0,0162 \mathrm{~m}^{3} \cdot \mathrm{m}^{-1} \\
-73,00 \% \\
\end{array}$ & $\begin{array}{c}32,46 \mathrm{~s} \\
0,0163 \mathrm{~m}^{3} \cdot \mathrm{m}^{-1} \\
-72,83 \% \\
\end{array}$ \\
\hline 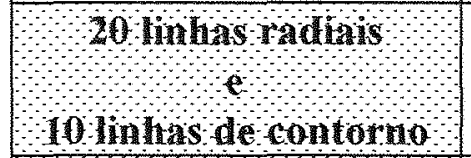 & $\begin{array}{c}1569,99 \mathrm{~s} \\
0,0670 \mathrm{~m}^{3} \cdot \mathrm{m}^{-1} \\
+11,67 \% \\
\end{array}$ & $\begin{array}{c}350,32 \mathrm{~s} \\
0,0643 \mathrm{~m}^{3} \cdot \mathrm{m}^{-1} \\
+7,17 \% \\
\end{array}$ & $\begin{array}{c}205,25 \mathrm{~s} \\
0,0631 \mathrm{~m}^{3} \cdot \mathrm{m}^{-1} \\
+5,17 \%\end{array}$ \\
\hline 1 & $\begin{array}{c}2224,25 \mathrm{~s} \\
0,1594 \mathrm{~m}^{3} \cdot \mathrm{m}^{-1} \\
+165,67 \%\end{array}$ & $\begin{array}{c}1273,67 \mathrm{~s} \\
0,1545 \mathrm{~m}^{3} \cdot \mathrm{m}^{-1} \\
+157,50 \%\end{array}$ & $\begin{array}{c}722,93 \mathrm{~s} \\
0,1520 \mathrm{~m}^{3} \cdot \mathrm{m}^{-1} \\
+153,33 \%\end{array}$ \\
\hline 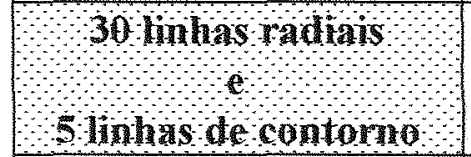 & $\begin{array}{c}189,55 \mathrm{~s} \\
0,0163 \mathrm{~m}^{3} \cdot \mathrm{m}^{-1} \\
-72,83 \%\end{array}$ & $\begin{array}{c}67,40 \mathrm{~s} \\
0,0163 \mathrm{~m}^{3} \cdot \mathrm{m}^{-1} \\
-72,83 \% \\
\end{array}$ & $\begin{array}{c}52,51 \mathrm{~s} \\
0,0164 \mathrm{~m}^{3} \cdot \mathrm{m}^{-1} \\
-72,67 \%\end{array}$ \\
\hline 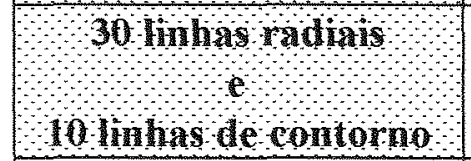 & $\begin{array}{c}2611,21 \mathrm{~s} \\
0,0659 \mathrm{~m}^{3} \cdot \mathrm{m}^{-1} \\
+9,83 \% \\
\end{array}$ & $\begin{array}{c}817,07 \mathrm{~s} \\
0,0493 \mathrm{~m}^{3} \cdot \mathrm{m}^{-1} \\
-17,83 \% \\
\end{array}$ & $\begin{array}{c}444,74 \mathrm{~s} \\
0,0481 \mathrm{~m}^{3} \cdot \mathrm{m}^{-1} \\
-19,83 \% \\
\end{array}$ \\
\hline 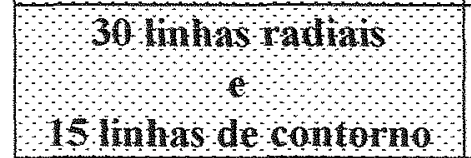 & $\begin{array}{c}34533,42 \mathrm{~s} \\
0,0953 \mathrm{~m}^{3} \cdot \mathrm{m}^{-1} \\
+58,83 \%\end{array}$ & $\begin{array}{c}6787,48 \mathrm{~s} \\
0,0926 \mathrm{~m}^{3} \cdot \mathrm{m}^{-1} \\
+54,33 \%\end{array}$ & $\begin{array}{c}3443,88 \mathrm{~s} \\
0,0915 \mathrm{~m}^{3} \cdot \mathrm{m}^{-1} \\
+52,50 \%\end{array}$ \\
\hline
\end{tabular}


Tabela 5. Tempo consumido em processamento, volume simulado de água infiltrado por unidade de comprimento de sulco e variação entre volume simulado de água infiltrado e volume aplicado a campo, em função do mímero de limhas radiais, de linhas de contorno, e da variação permitida no teor de água dentro de um laço de simulação, referente ao Ensaio II (volume de água aplicado igual a $0,030 \mathrm{~m}^{3} \cdot \mathrm{m}^{-1}$ ).

\begin{tabular}{|c|c|c|c|}
\hline numero le linas radiais & \multicolumn{3}{|c|}{ 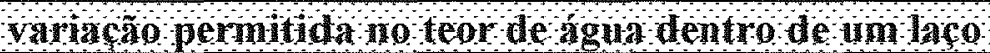 } \\
\hline de linhas de contomo & $0001 \mathrm{~m}^{3} \mathrm{~m}^{3}$ & $0,00 \mathrm{~m}^{3} \mathrm{~m}^{-3}$ & $0,0 \mathrm{~m}^{3} \mathrm{~m}^{-3}$ \\
\hline 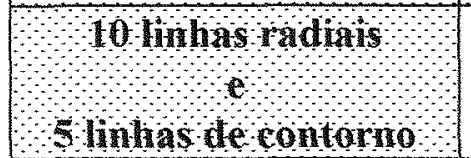 & $\begin{array}{c}28,34 \mathrm{~s} \\
0,0107 \mathrm{~m}^{3} \cdot \mathrm{m}^{-1} \\
-64,33 \%\end{array}$ & $\begin{array}{c}14,83 \mathrm{~s} \\
0,0107 \mathrm{~m}^{3} \cdot \mathrm{m}^{-1} \\
-64,33 \%\end{array}$ & $\begin{array}{c}13,18 \mathrm{~s} \\
0,0108 \mathrm{~m}^{3} \cdot \mathrm{m}^{-1} \\
-64,00 \%\end{array}$ \\
\hline ald & $\begin{array}{c}474,39 \mathrm{~s} \\
0,0279 \mathrm{~m}^{3} \cdot \mathrm{m}^{-1} \\
-7,00 \% \\
\end{array}$ & $\begin{array}{c}115,23 \mathrm{~s} \\
0,0275 \mathrm{~m}^{3} \cdot \mathrm{m}^{-1} \\
-8,33 \% \\
\end{array}$ & $\begin{array}{c}71,79 \mathrm{~s} \\
0,0273 \mathrm{~m}^{3} \cdot \mathrm{m}^{-1} \\
-9,00 \%\end{array}$ \\
\hline 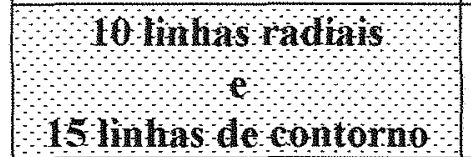 & $\begin{array}{c}1610,96 \mathrm{~s} \\
0,0536 \mathrm{~m}^{3} \cdot \mathrm{m}^{-1} \\
+78,67 \%\end{array}$ & $\begin{array}{c}356,19 \mathrm{~s} \\
0,0541 \mathrm{~m}^{3} \cdot \mathrm{m}^{-1} \\
+80,33 \%\end{array}$ & $\begin{array}{c}204,60 \mathrm{~s} \\
0,0551 \mathrm{~m}^{3} \cdot \mathrm{m}^{-1} \\
+83,67 \%\end{array}$ \\
\hline 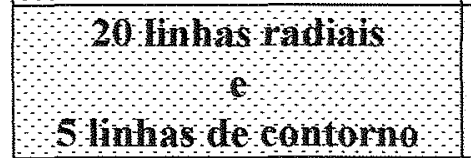 & $\begin{array}{c}79,03 \mathrm{~s} \\
0,0100 \mathrm{~m}^{3} \cdot \mathrm{m}^{-1} \\
-66,67 \%\end{array}$ & $\begin{array}{c}36,09 \mathrm{~s} \\
0,0100 \mathrm{~m}^{3} \cdot \mathrm{m}^{-1} \\
-66,67 \%\end{array}$ & $\begin{array}{c}31,09 \mathrm{~s} \\
0,0100 \mathrm{~m}^{3} \cdot \mathrm{m}^{-1} \\
-66,67 \%\end{array}$ \\
\hline 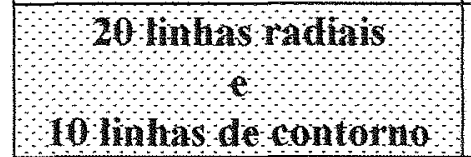 & $\begin{array}{c}1058,96 \mathrm{~s} \\
0,0283 \mathrm{~m}^{3} \cdot \mathrm{m}^{-1} \\
-5,67 \%\end{array}$ & $\begin{array}{c}258,51 \mathrm{~s} \\
0,0258 \mathrm{~m}^{3} \cdot \mathrm{m}^{-1} \\
-7,00 \%\end{array}$ & $\begin{array}{c}180,43 \mathrm{~s} \\
0,0259 \mathrm{~m}^{3} \cdot \mathrm{m}^{-1} \\
-13,67 \%\end{array}$ \\
\hline 15 & $\begin{array}{c}898,40 \mathrm{~s} \\
0,0529 \mathrm{~m}^{3} \cdot \mathrm{m}^{-1} \\
+76,33 \%\end{array}$ & $\begin{array}{c}955,49 \mathrm{~s} \\
0,0534 \mathrm{~m}^{3} \cdot \mathrm{m}^{-1} \\
+78,00 \%\end{array}$ & $\begin{array}{c}1005,47 \mathrm{~s} \\
0,0386 \mathrm{~m}^{3} \cdot \mathrm{m}^{-1} \\
+28,67 \%\end{array}$ \\
\hline 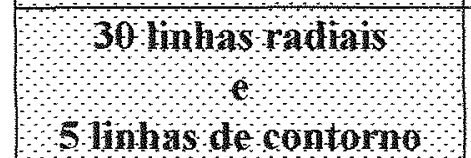 & $\begin{array}{c}150,22 \mathrm{~s} \\
0,0099 \mathrm{~m}^{3} \cdot \mathrm{m}^{-1} \\
-67,00 \%\end{array}$ & $\begin{array}{c}59,76 \mathrm{~s} \\
0,0099 \mathrm{~m}^{3} \cdot \mathrm{m}^{-1} \\
-67,00 \%\end{array}$ & $\begin{array}{c}48,83 \mathrm{~s} \\
0,0099 \mathrm{~m}^{3} \cdot \mathrm{m}^{-1} \\
-67,00 \%\end{array}$ \\
\hline 10 linhas de contorno & $\begin{array}{c}1956,23 \mathrm{~s} \\
0,0261 \mathrm{~m}^{3} \cdot \mathrm{m}^{-1} \\
-13,00 \%\end{array}$ & $\begin{array}{c}455,56 \mathrm{~s} \\
0,0257 \mathrm{~m}^{3} \cdot \mathrm{m}^{-1} \\
-14,33 \%\end{array}$ & $\begin{array}{c}282,43 \mathrm{~s} \\
0,0259 \mathrm{~m}^{3} \cdot \mathrm{m}^{-1} \\
-13,67 \%\end{array}$ \\
\hline 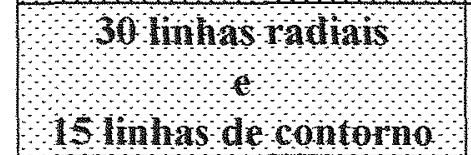 & $\begin{array}{c}706,47 \mathrm{~s} \\
0,0512 \mathrm{~m}^{3} \cdot \mathrm{m}^{-1} \\
+70,67 \%\end{array}$ & $\begin{array}{c}1629,11 \mathrm{~s} \\
0,0517 \mathrm{~m}^{3} \cdot \mathrm{m}^{-1} \\
+72,33 \% \\
\end{array}$ & $\begin{array}{c}1571,25 \mathrm{~s} \\
0,0389 \mathrm{~m}^{3} \cdot \mathrm{m}^{-1} \\
+29,67 \%\end{array}$ \\
\hline
\end{tabular}


Tabela 6. Tempo consumido em processamento, volume simulado de água infiltrado por unidade de comprimento de sulco e variação entre volume simulado de água infiltrado e volume aplicado a campo, em função do número de linhas radiais, de linhas de contorno, e da variação permitida no teor de água dentro de um laço de simulação, referente ao Ensaio III (volume de água aplicado igual a $0,020 \mathrm{~m}^{3} \cdot \mathrm{m}^{-1}$ ).

\begin{tabular}{|c|c|c|c|}
\hline \multirow{2}{*}{ 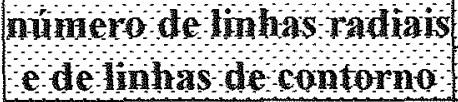 } & \multicolumn{3}{|c|}{ 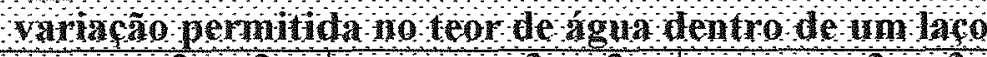 } \\
\hline & $0,00 \mathrm{~m}^{3} \mathrm{~m}^{-3}$ & $0,005 \mathrm{~m}^{3} \mathrm{~m}^{-3}$ & $0,01 \mathrm{~m}^{3} \mathrm{~m}^{-3}$ \\
\hline 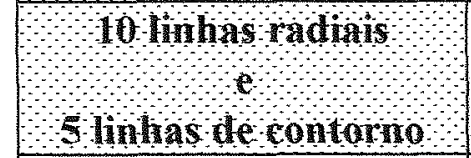 & $\begin{array}{c}20,98 \mathrm{~s} \\
0,0077 \mathrm{~m}^{3} \cdot \mathrm{m}^{-1} \\
-61,50 \%\end{array}$ & $\begin{array}{c}11,92 \mathrm{~s} \\
0,0078 \mathrm{~m}^{3} \cdot \mathrm{m}^{-1} \\
-61,00 \% \\
\end{array}$ & $\begin{array}{c}10,82 \mathrm{~s} \\
0,0078 \mathrm{~m}^{3} \cdot \mathrm{m}^{-1} \\
-61,00 \% \\
\end{array}$ \\
\hline 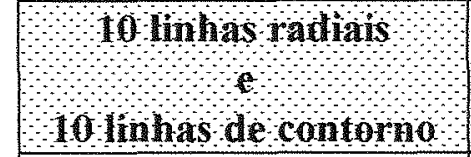 & $\begin{array}{c}269,63 \mathrm{~s} \\
0,0181 \mathrm{~m}^{3} \cdot \mathrm{m}^{-1} \\
-9,50 \% \\
\end{array}$ & $\begin{array}{c}72,94 \mathrm{~s} \\
0,0179 \mathrm{~m}^{3} \cdot \mathrm{m}^{-1} \\
-10,50 \% \\
\end{array}$ & $\begin{array}{c}48,99 \mathrm{~s} \\
0,0178 \mathrm{~m}^{3} \cdot \mathrm{m}^{-1} \\
-11,00 \% \\
\end{array}$ \\
\hline 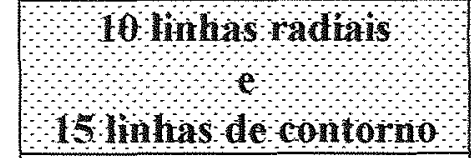 & $\begin{array}{c}916,88 \mathrm{~s} \\
0,0334 \mathrm{~m}^{3} \cdot \mathrm{m}^{-1} \\
+67,00 \% \\
\end{array}$ & $\begin{array}{c}216,08 \mathrm{~s} \\
0,0336 \mathrm{~m}^{3} \cdot \mathrm{m}^{-1} \\
+68,00 \% \\
\end{array}$ & $\begin{array}{c}131,93 \mathrm{~s} \\
0,0342 \mathrm{~m}^{3} \cdot \mathrm{m}^{-1} \\
+71,00 \% \\
\end{array}$ \\
\hline blow & $\begin{array}{c}59,65 \mathrm{~s} \\
0,0072 \mathrm{~m}^{3} \cdot \mathrm{m}^{-1} \\
-64,00 \% \\
\end{array}$ & $\begin{array}{c}30,60 \mathrm{~s} \\
0,0072 \mathrm{~m}^{3} \cdot \mathrm{m}^{-1} \\
-64,00 \% \\
\end{array}$ & $\begin{array}{c}27,25 \mathrm{~s} \\
0,0073 \mathrm{~m}^{3} \cdot \mathrm{m}^{-1} \\
-63,50 \% \\
\end{array}$ \\
\hline 10 & $\begin{array}{c}605,50 \mathrm{~s} \\
0,0178 \mathrm{~m}^{3} \cdot \mathrm{m}^{-1} \\
-11,00 \% \\
\end{array}$ & $\begin{array}{c}162,91 \mathrm{~s} \\
0,0175 \mathrm{~m}^{3} \cdot \mathrm{m}^{-1} \\
-12,50 \%\end{array}$ & $\begin{array}{c}115,90 \mathrm{~s} \\
0,0167 \mathrm{~m}^{3} \cdot \mathrm{m}^{-1} \\
-16,50 \%\end{array}$ \\
\hline 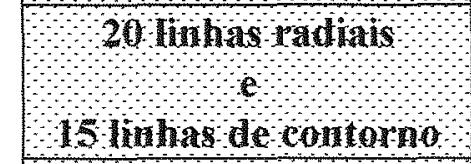 & $\begin{array}{c}2577,16 \mathrm{~s} \\
0,0311 \mathrm{~m}^{3} \cdot \mathrm{m}^{-1} \\
+55,50 \% \\
\end{array}$ & $\begin{array}{c}587,82 \mathrm{~s} \\
0,0311 \mathrm{~m}^{3} \cdot \mathrm{m}^{-1} \\
+55,50 \% \\
\end{array}$ & $\begin{array}{c}356,08 \mathrm{~s} \\
0,0313 \mathrm{~m}^{3} \cdot \mathrm{m}^{-1} \\
+56,50 \% \\
\end{array}$ \\
\hline 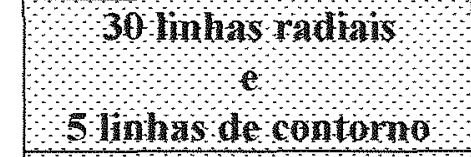 & $\begin{array}{c}109,19 \mathrm{~s} \\
0,0071 \mathrm{~m}^{3} \cdot \mathrm{m}^{-1} \\
-64,50 \% \\
\end{array}$ & $\begin{array}{c}49,99 \mathrm{~s} \\
0,0071 \mathrm{~m}^{3} \cdot \mathrm{m}^{-1} \\
-64,50 \% \\
\end{array}$ & $\begin{array}{c}43,23 \mathrm{~s} \\
0,0071 \mathrm{~m}^{3} \cdot \mathrm{m}^{-1} \\
-64,50 \% \\
\end{array}$ \\
\hline $\begin{array}{ll}y_{1} & \end{array}$ & $\begin{array}{c}985,18 \mathrm{~s} \\
0,0178 \mathrm{~m}^{3} \cdot \mathrm{m}^{-1} \\
-11,00 \% \\
\end{array}$ & $\begin{array}{c}282,59 \mathrm{~s} \\
0,0168 \mathrm{~m}^{3} \cdot \mathrm{m}^{-1} \\
-16,00 \% \\
\end{array}$ & $\begin{array}{c}187,79 \mathrm{~s} \\
0,0167 \mathrm{~m}^{3} \cdot \mathrm{m}^{-1} \\
-16,50 \% \\
\end{array}$ \\
\hline 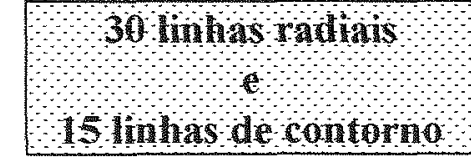 & $\begin{array}{c}7088,41 \mathrm{~s} \\
0,0237 \mathrm{~m}^{3} \cdot \mathrm{m}^{-1} \\
+18,50 \% \\
\end{array}$ & $\begin{array}{c}1518,70 \mathrm{~s} \\
0,0237 \mathrm{~m}^{3} \cdot \mathrm{m}^{-1} \\
+18,50 \% \\
\end{array}$ & $\begin{array}{c}851,29 \mathrm{~s} \\
0,0241 \mathrm{~m}^{3} \cdot \mathrm{m}^{-1} \\
+20,50 \% \\
\end{array}$ \\
\hline
\end{tabular}


Tabela 7. Tempo consumido em processamento, volume simulado de água infiltrado por unidade de comprimento de sulco e variação entre volume simulado de água infiltrado e volume aplicado a campo, em função do número de linhas radiais, de linhas de contorno, e da variação permitida no teor de água dentro de um laço de simulação, referente ao Ensaio IV (volume de água aplicado igual a $0,024 \mathrm{~m}^{3} \cdot \mathrm{m}^{-1}$ ).

\begin{tabular}{|c|c|c|c|}
\hline \multirow{2}{*}{ 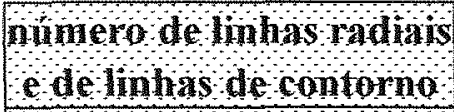 } & \multicolumn{3}{|c|}{ 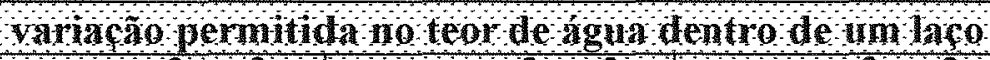 } \\
\hline & $0,001 \mathrm{~m}^{3} \mathrm{~m}^{3}$ & $0,005 \mathrm{~m} \mathrm{~m}^{3}$ & $0,01 \mathrm{~m}^{3}, \mathrm{~m}^{3}$ \\
\hline $\begin{array}{ll}b_{1} & \end{array}$ & $\begin{array}{c}25,48 \mathrm{~s} \\
0,0092 \mathrm{~m}^{3} \cdot \mathrm{m}^{-1} \\
-61,67 \% \\
\end{array}$ & $\begin{array}{c}13,73 \mathrm{~s} \\
0,0092 \mathrm{~m}^{3} \cdot \mathrm{m}^{-1} \\
-61,67 \% \\
\end{array}$ & $\begin{array}{c}12,36 \mathrm{~s} \\
0,0093 \mathrm{~m}^{3} \cdot \mathrm{m}^{-1} \\
-61,25 \% \\
\end{array}$ \\
\hline r & $\begin{array}{c}359,76 \mathrm{~s} \\
0,0222 \mathrm{~m}^{3} \cdot \mathrm{m}^{-1} \\
-7,50 \% \\
\end{array}$ & $\begin{array}{c}91,72 \mathrm{~s} \\
0,0218 \mathrm{~m}^{3} \cdot \mathrm{m}^{-1} \\
-9,17 \%\end{array}$ & $\begin{array}{c}58,77 \mathrm{~s} \\
0,0218 \mathrm{~m}^{3} \cdot \mathrm{m}^{-1} \\
-9,17 \%\end{array}$ \\
\hline 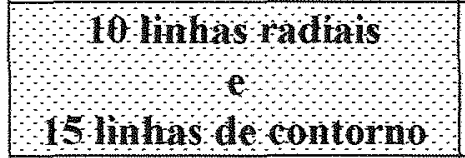 & $\begin{array}{c}1175,24 \mathrm{~s} \\
0,0423 \mathrm{~m}^{3} \cdot \mathrm{m}^{-1} \\
+76,25 \% \\
\end{array}$ & $\begin{array}{c}269,08 \mathrm{~s} \\
0,0424 \mathrm{~m}^{3} \cdot \mathrm{m}^{-1} \\
+76,67 \% \\
\end{array}$ & $\begin{array}{c}160,77 \mathrm{~s} \\
0,0429 \mathrm{~m}^{3} \cdot \mathrm{m}^{-1} \\
+78,75 \%\end{array}$ \\
\hline $\begin{array}{ll}b_{2} & \end{array}$ & $\begin{array}{c}67,29 \mathrm{~s} \\
0,0085 \mathrm{~m}^{3} \cdot \mathrm{m}^{-1} \\
-64,58 \% \\
\end{array}$ & $\begin{array}{c}30,87 \mathrm{~s} \\
0,0085 \mathrm{~m}^{3} \cdot \mathrm{m}^{-1} \\
-64,58 \% \\
\end{array}$ & $\begin{array}{c}26,42 \mathrm{~s} \\
0,0085 \mathrm{~m}^{3} \cdot \mathrm{m}^{-1} \\
-64,58 \% \\
\end{array}$ \\
\hline 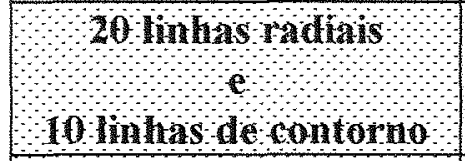 & $\begin{array}{c}768,68 \mathrm{~s} \\
0,0220 \mathrm{~m}^{3} \cdot \mathrm{m}^{-1} \\
-8,33 \% \\
\end{array}$ & $\begin{array}{c}214,60 \mathrm{~s} \\
0,0207 \mathrm{~m}^{3} \cdot \mathrm{m}^{-1} \\
-13,75 \% \\
\end{array}$ & $\begin{array}{c}135,94 \mathrm{~s} \\
0,0206 \mathrm{~m}^{3} \cdot \mathrm{m}^{-1} \\
-14,17 \% \\
\end{array}$ \\
\hline 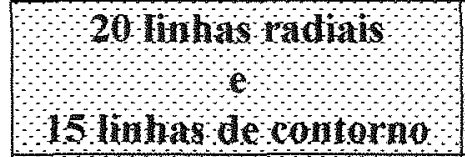 & $\begin{array}{c}3375,45 \mathrm{~s} \\
0,0386 \mathrm{~m}^{3} \cdot \mathrm{m}^{-1} \\
+60,83 \% \\
\end{array}$ & $\begin{array}{c}731,60 \mathrm{~s} \\
0,0388 \mathrm{~m}^{3} \cdot \mathrm{m}^{-1} \\
+61,67 \% \\
\end{array}$ & $\begin{array}{c}428,18 \mathrm{~s} \\
0,0393 \mathrm{~m}^{3} \cdot \mathrm{m}^{-1} \\
+63,75 \% \\
\end{array}$ \\
\hline 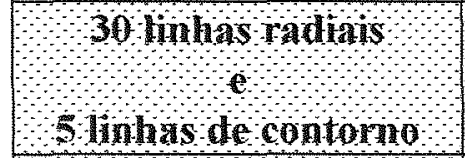 & $\begin{array}{c}128,92 \mathrm{~s} \\
0,0090 \mathrm{~m}^{3} \cdot \mathrm{m}^{-1} \\
-62,50 \% \\
\end{array}$ & $\begin{array}{c}50,98 \mathrm{~s} \\
0,0090 \mathrm{~m}^{3} \cdot \mathrm{m}^{-1} \\
-62,50 \%\end{array}$ & $\begin{array}{c}41,30 \mathrm{~s} \\
0,0090 \mathrm{~m}^{3} \cdot \mathrm{m}^{-1} \\
-62,50 \%\end{array}$ \\
\hline s & $\begin{array}{c}1397,35 \mathrm{~s} \\
0,0212 \mathrm{~m}^{3} \cdot \mathrm{m}^{-1} \\
-11,67 \% \\
\end{array}$ & $\begin{array}{c}339,39 \mathrm{~s} \\
0,0209 \mathrm{~m}^{3} \cdot \mathrm{m}^{-1} \\
-12,92 \% \\
\end{array}$ & $\begin{array}{c}222,67 \mathrm{~s} \\
0,0209 \mathrm{~m}^{3} \cdot \mathrm{m}^{-1} \\
-12,92 \% \\
\end{array}$ \\
\hline 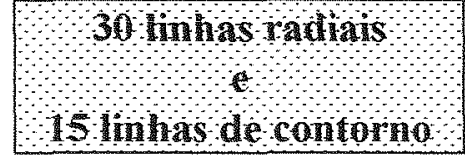 & $\begin{array}{c}9429,01 \mathrm{~s} \\
0,0296 \mathrm{~m}^{3} \cdot \mathrm{m}^{-1} \\
+23,33 \% \\
\end{array}$ & $\begin{array}{c}1996,65 \mathrm{~s} \\
0,0296 \mathrm{~m}^{3} \cdot \mathrm{m}^{-1} \\
+23,33 \% \\
\end{array}$ & $\begin{array}{c}1003,85 \mathrm{~s} \\
0,0303 \mathrm{~m}^{3} \cdot \mathrm{m}^{-1} \\
+26,25 \%\end{array}$ \\
\hline
\end{tabular}


Tabela 8. Tempo consumido em processamento, volume simulado de água infiltrado por unidade de comprimento de sulco e variação entre volume simulado de água infiltrado e volume aplicado a campo, em função do número de linhas radiais, de linhas de contorno, e da variação permitida no teor de água dentro de um laço de simulação, referente ao Ensaio $\mathrm{V}$ (volume de água aplicado igual a $\left.0,026 \mathrm{~m}^{3} \cdot \mathrm{m}^{-1}\right)$.

\begin{tabular}{|c|c|c|c|}
\hline \multirow{2}{*}{ 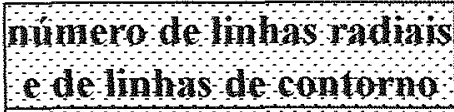 } & \multicolumn{3}{|c|}{ 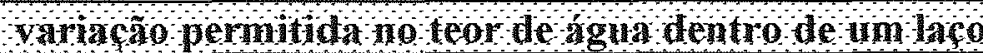 } \\
\hline & $00,00 \mathrm{~m} \mathrm{~m}^{3}$ & $00005 \mathrm{~m}^{3} \mathrm{~m}^{3}$ & $0,01 \mathrm{~m}^{3} \mathrm{~m}^{-3}$ \\
\hline s & $\begin{array}{c}30,04 \mathrm{~s} \\
0,0114 \mathrm{~m}^{3} \cdot \mathrm{m}^{-1} \\
-56,15 \%\end{array}$ & $\begin{array}{c}14,33 \mathrm{~s} \\
0,0114 \mathrm{~m}^{3} \cdot \mathrm{m}^{-1} \\
-56,15 \%\end{array}$ & $\begin{array}{c}12,83 \mathrm{~s} \\
0,0115 \mathrm{~m}^{3} \cdot \mathrm{m}^{-1} \\
-55,77 \%\end{array}$ \\
\hline 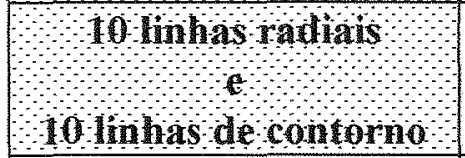 & $\begin{array}{c}402,53 \mathrm{~s} \\
0,0269 \mathrm{~m}^{3} \cdot \mathrm{m}^{-1} \\
+3,46 \% \\
\end{array}$ & $\begin{array}{c}100,02 \mathrm{~s} \\
0,0263 \mathrm{~m}^{3} \cdot \mathrm{m}^{-1} \\
+1,15 \% \\
\end{array}$ & $\begin{array}{c}62,23 \mathrm{~s} \\
0,0263 \mathrm{~m}^{3} \cdot \mathrm{m}^{-1} \\
+1,15 \% \\
\end{array}$ \\
\hline 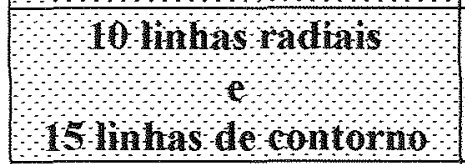 & $\begin{array}{c}1307,51 \mathrm{~s} \\
0,0536 \mathrm{~m}^{3} \cdot \mathrm{m}^{-1} \\
+106,15 \% \\
\end{array}$ & $\begin{array}{c}296,42 \mathrm{~s} \\
0,0533 \mathrm{~m}^{3} \cdot \mathrm{m}^{-1} \\
+105,00 \% \\
\end{array}$ & $\begin{array}{c}176,64 \mathrm{~s} \\
0,0535 \mathrm{~m}^{3} \cdot \mathrm{m}^{-1} \\
+105,77 \% \\
\end{array}$ \\
\hline 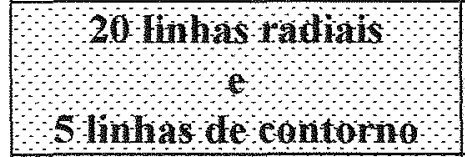 & $\begin{array}{c}87,94 \mathrm{~s} \\
0,0103 \mathrm{~m}^{3} \cdot \mathrm{m}^{-1} \\
-60,38 \%\end{array}$ & $\begin{array}{c}33,00 \mathrm{~s} \\
0,0103 \mathrm{~m}^{3} \cdot \mathrm{m}^{-1} \\
-60,38 \% \\
\end{array}$ & $\begin{array}{c}26,91 \mathrm{~s} \\
0,0104 \mathrm{~m}^{3} \cdot \mathrm{m}^{-1} \\
-60,00 \%\end{array}$ \\
\hline 10 & $\begin{array}{c}1053,36 \mathrm{~s} \\
0,0245 \mathrm{~m}^{3} \cdot \mathrm{m}^{-1} \\
-5,77 \% \\
\end{array}$ & $\begin{array}{c}217,50 \mathrm{~s} \\
0,0256 \mathrm{~m}^{3} \cdot \mathrm{m}^{-1} \\
-1,54 \% \\
\end{array}$ & $\begin{array}{c}150,01 \mathrm{~s} \\
0,0238 \mathrm{~m}^{3} \cdot \mathrm{m}^{-1} \\
-8,46 \% \\
\end{array}$ \\
\hline 20 & $\begin{array}{c}3908,55 \mathrm{~s} \\
0,0488 \mathrm{~m}^{3} \cdot \mathrm{m}^{-1} \\
+87,69 \%\end{array}$ & $\begin{array}{c}849,53 \mathrm{~s} \\
0,0485 \mathrm{~m}^{3} \cdot \mathrm{m}^{-1} \\
+86,54 \%\end{array}$ & $\begin{array}{c}483,29 \mathrm{~s} \\
0,0489 \mathrm{~m}^{3} \cdot \mathrm{m}^{-1} \\
+88,08 \%\end{array}$ \\
\hline 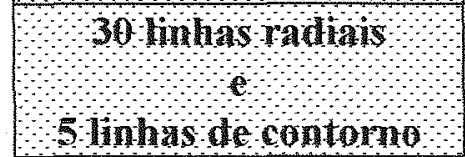 & $\begin{array}{c}164,29 \mathrm{~s} \\
0,0102 \mathrm{~m}^{3} \cdot \mathrm{m}^{-1} \\
-60,77 \%\end{array}$ & $\begin{array}{c}55,47 \mathrm{~s} \\
0,0102 \mathrm{~m}^{3} \cdot \mathrm{m}^{-1} \\
-60,77 \%\end{array}$ & $\begin{array}{c}42,74 \mathrm{~s} \\
0,0103 \mathrm{~m}^{3} \cdot \mathrm{m}^{-1} \\
-60,38 \%\end{array}$ \\
\hline s & $\begin{array}{c}1675,45 \mathrm{~s} \\
0,0244 \mathrm{~m}^{3} \cdot \mathrm{m}^{-1} \\
-6,15 \%\end{array}$ & $\begin{array}{c}385,58 \mathrm{~s} \\
0,0240 \mathrm{~m}^{3} \cdot \mathrm{m}^{-1} \\
-7,69 \%\end{array}$ & $\begin{array}{c}235,30 \mathrm{~s} \\
0,0239 \mathrm{~m}^{3} \cdot \mathrm{m}^{-1} \\
-8,08 \%\end{array}$ \\
\hline bls & $\begin{array}{c}11631,90 \mathrm{~s} \\
0,0358 \mathrm{~m}^{3} \cdot \mathrm{m}^{-1} \\
+37,69 \% \\
\end{array}$ & $\begin{array}{c}2397,25 \mathrm{~s} \\
0,0356 \mathrm{~m}^{3} \cdot \mathrm{m}^{-1} \\
+36,92 \% \\
\end{array}$ & $\begin{array}{c}1289,87 \mathrm{~s} \\
0,0360 \mathrm{~m}^{3} \cdot \mathrm{m}^{-1} \\
+38,46 \%\end{array}$ \\
\hline
\end{tabular}


Dos dados apresentados nessas tabelas pode-se inferir quanto à sensibilidade do modelo aos três parâmetros analisados. Fazendo-se variar o número de linhas radiais, mantidos os dois outros parâmetros constantes, tem-se um coeficiente de variação médio para o volume simulado, referente aos cinco ensaios realizados, igual a $9,40 \%$. O mesmo procedimento, fazendo-se variar primeiro o número de linhas de contorno e depois o valor da variação permitida no teor de água dentro de um laço de simulação, resulta em coeficientes de variação igual a $68,05 \%$ e $2,31 \%$, respectivamente. Estes valores de coeficiente de variação indicam que a principal fonte de erros sistemáticos do modelo é o número de linhas de contorno, com os dois outros fatores representando menor amplitude nos resultados simulados.

Detectada a influência da escolha do número de linhas de contorno no resultado da simulação, tem-se que a variação percentual do volume simulado em relação ao volume aplicado a campo assume menores valores quando da utilização de 10 linhas de contorno.

Prosseguindo a análise e limitando-a às situações cujo número de linhas de contorno é igual a 10, observa-se que os resultados simulados mais próximos aos experimentais foram obtidos para a condição de 10 linhas radiais, à exceção do Ensaio I. Juntamente ao valor relativamente baixo do coeficiente de variação referente a esta fonte de erros, calculado anteriormente e igual a 9,40\%, a análise permite assumir o valor de 10 linhas radiais como a mais apropriada para a simulação. Deste modo define-se o número máximo de compartimentos do perfil computacional, formados por 10 linhas radiais e 10 linhas de contorno, igual a 81 compartimentos.

A última fonte de erros sistemáticos analisada, por ser a de menor coeficiente de variação das três e igual a $2,31 \%$, o valor da variação permitida no teor de água dentro de um laço de simulação não tem um valor que predomina nos cinco ensaios. 
Esta análise, aplicada às condições de compartimentação escolhida, resulta na seleção do valor de $0,001 \mathrm{~m}^{3} \cdot \mathrm{m}^{-3}$ para ser utilizado nas simulações. Este valor aparece como o mais apropriado em três ensaios, contudo apresenta a maior variação percentual média do volume simulado em relação ao volume aplicado a campo, mas com uma diferença de $0,93 \%$ da menor variação percentual média, referente ao valor de $0,01 \mathrm{~m}^{3} \cdot \mathrm{m}^{-3}$.

Quanto ao tempo consumido em processamento, tem-se que quanto maior o número de compartimentos no perfil computacional e menor o valor da variação permitida no teor de água dentro de um laço de simulação, maior é o tempo consumido.

Selecionado o número de linhas radiais e de linhas de contorno do perfil computacional, bem como o valor da variação permitida no teor de água dentro de um laço de simulação, montaram-se os padrões de distribuição de teor de água no perfil, os quais são apresentados nas cinco figuras a seguir (Figura 11 até Figura 15).

distância na horizontal $(\mathrm{m})$

$\begin{array}{lllllllllllll}0,0 & 0,1 & 0,2 & 0,3 & 0,4 & 0,5 & 0,6 & 0,7 & 0,8 & 0,9 & 1,0 & 1,1\end{array}$

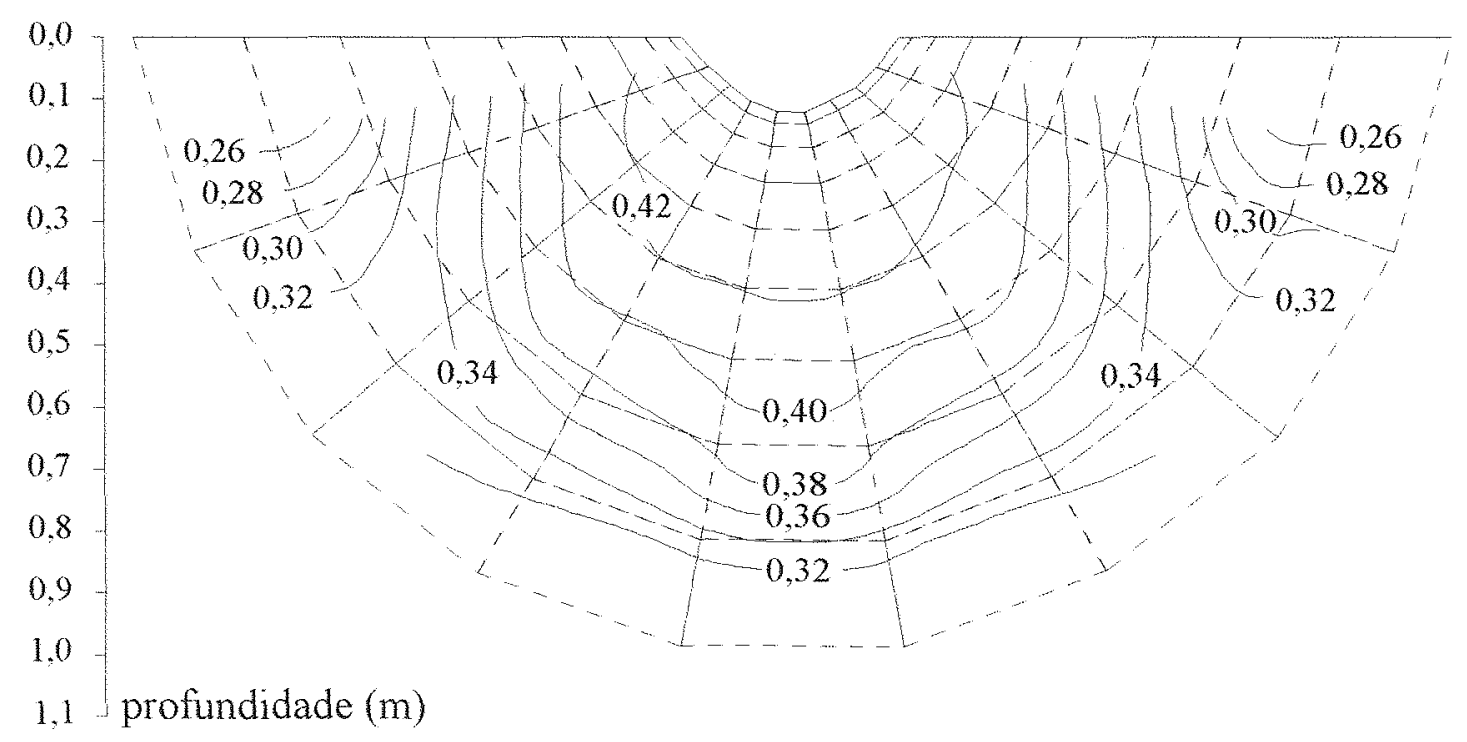

Figura 11. Padrão de distribuição de água no perfil computacional para o Ensaio I (volume de água aplicado simulado igual a $0,0707 \mathrm{~m}^{3} \cdot \mathrm{m}^{-1}$ ). 
distância na horizontal $(\mathrm{m})$

$\begin{array}{lllllllllllll}0,0 & 0,1 & 0,2 & 0,3 & 0,4 & 0,5 & 0,6 & 0,7 & 0,8 & 0,9 & 1,0 & 1,1\end{array}$

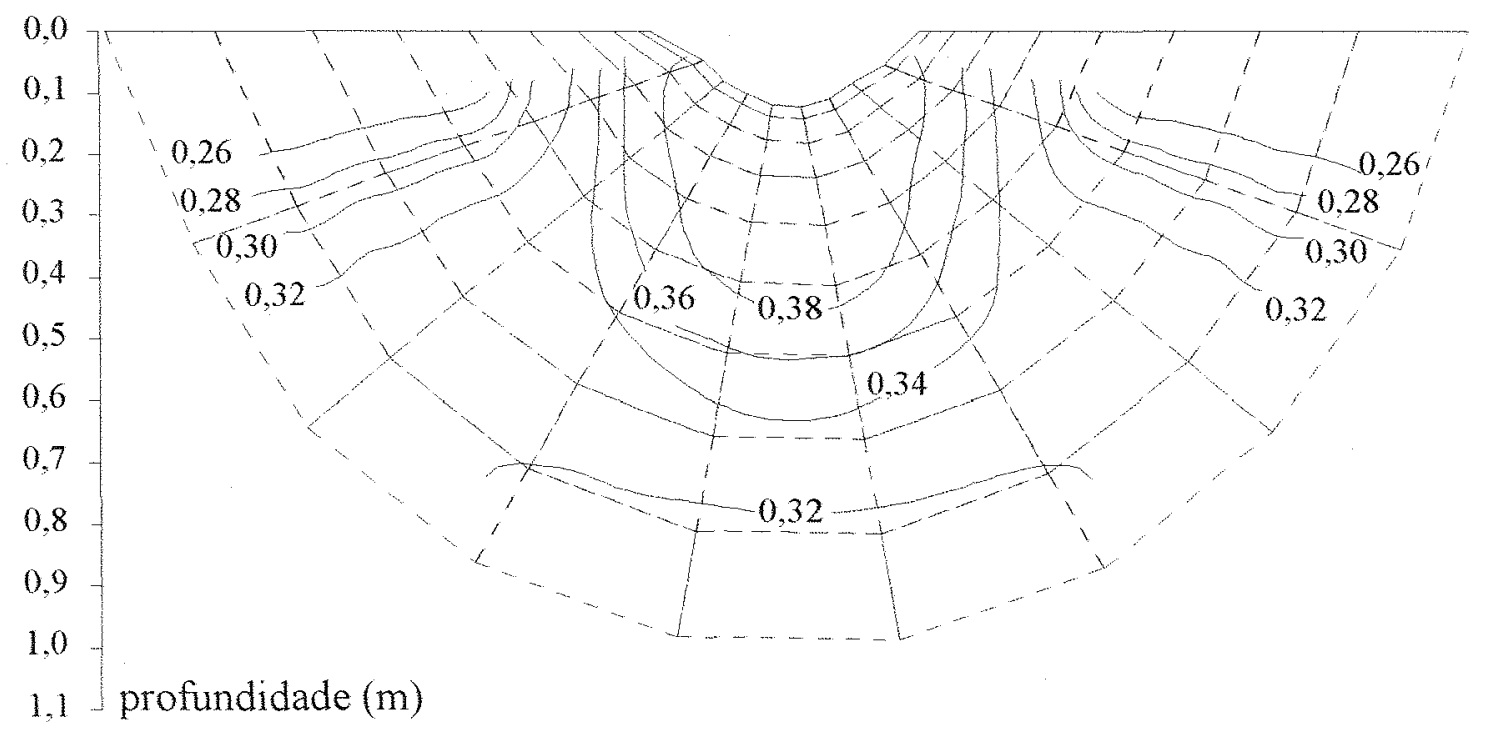

Figura 12. Padrão de distribuição de água no perfil computacional para o Ensaio II (volume de água aplicado simulado igual a $0,0279 \mathrm{~m}^{3} \cdot \mathrm{m}^{-1}$ ).

distância na horizontal $(\mathrm{m})$ $\begin{array}{lllllllllllll}0,0 & 0,1 & 0,2 & 0,3 & 0,4 & 0,5 & 0,6 & 0,7 & 0,8 & 0,9 & 1,0 & 1,1\end{array}$

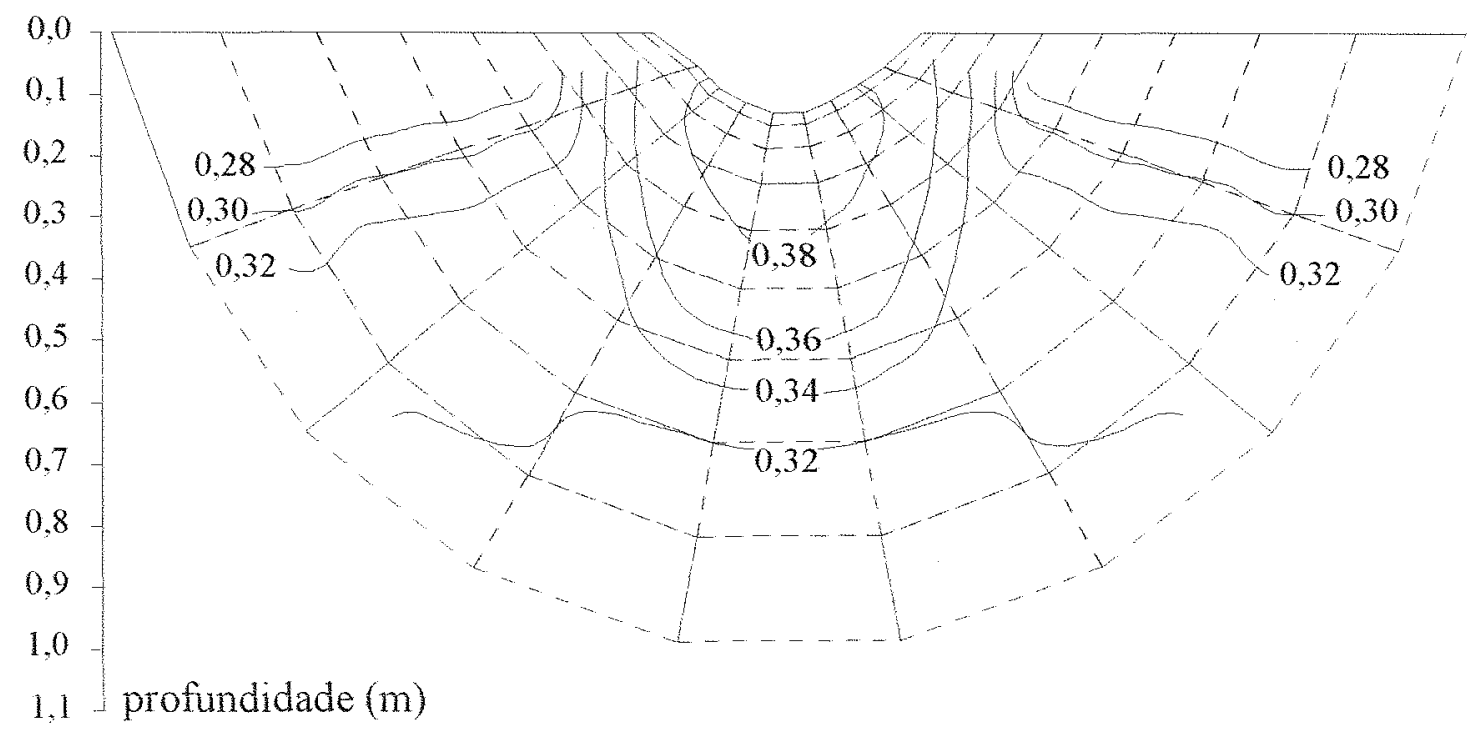

Figura 13. Padrão de distribuição de água no perfil computacional para o Ensaio III (volume de água aplicado simulado igual a $0,0181 \mathrm{~m}^{3} \cdot \mathrm{m}^{-1}$ ). 
distância na horizontal $(\mathrm{m})$

$\begin{array}{lllllllllllll}0,0 & 0,1 & 0,2 & 0,3 & 0,4 & 0,5 & 0,6 & 0,7 & 0,8 & 0,9 & 1,0 & 1,1\end{array}$

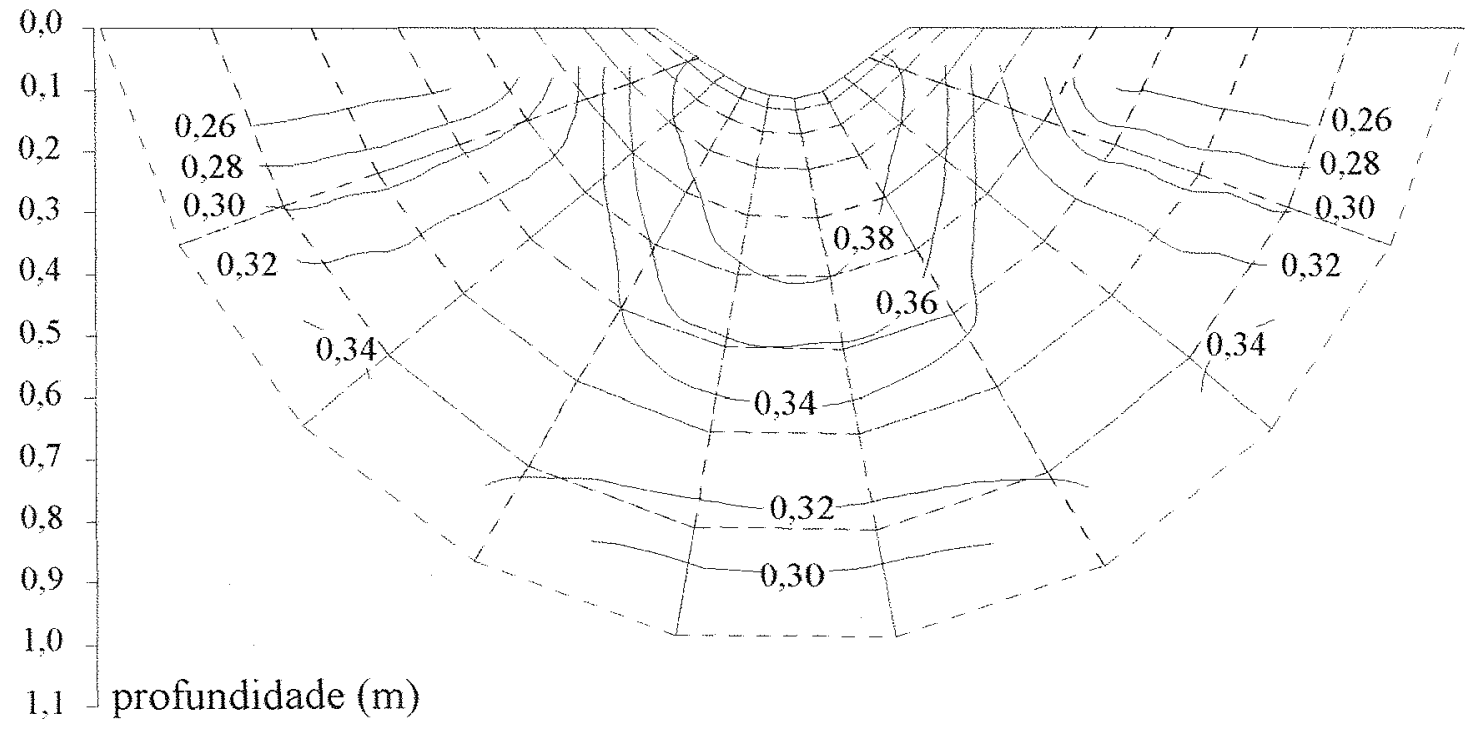

Figura 14. Padrão de distribuição de água no perfil computacional para o Ensaio IV (volume de água aplicado simulado igual a $0,0222 \mathrm{~m}^{3} \cdot \mathrm{m}^{-1}$ ).

distância na horizontal ( $\mathrm{m}$ ) $\begin{array}{lllllllllllll}0,0 & 0,1 & 0,2 & 0,3 & 0,4 & 0,5 & 0,6 & 0,7 & 0,8 & 0,9 & 1,0 & 1,1\end{array}$

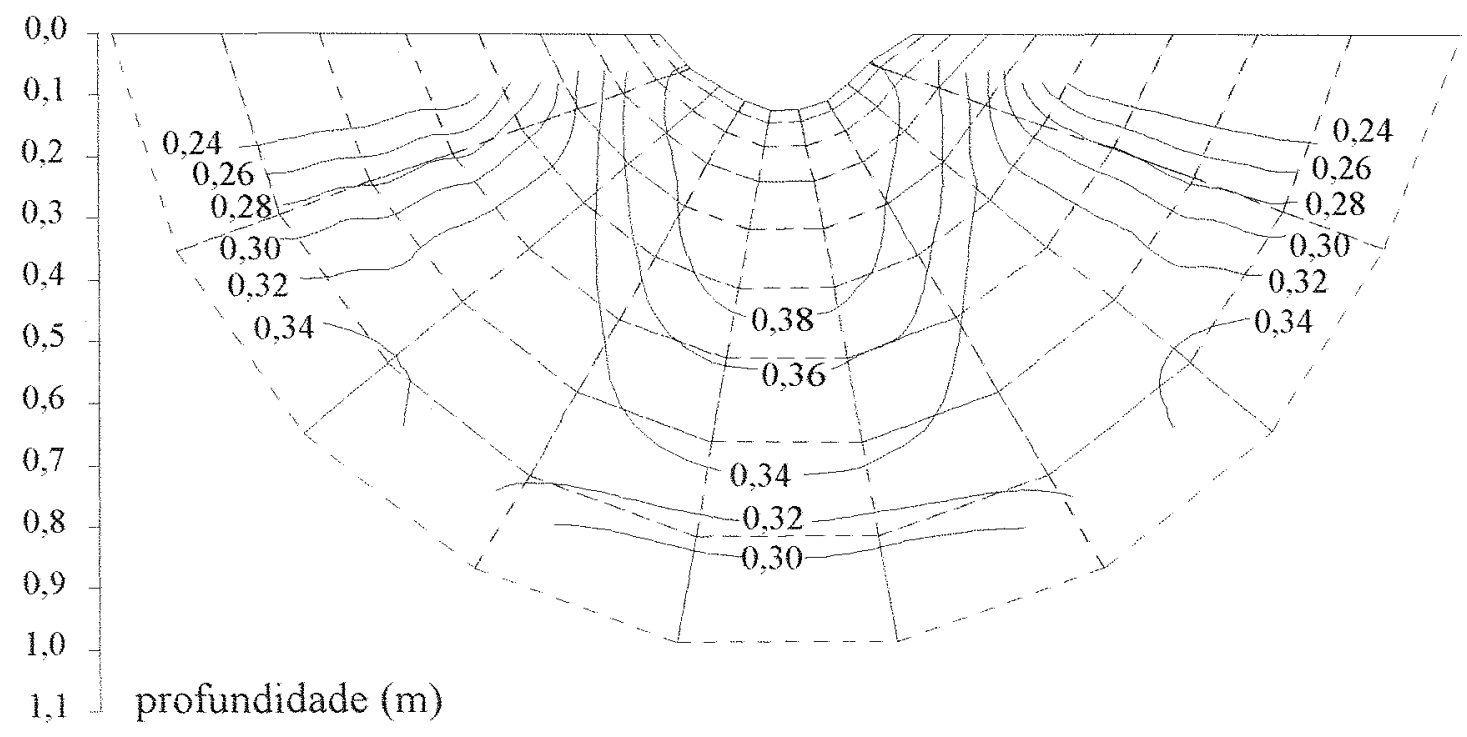

Figura 15. Padrão de distribuição de água no perfil computacional para o Ensaio $\mathrm{V}$ (volume de água aplicado simulado igual a $0,0269 \mathrm{~m}^{3} \cdot \mathrm{m}^{-1}$ ). 
As linhas pontilhadas representam a compartimentação do perfil computacional, com formatos definidos a partir da seção transversal do sulco.

Os valores intercalados às linhas contínuas são os teores de água por elas representados, expressos em $\mathrm{m}^{3} \cdot \mathrm{m}^{-3}$

Os perfis computacionais foram definidos com 10 linhas radiais e 10 linhas de contorno, abrangendo uma profundidade de $1,0 \mathrm{~m}$, com o sulco ao centro. A variação permitida no teor de água no intervalo de tempo $\Delta t$ foi adotada igual a 0,001 $\mathrm{m}^{3} \cdot \mathrm{m}^{-3}$. Os tempos consumidos em processamento, para o Ensaio I até o Ensaio $\mathrm{V}$ respectivamente, são iguais a $583,55 \mathrm{~s}, 474,39 \mathrm{~s}, 269,63 \mathrm{~s}, 359,76 \mathrm{~s}, \mathrm{e} 402,53 \mathrm{~s}$, valores que podem ser reduzidos com a utilização de computadores mais velozes hoje existentes.

O que pode ser observado nas Figuras 11 até 15 é que o modelo DASIS apresenta coerência na simulação da infiltração e da redistribuição da água no solo. O perfil simulado apresenta valores médios a altos de condutividade hidráulica saturada, refletindo na formação de bulbos molhados mais profundos que largos.

A Figura 11, referente ao Ensaio I, apresenta um formato de bulbo molhado mais arredondado. O maior volume de água aplicado ao sulco, a pouca profundidade do perfil computacional e a consideração de fluxo nulo entre a última camada e o solo exterior retiveram a água na parte inferior do perfil, enquanto o movimento lateral nas camadas acima transcorreu normalmente, o que não teria acontecido caso permitisse drenagem livre

Para os demais ensaios, os menores volumes de água aplicados resultaram em bulbos molhados mais característicos, podendo-se observar os resultados da utilização de diferentes volumes e do tempo de aplicação em seus formatos.

A partir dos padrões de distribuição de água no perfil computacional, para cada um dos ensaios simulados obteve-se valores de teor de água correspondentes 
às posições amostradas a campo. Estes valores estão apresentados na Tabela 9.

Tabela 9. Teores de água com base em volume no perfil computacional, correspondentes a cada ponto de amostragem.

pos anda
1 madgem

O comportamento do volume de água infiltrado no solo e da velocidade de infiltração em função do tempo foram registrados pelo programa DASIS. Estas informações são apresentadas graficamente nas Fỉguras 16 até 20. 


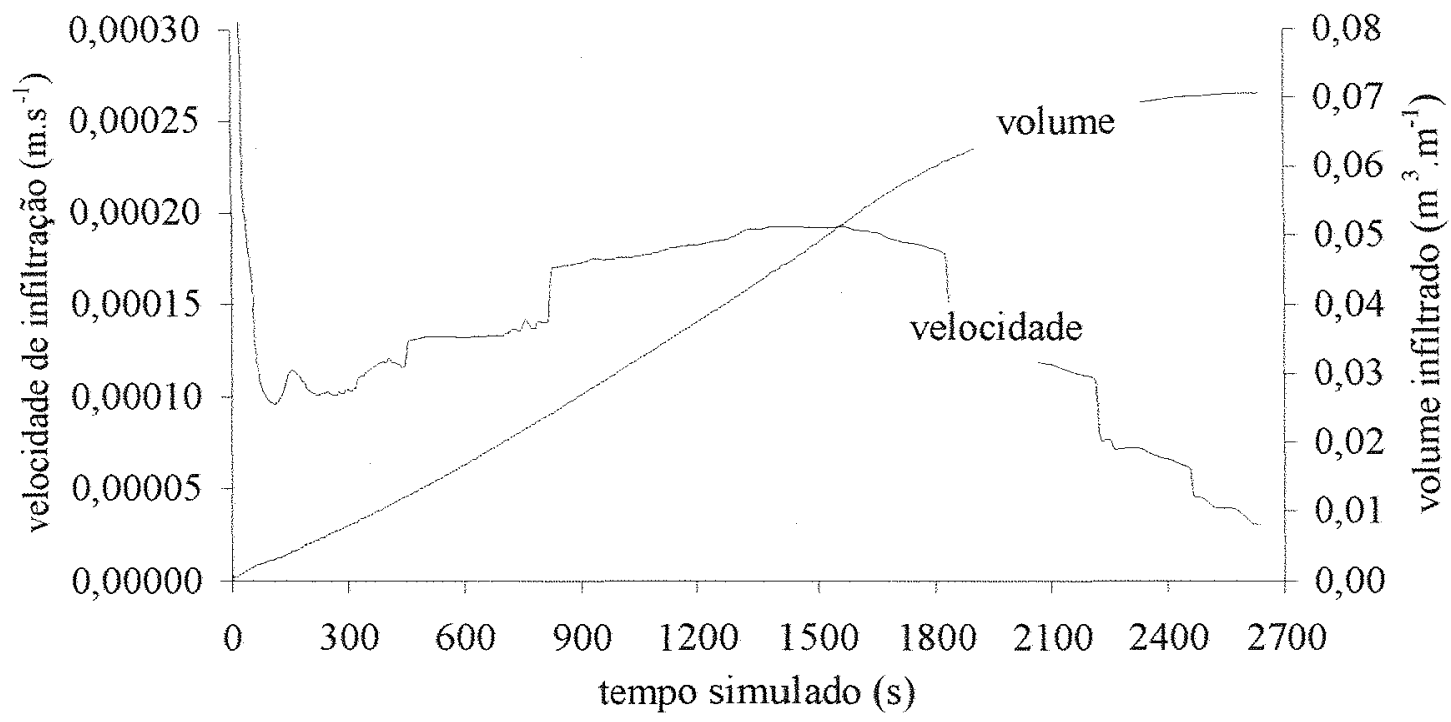

Figura 16. Comportamento do volume de água infiltrado no solo por unidade de comprimento de sulco e da velocidade de infiltração, em função do tempo após inicio de aplicação de água ao sulco, para a simulação referente ao Ensaio I (volume de água aplicado simulado igual a $0,0707 \mathrm{~m}^{3} \cdot \mathrm{m}^{-1}$ ).

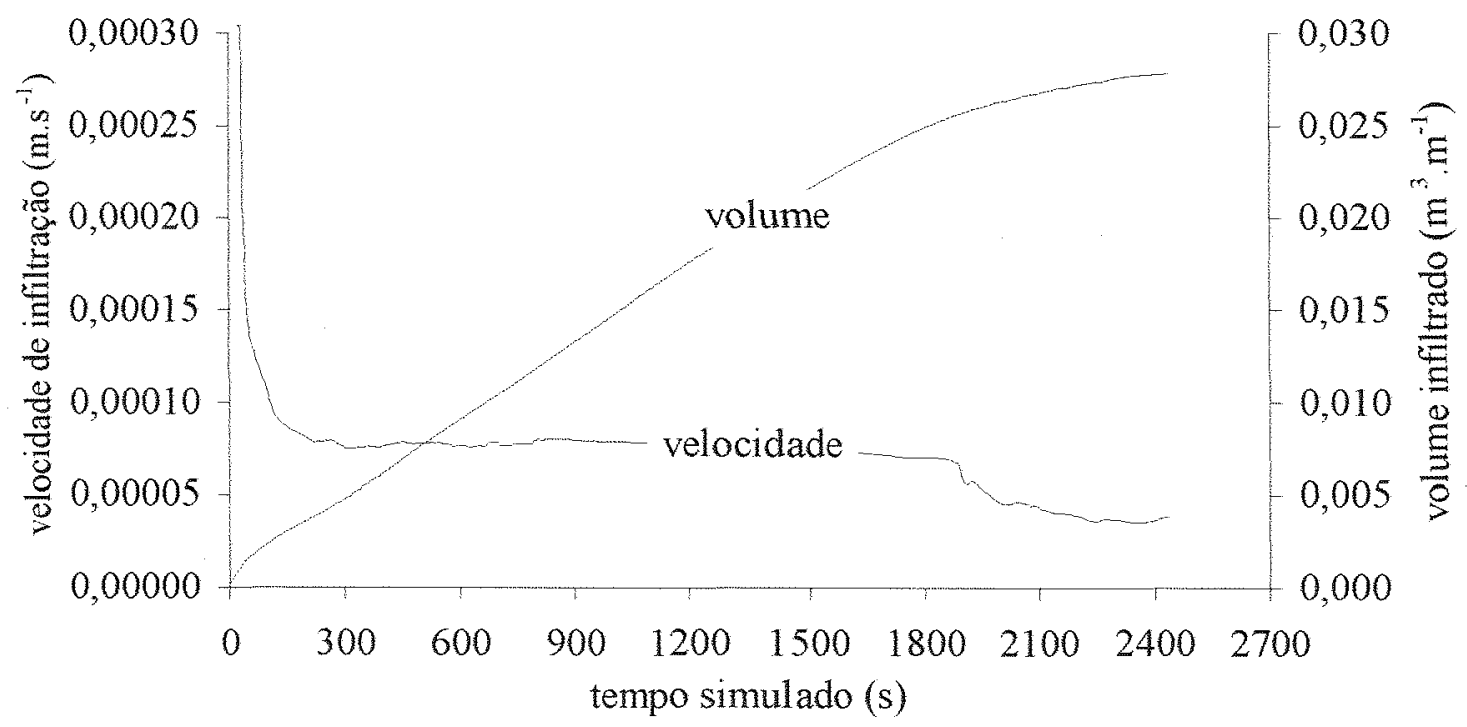

Figura 17. Comportamento do volume de água infiltrado no solo por unidade de comprimento de sulco e da velocidade de infiltração, em função do tempo após início de aplicação de água ao sulco, para a simulação referente ao Ensaio II (volume de água aplicado simulado igual a $0,0279 \mathrm{~m}^{3} \cdot \mathrm{m}^{-1}$ ). 


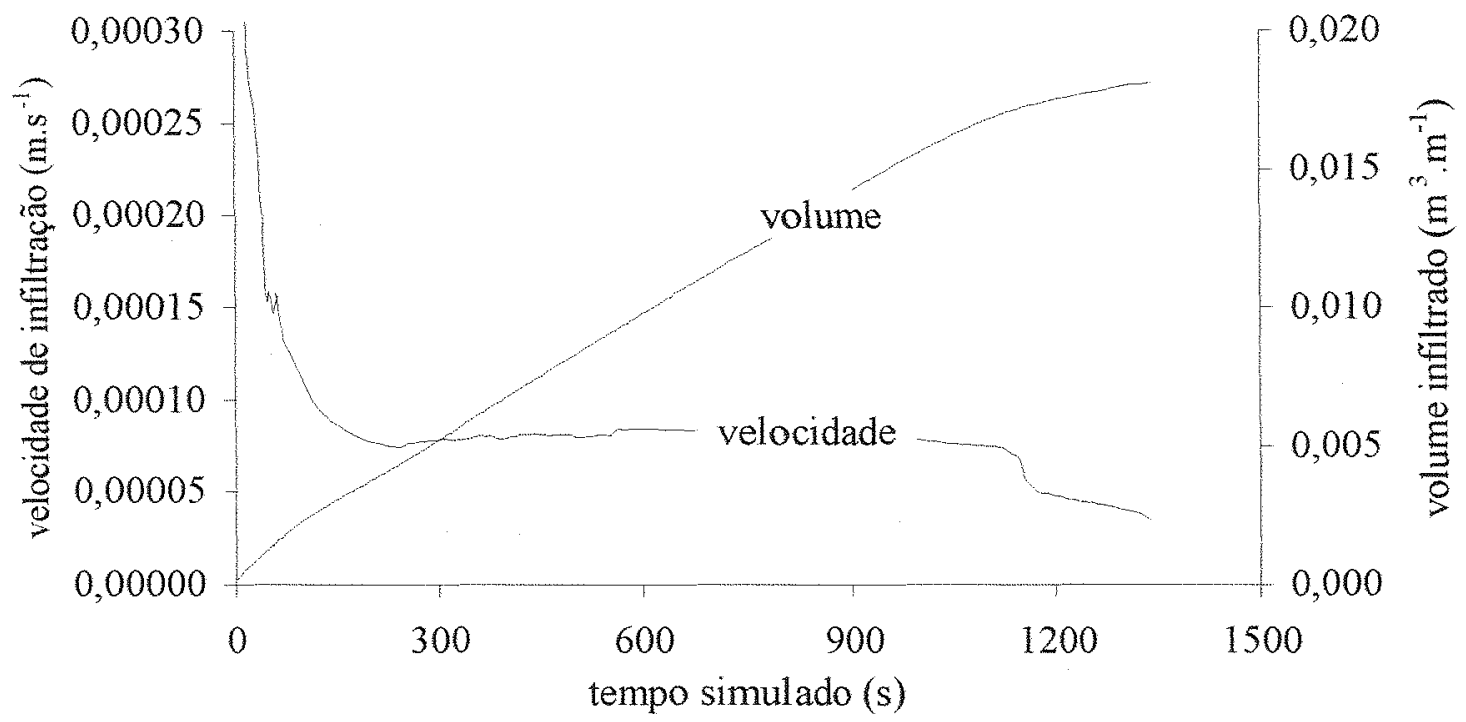

Figura 18. Comportamento do volume de água infiltrado no solo por unidade de comprimento de sulco e da velocidade de infiltração, em função do tempo após inicio de aplicação de água ao sulco, para a simulação referente ao Ensaio III (volume de água aplicado simulado igual a $0,0181 \mathrm{~m}^{3} \cdot \mathrm{m}^{-1}$ ).

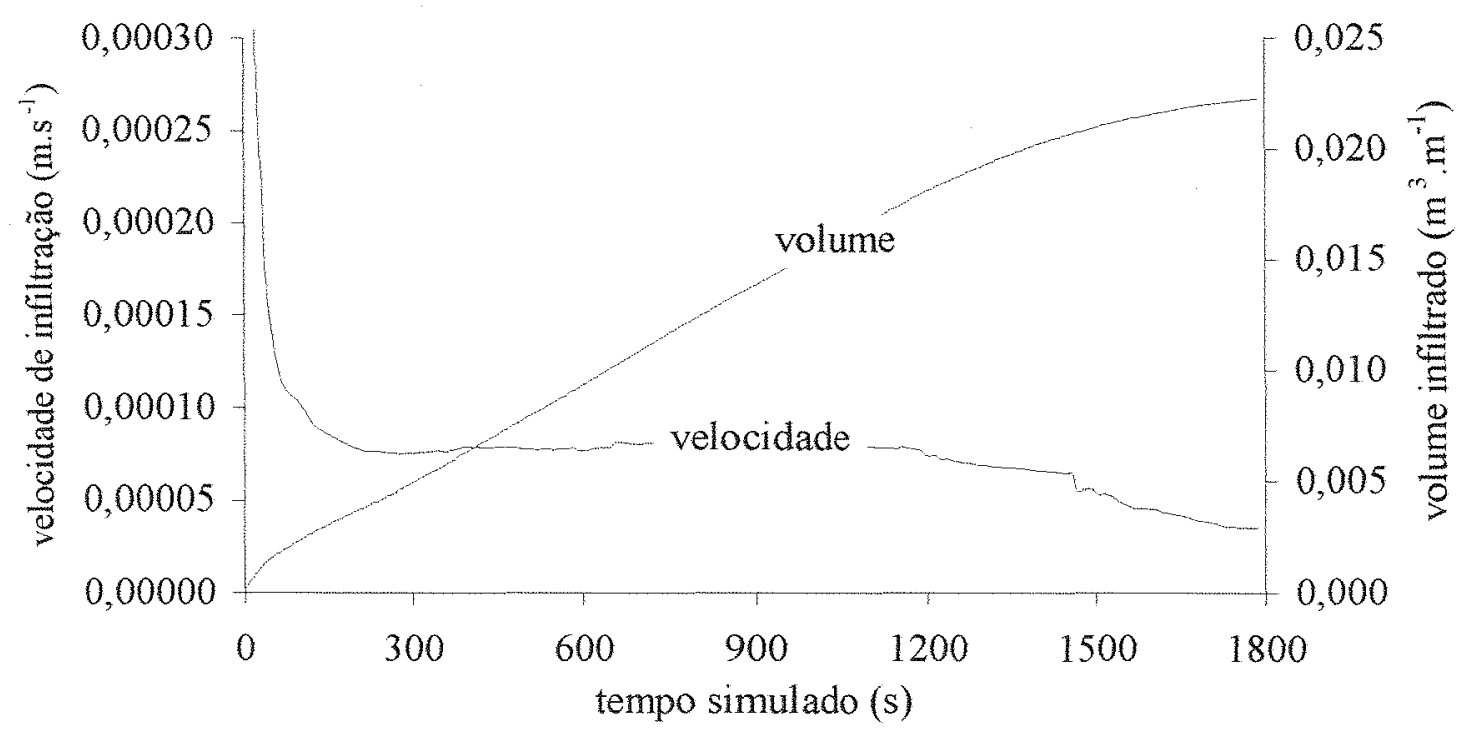

Figura 19. Comportamento do volume de água infiltrado no solo por unidade de comprimento de sulco e da velocidade de infiltração, em função do tempo após início de aplicação de água ao sulco, para a simulação referente ao Ensaio IV (volume de água aplicado simulado igual a $0,0222 \mathrm{~m}^{3} \cdot \mathrm{m}^{-1}$ ). 


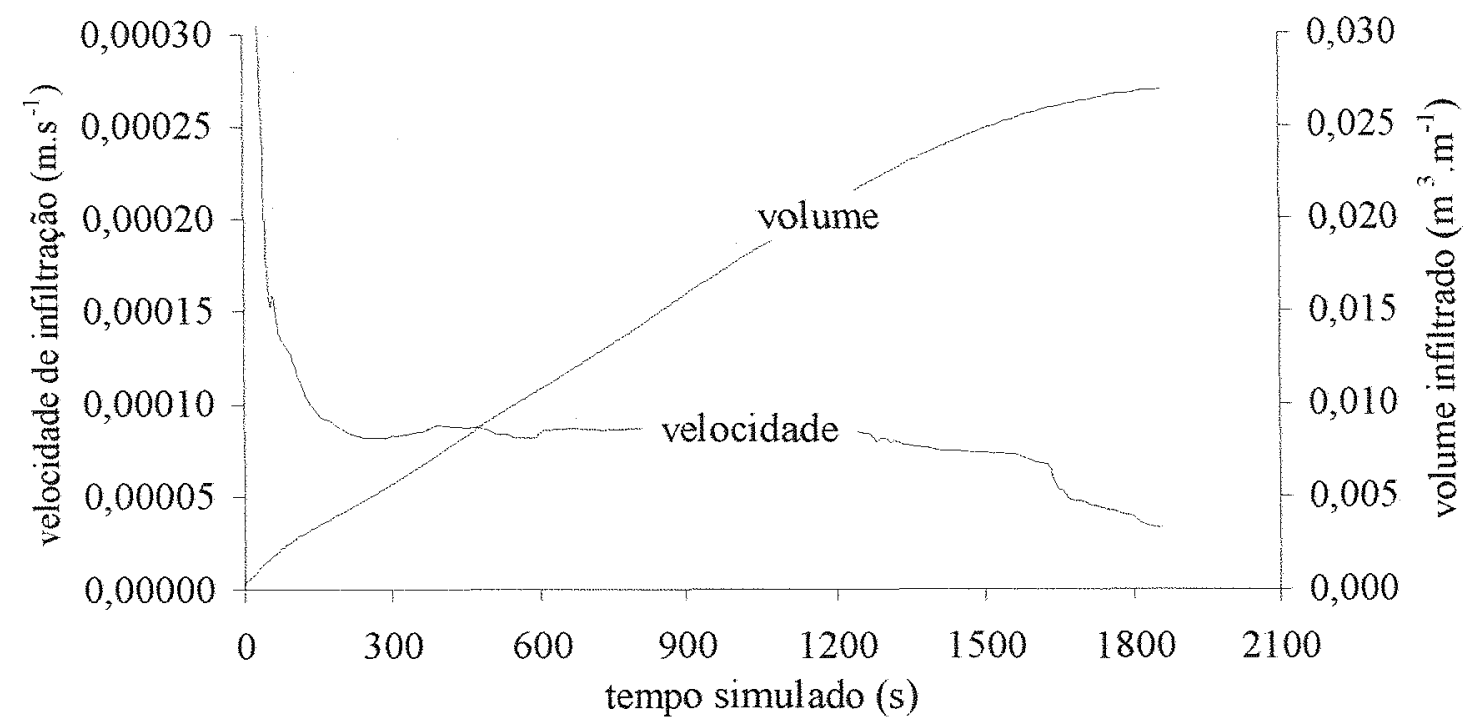

Figura 20. Comportamento do volume de água infiltrado no solo por unidade de comprimento de sulco e da velocidade de infiltração, em função do tempo após inicio de aplicação de água ao sulco, para a simulação referente ao Ensaio V (volume de água aplicado simulado igual a $0,0269 \mathrm{~m}^{3} \cdot \mathrm{m}^{-1}$ ).

Observa-se que o volume de água infiltrado simulado é praticamente igual ao volume aplicado durante a realização dos ensaios. Isto representa a boa qualidade dos parâmetros hidráulicos do solo utilizados, além da representatividade dos dados de altura da lâmina d'água sobre o sulco e de seu perfil transversal.

Em relação à velocidade de infiltração, seu comportamento é caracterizado por uma estabilização relativamente rápida, o que é devido ao pouco tempo de aplicação de água, conjugado com a rápida variação da altura da lâmina de água sobre o sulco, não definindo a lei de infiltração.

Para se obter a lei de infiltração do solo deve-se manter condições estáveis de altura da lâmina de água no sulco, durante tempo suficiente para que os valores de velocidade de infiltração tornem-se praticamente constantes, ou variem muito pouco ao longo do tempo. 


\subsection{Resultados experimentais}

Como resultados experimentais entende-se aqueles obtidos ao término dos ensaios a campo, que são os teores de água no perfil de solo em cada um dos 15 pontos de amostragem existentes, isto para cada um dos ensaios realizados.

As tradagens realizadas 24 horas após o início de aplicação de água, em três posições para cada um dos cinco ensaios (uma ao centro do sulco e as demais às margens, afastados do central de $0,5 \mathrm{~m}$ ), resultaram na confecção de perfis de teor de água em base de volume. Estes perfis servem de base comparativa com o resultado da simulação com o modelo DASIS, e podem ser observados na Tabela 10 , sendo que a referência para o posicionamento à esquerda ou à direita é o ponto de vista de jusante para montante do sulco.

A referência para a definição da profundidade amostrada é a superficie do solo para as tradagens às margens do sulco. Quanto à posição de tradagem no centro do sulco, o fundo deste é considerado como referência zero, sendo a primeira camada considerada até $0,2 \mathrm{~m}$ abaixo do fundo do sulco, e assim sucessivamente.

Os valores apresentados na Tabela 10 mostram uma maior concentração de água logo abaixo do sulco, em especial na camada entre $0,2 \mathrm{~m}$ e $0,4 \mathrm{~m}$. Nas camadas mais profundas os valores de teor de água apresentam uma tendência de variarem menos quanto à condição inicial.

Os valores referentes ao Ensaio I apresentam um maior contraste em relação aos demais, o que é explicável pelo maior volume de água aplicado ao sulco.

Um fator originando diferenças é a heterogeneidade do solo, uma vez que as amostragens, para cada um dos ensaios, foram feitas em locais próximos mas não coincidentes. 
Tabela 10. Teores de água com base em volume no perfil de solo, para cada ponto de amostragem.

\begin{tabular}{|c|c|c|c|c|c|}
\hline \multirow{2}{*}{ 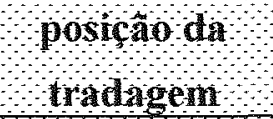 } & \multicolumn{5}{|c|}{ profindidade (ii) } \\
\hline & $0,0,0,2$ & $0,2,0,4$ & $0,4,0,6$ & $0,6,0,8$ & $0,8,1,0$ \\
\hline \multicolumn{6}{|c|}{ 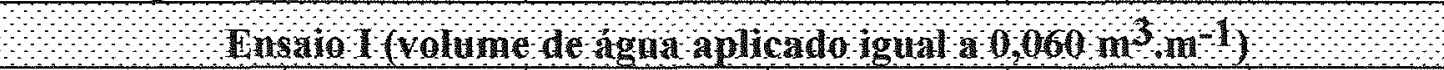 } \\
\hline $0,5 \mathrm{~m}$ esquerda & 0,3381 & 0,3516 & 0,3549 & 0,3421 & 0,3091 \\
\hline centro & 0,3956 & 0,4068 & 0,4074 & 0,3716 & 0,3209 \\
\hline $0,5 \mathrm{~m}$ direita & 0,3413 & 0,3524 & 0,3580 & 0,3475 & 0,3120 \\
\hline \multicolumn{6}{|c|}{ 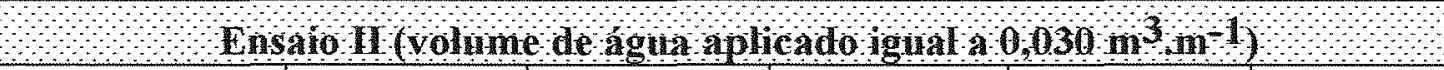 } \\
\hline $0,5 \mathrm{~m}$ esquerda & 0,2791 & 0,3327 & 0,3364 & 0,3271 & 0,2988 \\
\hline centro & 0,3675 & 0,3768 & 0,3697 & 0,3511 & 0,3220 \\
\hline $0,5 \mathrm{~m}$ direita & 0,2671 & 0,3277 & 0,3416 & 0,3360 & 0,3092 \\
\hline \multicolumn{6}{|c|}{ 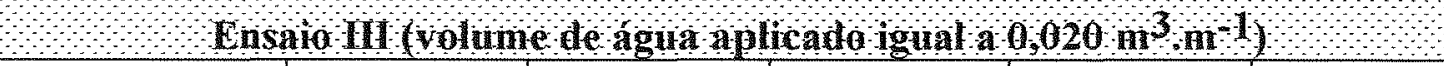 } \\
\hline $0,5 \mathrm{~m}$ esquerda & 0,2796 & 0,3425 & 0,3470 & 0,3233 & 0,2973 \\
\hline centro & 0,3760 & 0,3775 & 0,3665 & 0,3420 & 0,3127 \\
\hline $0,5 \mathrm{~m}$ direita & 0,2813 & 0,3342 & 0,3428 & 0,3292 & 0,3000 \\
\hline \multicolumn{6}{|c|}{ 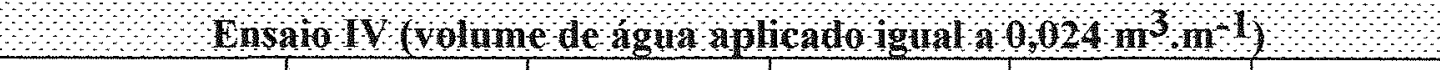 } \\
\hline $0,5 \mathrm{~m}$ esquerda & 0,2781 & 0,3295 & 0,3318 & 0,3273 & 0,3048 \\
\hline centro & 0,3752 & 0,3775 & 0,3617 & 0,3372 & 0,3095 \\
\hline $0,5 \mathrm{~m}$ direita & 0,2827 & 0,3269 & 0,3350 & 0,3282 & 0,3104 \\
\hline \multicolumn{6}{|c|}{ 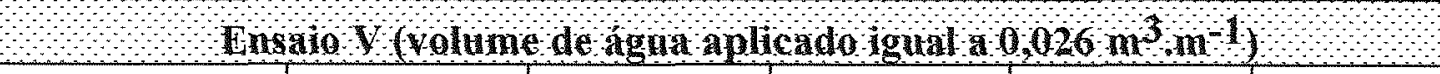 } \\
\hline $0,5 \mathrm{~m}$ esquerda & 0,2596 & 0,3287 & 0,3400 & 0,3219 & 0,2964 \\
\hline centro & 0,3691 & 0,3717 & 0,3604 & 0,3298 & 0,3044 \\
\hline $0,5 \mathrm{~m}$ direita & 0,2680 & 0,3263 & 0,3337 & 0,3194 & 0,3018 \\
\hline
\end{tabular}

\subsection{Resultados comparativos}

Os resultados comparativos, ou resultados referentes à análise de acuracidade do modelo DASIS, são considerados neste item, utilizando-se de comparações estatísticas e visuais. 
Os valores de teor de água simulados apresentados na Tabela 9 foram comparados com os valores experimentais apresentados na Tabela 10 utilizando um método de análise estatística de dados emparelhados para médias, aplicando o teste " $t$ ". A Tabela 11 apresenta o resumo da análise estatística.

Tabela 11. Resumo estatístico das comparações entre valores experimentais $e$ simulados para os perfis de teor de água no solo, referente aos cinco ensaios realizados.

\begin{tabular}{|c|c|c|c|c|}
\hline Consa & $\mathrm{m}^{3} \mathrm{~m}^{-3}$ & 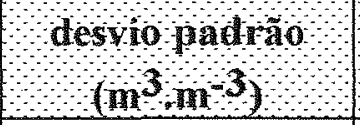 & corelacade & siguiffcanch \\
\hline I & $\begin{array}{c}0,3540 \text { (observado) } \\
0,3498 \text { (simulado) }\end{array}$ & $\begin{array}{c}0,0307 \text { (observado) } \\
0,0408 \text { (simulado) }\end{array}$ & 0,9081 & 0,3970 \\
\hline II & $\begin{array}{c}0,3295 \text { (observado) } \\
0,3192 \text { (simulado) }\end{array}$ & {$\left[\begin{array}{c}0,0315 \text { (observado) } \\
0,0381 \text { (simulado) }\end{array}\right.$} & 0,9154 & 0,0239 \\
\hline III & $\begin{array}{c}0,3301 \text { (observado) } \\
0,3184 \text { (simulado) }\end{array}$ & $\begin{array}{c}0,0313 \text { (observado) } \\
0,0317 \text { (simulado) }\end{array}$ & 0,9157 & 0,0034 \\
\hline IV & $\begin{array}{c}0,3277 \text { (observado) } \\
0,3210 \text { (simulado) }\end{array}$ & $\begin{array}{c}0,0289 \text { (observado) } \\
0,0354 \text { (simulado) }\end{array}$ & 0,9629 & 0,0312 \\
\hline $\mathrm{V}$ & $\begin{array}{c}0,3221 \text { (observado) } \\
0,3156(\text { simulado })\end{array}$ & $\mid \begin{array}{c}0,0327 \text { (observado) } \\
0,0455 \text { (simulado) }\end{array}$ & 0,9711 & 0,1385 \\
\hline
\end{tabular}

Os valores de correlação de Pearson (r) refletem a boa aderência existente entre teores de água obtidos a campo e simulados. Quanto aos valores de nível de significância, referentes à aplicação do teste " $t$ ", apresentam uma heterogeneidade com amplitude de variação de $39,36 \%$, elevada para este tipo de análise. Contudo, os valores para todos os ensaios, com exceção do Ensaio I, são baixos o bastante para caracterizar uma homogeneidade de médias entre as amostras, em especial quanto ao Ensaio III. As médias observadas foram sempre maiores às simuladas. 
Este comportamento pode ser visualizado na Figura 21, que é uma representação gráfica dos desvios existentes entre resultados simulados e experimentais, apresentando na abcissa os valores de teor de água no solo em base de volume obtidos nos cinco ensaios a campo, enquanto que na ordenada estão os respectivos teores de água simulados.

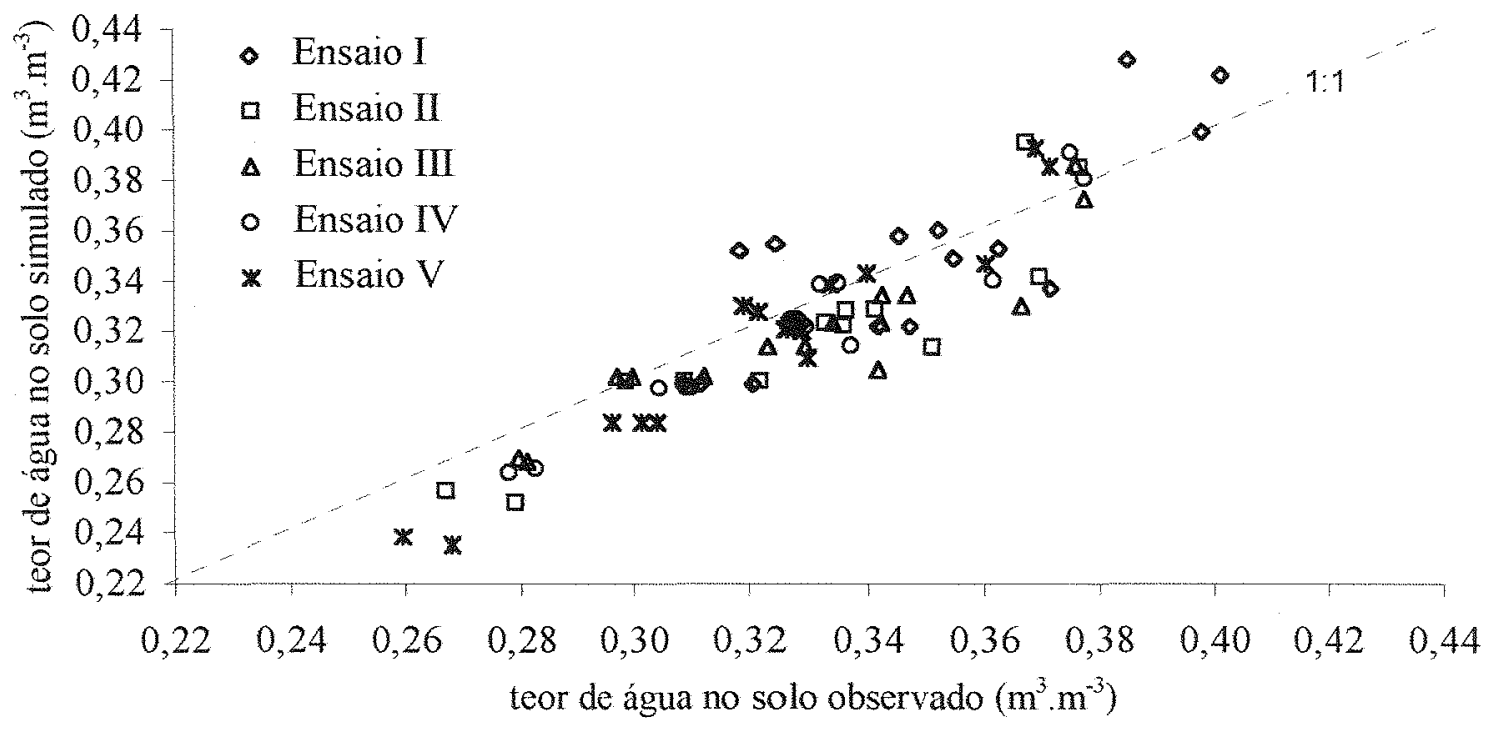

Figura 21. Comparação entre teores de água no solo com base em volume observados a campo e simulados, correspondentes aos três pontos amostrados dos cinco ensaios realizados.

A tendência observada é a simulação superestimar os teores de água na região mais molhada do perfil, além de subestimar os teores na região mais seca, contudo a região intermediária apresenta uma aderência entre os valores simulados e experimentais, o que pode ser visualizado na Figura 21 quanto ao deslocamento dos pontos em relação à linha 1:1. Esta diferença é atribuída principalmente ao processo evaporativo ocorrendo em condições reais, não considerado no modelo DASIS. 


\section{CONCLUSÕES E RECOMENDACÕ̃ES}

Fundamentadas nas discussões referentes aos resultados obtidos com este trabalho, as seguintes conclusões podem ser feitas:

i. A escolha do número de linhas de contorno deve ser criteriosa, visto que esse foi o parâmetro que mais afetou a simulação, contribuindo para variações acima de $100 \%$ entre os volumes simulados e aplicados. A compartimentação mais apropriada nas condições estudadas foi formada por 10 linhas radiais e 10 linhas de contorno;

ii. O parâmetro estudado que menos afetou a simulação foi a variação permitida no teor de água dentro de um laço de simulação, entretanto afetou consideravelmente o tempo de processamento. A variação permitida escolhida foi de $0,001 \mathrm{~m}^{3} \cdot \mathrm{m}^{-3}$, com um tempo médio de processamento igual a 418 segundos;

iii. O modelo DASIS superestimou o teor de água no solo na região mais úmida do perfil e subestimou na região mais seca. Se a evaporação na superfície do solo tivesse sido considerada, poderia resultar na subestimativa do teor de água em todo o perfil; 
iv. O modelo DASIS, para as condições estudadas, simula os perfis de teor de água no solo de forma aceitável à utilização prática, podendo ser utilizado no dimensionamento e manejo de sistemas de irrigação por sulcos;

v. A utilização de intervalo de tempo variável em função da variação permitida no teor de água dentro de um laço de simulação, aliado ao contorno inferior móvel do perfil computacional, garante um consumo de tempo de processamento viável à aplicação do modelo DASIS a problemas práticos.

Como recomendação a novos estudos com este tema, tem-se:

i. A dificuldade em se determinar as características hidráulicas do solo sugere a utilização de métodos expeditos, baseados em parâmetros de mais fácil obtenção, como granulometria, cor, teor de matéria orgânica;

ii. O processo evaporativo à superficie, em especial no perímetro do sulco de irrigação, deve ser modelado de forma simples e inserido ao modelo, contemplando a variação ocorrida ao longo do dia e o efeito do teor de água do solo. 


\section{REFERÊNCIAS BIBLIOGRÁFICAS}

ALEXANDER, L.; SKAGGS, R.W. Predicting unsaturated hydraulic conductivity from the soil water characteristic. Transactions of the ASAE, v.29, n.1, p. 176-184, january/february 1986.

ARMSTRONG, C.F.; WILSON, T.V. Computer model for moisture distribution in stratified soils under a trickle source. Transactions of the ASAE, v. 26, n.6, p. 17041709 , november/december 1983.

BOTREL T.A. Simulação da distribuição espacial da água em solo irrigado com gotejador. Piracicaba, 1988. 61p. Tese (Doutorado) - Escola Superior de Agricultura "Luiz de Queiroz", Universidade de São Paulo.

BRESLER, E; KEMPER, W.D; HANKS R.J. Infiltration, redistribution, and subsequent evaporation of water from soil as affected by wetting rate and hysteresis. Soil Science Society of America Proceedings, v.33, n.6, p.832-840, november/december 1969 . 
BROWN, M.J.; KEMPER, W.D.; TROUT, T.J.; HUMPHERYS, A.S. Sediment, erosion and water intake in furrows. Irrigation Science, v.9, n.1, p.45-55, february 1988

BROWNING, G.M.; MILAM, F.M. The lateral movement of water in relation to pasture contour furrows. Soil Science Society of America Proceedings, v.5, p.386-389, 1940.

CAMPBELL, G.S. Soil physics with Basic: transport models for soil-plant systems. New York: Elsevier Sci. Publ. Co. Inc., 1985. 149p. (Developments in soil science, 14)

DUKE, H.R. Water temperature fluctuations and effect on irrigation infiltration. Transactions of the ASAE, v.35, n. 1, p.193-199, january/february 1992.

FEDDES, R.A.; NEUMAN, S.P.; BRESLER, E. Finite element analysis of twodimensional flow in soils considering water uptake by roots: II. field aplications. Soil Science Society of America Proceedings, v.39, n.2, p.231-237, march/april 1975.

FRIZZONE, J.A. Irrigação por superfície. Piracicaba: ESALQ, Departamento de Engenharia Rural, 1993. 183p. (LER. Série didática, 5)

GARDNER, W.R. Some steady-state solutions of the unsaturated moisture flow equation with application to evaporation from a water table. Soil Science, v. 85 , n. 4 , p.228-232, april 1958 . 
HANKS, R.J.; BOWERS, S.A. Numerical solution of the moisture flow equation for infiltration into layered soils. Soil Science Society of America Proceedings, v.26, n.6, p.530-534, november/december 1962.

HILLEL, D.; VAN BAVEL, C.H.M. Simulation of profile storage as related to soil hydraulic properties. Soil Science Society of America Journal, v.40, n.6, p.807815, november/december 1976.

HILLEL, D.; VAN BAVEL, C.H.M.; TALPAZ, H. Dynamic simulation of water storage in fallow soil as affected by mulch of hydrophobic aggregates. Soil Science Society of America Proceedings, v.39, n.5, p.826-833, september/october 1975.

JABRO, J.D. Estimation of saturated hydraulic conductivity of soils from paticle size distribution and bulk density data. Transactions of the ASAE, v.35, n.2, p.557-560, march/april 1992.

KARRAKER, P.E. The effect of the initial moisture in a soil on moisture movement. Soil Science, v.10, n.3, p.143-152, 1920.

KAY, M. Surface irrigation: systems and practice. 2.ed. Oxford: Cotswold Press, 1989. $142 p$.

MUALEM, Y. A new model for predicting the hydraulic conductivity of unsaturated porous media. Water Resources Research, v.12, n.3, p.513-522, march 1976. 
NAYLOR, T.H.; BALINTFY, J.L; BURDICK, D.S.; CHU, K. Técnicas de simulação em computadores. Editora Vozes Ltda., 1971. 402p. (Tradução por Edmundo Emanuel Teixeira).

NEUMAN, S.P. Saturated-unsaturated seepage by finite elements. Proceedings of the ASCE, Journal of Hydraulic Division, v.99, n.HY12, p.2233-2250, 1973.

NEUMAN, S.P.; FEDDES, R.A; BRESLER, E. Finite element analysis of twodimensional flow in soils considering water uptake by roots: I. theory. Soil Science Society of America Proceedings, v.39, n.2, p.224-230, march/april 1975.

NIELSEN, D.R.; BIGGAR, J.W. Measuring capillary conductivity. Soil Science, v.92, n.3, p.192-193, september, 1961.

PAIGE, G.B; HILLEL, D. Comparison of three methods for assessing soil hydraulic properties. Soil Science, v.155, n.3, p. 175-189, march 1993.

PHILIP, J.R. The theory of infiltration: 3. moisture profiles and relation to experiment. Soil Science, v.84, p.163-178, 1957a.

PHILIP, J.R. The theory of infiltration: 5 , the influence of the initial moisture content. Soil Science, v.84, p.329-339, $1957 b$.

PHILIP, J.R. Theory of infiltration. In: CHOW, V.T., ed. Advances in Hydroscience. New York: Academic Press, 1969. v.5, p.215-297. 
PHILIP, J.R. General theorem on steady infiltration from surface sources, with application to point and line sources. Soil Science Society of America Proceedings, v.35, n.6, p.867-871, november/december 1971 .

PHILIP, J.R. Steady infiltration from buried, surface, and perched point and line sources in heterogeneous soils: I. analysis. Soil Science Society of America Proceedings, v.36, n.2, p.268-273, march/april 1972 .

PHILIP, J.R.; FORRESTER, R.I. Steady infiltration from buried, surface, and perched point and line sources in heterogeneous soils. II. flow details and discussion. Soil Science Society of America Proceedings, v.39, n.3, p.408-414, may/june 1975.

POULOVASSILIS, A. The effect of hysteresis of pore-water on the hydraulic conductivity. Journal of Soil Science, v.20, p.52-56, 1969.

POULOVASSILIS, A. Hysteresis of pore water in granular porous bodies. Soil Science, v.109, n.1, p.5-12, january 1970.

POULOVASSILIS, A.; POLYCHRONIDES, M.; KERKIDES, P. Evaluation of various computational schemes in calculating unsaturated hydraulic conductivity. Agricultural Water Management, v.13, n.2-4, p.317-327, june 1988.

POULOVASSILIS,A.; TZIMAS, E. The hysteresis in the relatinship between hydraulic conductivity and soil water content. Soil Science, v.120, n. 5, p.327-331, may 1975. 
RAATS, P.A.C. Steady infiltration from line sources and furrows. Soil Science Society of America Proceedings, v.34, n.5, p.709-714, september/october 1970.

ROSS, P.J.; WILLIAMS, J.; BRISTOW, K.L. Equation for extending water-retention curves to dryness. Soil Science Society of America Journal, v.55, n.4, p.923-927, july/august 1991.

ROYER, J.M; VACHAUD, G. Field determination of hysteresis in soil-water characteristics. Soil Science Society of America Proceedings, v.39, n.2, p.221-223, march/april 1975.

RUSSO, D. Determining soil hydraulic properties by parameter estimation: on the selection of a model for the hydraulic properties. Water Resources Research, v.24, n. 3 , p. $453-459$, march 1988.

SAMANI, Z.A.; WALKER, W.R.; JEPPSON, R.W.; WILLARDSON, L.S. Numerical solution for unsteady two-dimensional infiltration in irrigation furrows. Transactions of the ASAE, v.28, n.4, p.1186-1190, july-august, 1985.

SCHMITZ, G.H. Transient infiltration from cavities. I: theory. Journal of Irrigation and Drainage Engineering, v.119, n.3, p.443-457, may/june 1993.

SEGEREN, A.G.; TROUT, T.J. Hydraulic resistance of soil surface seals in irrigated furrows. Soil Science Society of America Journal, v.55, n.3, p.640-646, may/june 1991. 
SPOSITO, G. The "physics" of soil water physics. Water Resources Research, v.22, n. 9, p. 83 S-88S, august 1986.

STAPLE, W.J. Comparison of computed and measured moisture redistribution following infiltration. Soil Science Society of America Proceedings, v.33, n.6, p.840-847, november/december 1969.

TABUADA, M.A. Modelação bidimensional e tridimensional da rega por sulcos. Lisboa, 1989. 299p. Tese (Doutorado) - Instituto Superior de Agronomia, Universidade Técnica de Lisboa.

TOPP, G.C.; MILLER, E.E. Hysteretic moisture characteristics and hydraulic conductivities for glass-bead media. Soil Science Society of America Proceedings, v.30, n.2, p.156-162, march/april 1966.

TROUT, T.J. Flow velocity and wetted perimeter effects on furrow infiltration. Transactions of the ASAE, v.35, n.3, p.855-863, may/june 1992.

U.S. DEPARTMENT OF AGRICULTURE, SOIL CONSERVATION SERVICE. Furrow irrigation. In: National Engineering Handook. 2.ed. U.S. Government Printing Office, 1967. Section 15, Chapter 5.

VAN DER PLOEG, R.R.; BENECKE, P. Unsteady, unsaturated, n-dimensional moisture flow in soil: a computer simulation program. Soil Science Society of America Proceedings, v.38, n.6, p.881-885, november/december 1974. 
VAN GENUCHTEN, M.TH. A closed-form equation for predicting the hydraulic conductivity of unsaturated soils. Soil Science Society of America Journal, v.44, n.5, p.892-898, september/october 1980

VIDAL TORRADO, P.; SPAROVEK, G. Mapa pedológico detalhado do campus "Luiz de Queiroz" da Universidade de São Paulo. Piracicaba, 1993. (1:10.000)

VOGEL, T.; HOPMANS, J.W. Two-dimensional analysis of furrow infiltration. Journal of Irrigation and Drainage Engineering, v. 118, n.5, p.791-806, september/october 1992.

WALKER, W.R; SKOGERBOE, G.V. Surface irrigation: theory and practice. Englewood Cliffs, Prentice-Hall Inc., 1987. 386p.

WHISLER, F.D; KLUTE, A. The numerical analysis of infiltration, considering hysteresis, into a vertical soil column at equilibrium under gravity. Soil Science Society of America Proceedings, v.29, n.5, p.489-494, september/october 1965.

WÖSTEN, J.H.M; VAN GENUCHTEN, M. TH. Using texture and other soil properties to predict the unsaturated soil hydraulic fuctions. Soil Science Society of America Journal, v.52, n.6, p.1762-1770, november/december 1988.

YOUNGS, E.G. Redistribution of moisture in porous materials after infiltration: 1. Soil Science, v.86, n.3, p.117-125, march 1958a. 
YOUNGS, E.G. Redistribution of moisture in porous materials after infiltration: 2. Soil Science, v.86, n.4, p.202-207, april 1958 b.

ZACHMANN, D.W; THOMAS, A.W. A mathematical investigation of steady infiltration from line sources. Soil Science Society of America Proceedings, v.37, n.4, p.495-500, july/august 1973. 


\section{APÊNDICE 1}

Página

Tabela 1. Valores de pares de dados de potencial matricial versus teor de água no solo em base de volume, em função da profundidade, para o perfil ensaiado.

Tabela 2. Leituras de profundidade do sulco obtidas através do perfilômetro de varetas ao longo do perfil transversal, para cada um dos ensaios realizado.

Tabela 3. Tempo após início de aplicação de água e altura da lâmina sobre o sulco para cada um dos ensaios realizados. 88 
Tabela 1. Valores de pares de dados de potencial matricial versus teor de água no solo em base de volume, em função da profundidade, para o perfil ensaiado.

\begin{tabular}{|c|c|c|c|c|c|}
\hline \multirow{2}{*}{ potercal } & \multicolumn{5}{|c|}{ propladidade } \\
\hline & $0,0=0,2$ & $0,2=0,4$ & $0,4=0,6$ & $0,6=0,8$ & $0,8=1,0$ \\
\hline$-0,01$ & 0,5847 & 0,5394 & 0,5521 & 0,5309 & 0,5318 \\
\hline$-0,1$ & 0,5688 & 0,5231 & 0,5365 & 0,5211 & 0,5104 \\
\hline$-0,2$ & 0,5415 & 0,5103 & 0,4733 & 0,4955 & 0,4659 \\
\hline$-0,4$ & 0,5209 & 0,4926 & 0,4515 & 0,4617 & 0,4158 \\
\hline-1 & 0,4469 & 0,4332 & 0,4094 & 0,4326 & 0,3601 \\
\hline-3 & 0,4000 & 0,4004 & 0,3947 & 0,3898 & 0,3334 \\
\hline-5 & 0,3716 & 0,3778 & 0,3733 & 0,3712 & 0,3175 \\
\hline-10 & 0,3477 & 0,3555 & 0,3566 & 0,3535 & 0,3008 \\
\hline-50 & 0,3116 & 0,3173 & 0,3262 & 0,3150 & 0,2751 \\
\hline-150 & 0,2976 & 0,3020 & 0,3238 & 0,3114 & 0,2776 \\
\hline
\end{tabular}


Tabela 2. Leituras de profundidade do sulco (m) obtidas através do perfilômetro de varetas ao longo do perfil transversal, para cada um dos ensaios realizados.

\begin{tabular}{|c|c|c|c|c|c|c|c|c|c|c|c|}
\hline \multirow{2}{*}{ ponto } & \multicolumn{5}{|c|}{ Profundidade (m) } & \multirow{2}{*}{ ponto } & \multicolumn{5}{|c|}{ Profuindidade (m) } \\
\hline & 1 & it & ii: & $y$ & $X$ & & 1 & II & ii & $\mathrm{I}$ & $\mathrm{V}$ \\
\hline-21 & - & 0 & 0 & & - & 4 & $-0,123$ & $-0,122$ & $-0,131$ & $-0,114$ & $-0,126$ \\
\hline-20 & - & $-0,003$ & 005 & 0,000 & 0,000 & 1 &, 123 & $-0,124$ & $-0,130$ & -6 & $-0,125$ \\
\hline-1 & - & 3 & 2 & -- & $-0,007$ & 2 & $-0,122$ & $-0,124$ & $-0,128$ & $-0,114$ & $\mid-0,124$ \\
\hline-1 & - & 5 & 21 & 2 & $-0,020$ & 3 & 19 & $-0,124$ & $-0,126$ & 5 & $-0,122$ \\
\hline-1 & 000 & 9 & 29 & 16 & $-0,034$ & 4 & 13 & $-0,122$ & $-0,123$ & 11 & $-0,119$ \\
\hline-1 & & 4 & 4 & 0 & $-0,047$ & 5 & 08 & $-0,117$ & $-0,119$ & -0 & $-0,114$ \\
\hline-1 & & & & 7 & $-0,056$ & 6 & & $-0,112$ & $-0,112$ & -0 & $-0,108$ \\
\hline-1 & & & & 6 & $-0,063$ & 7 & & $-0,107$ & $-0,105$ & -0 & $-0,100$ \\
\hline-1 & & & & & $-0,070$ & & & 01 & 98 & & $-0,092$ \\
\hline-1 & & & & & 6 & & & 96 & 93 & & $-0,086$ \\
\hline-1 & $-0,061$ & 5 & & & 32 & & & & - & & $-0,08$ \\
\hline-10 & 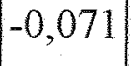 & - & -1 & $-(-$ & $-0,086$ & & & & 3 & & $-0,07$ \\
\hline-9 & $-0,081$ & $-0,086$ & -0 & $-0,076$ & $-0,092$ & & & & & & -0, \\
\hline-8 & $-0,090$ & $-0,092$ & $-0,105$ & $-0,080$ & $-0,099$ & 13 & $-0,049$ & $|-0,069|$ & $-0,071$ & & $-0,047$ \\
\hline-7 & $-0,099$ & $-0,097$ & $-0,111$ & $-0,088$ & $-0,106$ & 14 & 33 & 54 & $-0,064$ & $-0,043$ & $-0,039$ \\
\hline-6 & $-0,106 \mid$ & $-0,102$ & $-0,116$ & $-0,094$ & $-0,112$ & 15 & $-0,016$ & $-0,058$ & $-0,056$ & -0 & $-0,034$ \\
\hline-5 & $-0,111 \mid$ & $-0,105$ & $-0,122$ & $-0,100$ & $-0,117$ & 16 & $-0,006$ & $-0,049$ & $-0,047$ & $-0,028$ & $-0,031$ \\
\hline-4 & $-0,114$ & $-0,111$ & $-0,126$ & $-0,105$ & $-0,120$ & 17 & 0,000 & $-0,039$ & $-0,038$ & 21 & $-0,026$ \\
\hline-3 & {$[-0,118]$} & $-0,118 \mid$ & $-0,130$ & $-0,107$ & $-0,123$ & 1 & - & $-0,029$ & $-0,029$ & 4 & $-0,019$ \\
\hline-2 & $-0,120$ & $-0,120 \mid$ & $-0,131$ & $-0,110$ & $-0,126$ & 19 & - & $-0,020$ & $-0,022$ & $-0,008$ & $-0,012$ \\
\hline-1 & $-0,122$ & $-0,122$ & $-0,132$ & $-0,113$ & $-0,127$ & & - & $-0,011$ & $-0,013$ & $-0,000 \mid$ & 0,000 \\
\hline & & & & & & 21 & - & 0,000 & 0,000 & - & E \\
\hline
\end{tabular}

OBS: Distância entre pontos igual a $0,01 \mathrm{~m}$. 
Tabela 3. Tempo após inicio de aplicação de água e altura da lâmina sobre o sulco para cada um dos ensaios realizados.

\begin{tabular}{|c|c|c|c|c|c|c|c|c|c|c|c|}
\hline \multirow{2}{*}{ tempo } & \multicolumn{5}{|c|}{ Alura dalamma deagna $(\mathrm{m})$} & \multirow{2}{*}{ (senpo } & \multicolumn{5}{|c|}{ Aluradalamandedanalm) } \\
\hline & 1 & iI & 1 & IV & $y$ & & 1 & I: & III & 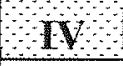 & 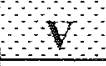 \\
\hline 0 & 0,000 & & & & & & & & & & \\
\hline 3 & & & & & & & & & & & \\
\hline 6 & & & & & c & & & & & 0,050 & \\
\hline 9 & & & & & & & & & & 0,050 & \\
\hline 120 & 240 & & 24 & 0,021 & 1 & 960 & & 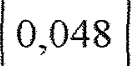 & 0,048 & 50 &, 00 \\
\hline 15 & 047 & 020 & & 1 & 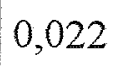 & & & & & & \\
\hline 180 & 0051 & 020 & 9 & 10 & 6 & 1020 & & 1 & & & 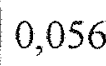 \\
\hline 2 & 0057 & 020 & 0.031 & 0 & 7 & 0 & 9 & 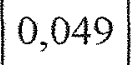 & & & \\
\hline 2. & 2 & 022 & 2 & 0 & 0 & & 9 & 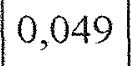 & & 50 & 0,056 \\
\hline 270 & $0,0 \mathrm{r}$ & 026 & & 0 & & & & & & & \\
\hline 300 & 06 & 7 & 7 & 0 & 0,035 & 0 & 0 & 9 & 0,030 & 50 & 055 \\
\hline 33 & & & & 0 & 0 & 0 & 0 & 9 & 0,025 & 0 & 0,055 \\
\hline 360 & & & & & 0 & 1 & 0 & 19 & 2 & 0,045 & 0,054 \\
\hline 390 & & & 0 & 0 & 0 & 1230 & 0,090 & 0,049 & 0,019 & 0,043 & 0,053 \\
\hline 420 & & & & & & 1260 & 0,090 & 0,049 & 0,015 & 0,042 & 0,051 \\
\hline & & & & & & U & & 49 & 12 & 0,039 & 0,049 \\
\hline & & & & & & & & & & 81 & 148 \\
\hline 5 & & & & & & & & & & 0,0, & 30 \\
\hline 540 & 3 & & & 0,04 & & 1380 & & & & 0, & 0,044 \\
\hline 570 & 0,089 & 0 & 7 & & & & & & &, & 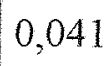 \\
\hline 600 & 0,089 & c & 8 & 0 & 0 & 1440 & & & & & $0,0 \rightarrow 0$ \\
\hline 630 & 0,090 & 0 & 0,048 & 0 & 0 & 1470 & 5 & & & 7 & 0,038 \\
\hline 660 & 0,092 & 043 & 0,048 & 0,049 & 0,052 & 1500 & 5 & 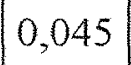 & & 25 & 0,00 \\
\hline 690 & 0,094 & 44 & 0,048 & 49 & 52 & 0 & 0,095 & 4 & & 24 & צד \\
\hline 1 & .095 & 45 & 0,049 & 50 & 52 & 60 & 6 & 4 & & 21 & 031 \\
\hline 1. & 0,095 & 0,046 & 0,049 & 0,050 & 0,053 & 1590 & 0,094 & 0 & & 0,020 & 029 \\
\hline 780 &, 095 & 346 & 0,049 & 0,050 & 0,054 & 1620 & 0,093 & 0,042 & & 0,017 & 0,028 \\
\hline 810 & 075 & 046 & 0,049 & 0,050 & 0,055 & 1650 & 0,091 & 0,041 & & 0,015 & 0,025 \\
\hline
\end{tabular}




\begin{tabular}{|c|c|c|c|c|c|c|c|c|c|c|c|}
\hline \multicolumn{12}{|c|}{ Continuação Tabela 3} \\
\hline $\operatorname{te} \mathrm{l} \alpha$ & \multicolumn{5}{|c|}{ Cinsalo $($ ) } & temo & \multicolumn{5}{|c|}{ Ensatio $(1)$} \\
\hline$(\mathrm{s})$ & 1 & ii & III & $\mathrm{IV}$ & 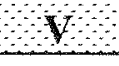 & $(\mathrm{s})$ & 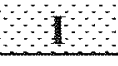 & II & III & $\mathrm{IV}$ & $x$ \\
\hline 1680 & 0,087 & 0,040 & & 0,012 & 0,022 & 2190 & 0,046 & 0,013 & & & \\
\hline 1710 & 0,084 & 0,039 & & 0,010 & 0,020 & 2220 & 0,042 & 0,010 & & & \\
\hline 1740 & 0,083 & 0,037 & & 0,007 & 0,018 & 2250 & 0,039 & 0,009 & & & \\
\hline 1770 & 0,080 & 0,035 & & 0,003 & 0,013 & 2280 & 0,036 & 0,009 & & & \\
\hline 1800 & 0,078 & 0,034 & & 0,000 & 0,010 & 2310 & 0,034 & 0,008 & & & \\
\hline 1830 & 0,074 & 0,033 & & & 0,006 & 2340 & 0,031 & 0,006 & & & \\
\hline 1860 & 0,072 & 0,031 & & & 0,000 & 2370 & 0,027 & 0,004 & & & \\
\hline 1890 & 0,070 & 0,029 & & & & 2400 & 0,025 & 0,003 & & & \\
\hline 1920 & 0,068 & 0,027 & & & & 2430 & 0,022 & 0,002 & & & \\
\hline 1950 & 0,065 & 0,025 & & & & 2460 & 0,020 & 0,000 & & & \\
\hline 1980 & 0,061 & 0,023 & & & & 2490 & 0,018 & & & & \\
\hline 2010 & 0,059 & 0,021 & & & & 2520 & 0,015 & & & & \\
\hline 2040 & 0,057 & 0,020 & & & & 2550 & 0,013 & & & & \\
\hline 2070 & 0,054 & 0,019 & & & & 2580 & 0,010 & & & & \\
\hline 2100 & 0,053 & 0,017 & & & & 2610 & 0,006 & & & & \\
\hline 2130 & 0,050 & 0,015 & & & & 2640 & 0,000 & & & & \\
\hline 2160 & 0,048 & 0,014 & & & & & & & & & \\
\hline
\end{tabular}




\section{APÊNDICE 2}

Página

Anexo 1. Listagem do programa DASIS, escrito em linguagem de programação

Pascal.

Anexo 2. Exemplo de arquivo de entrada de dados de perfil (extensão ADP). ..... 103

Anexo 3. Exemplo de arquivo de dados de entrada de solo (extensão ADS) . ...... 104

Anexo 4. Exemplo de arquivo de dados de entrada de lâmina (extensão ADL) ... 105

Anexo 5. Exemplo de arquivo de dados de entrada de controle (extensão ADC) .. 107

Anexo 6. Exemplo de arquivo de dados de saida de compartimentos e teor de água (extensão SCR).

Anexo 7. Exemplo de arquivo de dados de saída de infiltração (extensão INF). ... 108

Anexo 8. Exemplo de arquivo de dados de saída resumo (extensão RES). 109 
Anexo 1. Listagem do programa DASIS, escrito em linguagem de programação Pascal.

program DASIS;

uses

crt,dos;

const

$P M L=-150 ;\{$ potencial no teor de agua residual $(\mathrm{m})\}$

PMS $=-100000 ;\{$ potencial no teor de agua zero $(\mathrm{m})$ \}

type

PTR_GEOMETRIA $=\wedge$ GEOMETRIA;

GEOMETRIA = record \{dados geometricos dos compartimentos formados na malha\}

$\mathrm{VC}$ : real; \{volume do compartimento $(\mathrm{m} 3)$ \}

BY : real; \{coordenada y do baricentro do compartimento (m) \}

$\mathrm{BZ}$ : real; \{coordenada $\mathrm{z}$ do baricentro do compartimento $(\mathrm{m})$ \}

L1 : real; \{distancia do baricentro ate limite $1(\mathrm{~m})$ \}

L2 : real; \{distancia do baricentro ate limite $2(\mathrm{~m})$ \}

L3 : real; \{distancia do baricentro ate limite $3(\mathrm{~m})$ \}

L4 : real; \{distancia do baricentro ate limite $4(\mathrm{~m})$ \}

Al : real; \{area de contato no limite $1(\mathrm{~m} 2)\}$

A2 : real; \{area de contato no limite $2(\mathrm{~m} 2)\}$

A3 : real; \{area de contato no limite $3(\mathrm{~m} 2)\}$

A4 : real; \{area de contato no limite $4(\mathrm{~m} 2)$ \}

end;

PTR_HIDRAULICA $=\wedge$ HIDRAULICA:

HIDRAULICA = record \{dados hidraulicos do solo dos compartimentos\}

UI : real; \{teor de agua inicial $(\mathrm{m} 3 / \mathrm{m} 3)\}$

UC : real; \{teor de agua atual $(\mathrm{m} 3 / \mathrm{m} 3)\}$

US : real; \{teor de agua na saturacao $(\mathrm{m} 3 / \mathrm{m} 3)\}$

UR : real; \{teor de agua residual $(\mathrm{m} 3 / \mathrm{m} 3)\}$

UL : real; \{teor de agua calculado no potencial $-150 \mathrm{~m}(\mathrm{~m} 3 / \mathrm{m} 3)\}$

$\mathrm{CA}$ : real; \{coeficiente alfa de van Genuchten $(1 / \mathrm{m})$ \}

$\mathrm{CM}$ : real; \{coeficiente $\mathrm{m}$ de van Genuchten (adimensional)\}

KS : real; \{condutividade hidraulica saturada $(\mathrm{m} / \mathrm{s})$ \}

PM : real; \{potencial matricial atual $(\mathrm{m})$ \}

$\mathrm{CH}$ : real; \{condutividade hidraulica atual $(\mathrm{m} / \mathrm{s})\}$

end;

PTR_SULCO $=\wedge$ SULCO;

SULCO $=$ record $\{$ dados do contorno original do sulco $\}$

$\mathrm{Y}$ : real; \{coordenada y para um dos intervalos no contorno $(\mathrm{m})$ \}

$Z$ : real; \{coordenada $Z$ correspondente a y $(\mathrm{m})$ \}

$\mathrm{N}$ : PTR_SULCO;

end;

PTR_MALHA $=\wedge$ MALHA;

MALHA = record \{dados das intersecoes entre linhas radiais e linhas de contorno\}

$\mathrm{Y}:$ real; $\{$ coordenada y $(\mathrm{m})\}$

$Z$ : real; $\{$ coordenada $z,(\mathrm{~m})\}$

end;

PTR_LAMINA $=\wedge$ LAMINA;

LAMINA $=$ record $\{$ dados do comportamento da lamina de agua sobre o sulco $\}$ 
$\mathrm{T}$ : real; \{tempo transcorrido apos inicio de aplicacao de agua (s)\}

$\mathrm{L}$ : real; \{altura da lamina de agua $(\mathrm{m})$ \}

N : PTR_LAMINA;

end;

PTR INFILTRA = AINFILTRA;

INFILTRA $=$ record $\{$ dados de infiltracao de agua $\}$

$\mathrm{T}$ : real; \{tempo transcorrido apos inicio de aplicacao de agua (s)\}

A : real; \{area molhada média por metro de sulco $(\mathrm{m} 2)$ \}

$\mathrm{V}$ : real; \{volume acumulado de agua infiltrado por metro de sulco $(\mathrm{m} 3)$ \}

N : PTR_INFILTRA:

end:

var

ARQ : text; \{assinala um arquivo em disco\}

G1,G2 : PTR GEOMETRIA; \{aponta para os dados geometricos dos compartimentos\}

PG : array $[1.50,1 . .50]$ of PTR_GEOMETRIA;

H1,H2 : PTR_HIDRAULICA; \{aponta para os dados hidraulicos dos compartimentos\}

PH : array $[1 . .50,1 . .50]$ of PTR_HIDRAULICA;

C : PTR_SULCO; \{aponta para os dados do contorno original do sulco\}

PC : PTR_SULCO;

L : PTR_LAMINA; \{aponta para os dados do comportamento da lamina de agua sobre o sulco\}

PL : PTR_LAMINA;

LR : byte; \{numero de linhas radiais\}

$\mathrm{NF}$ : byte; \{numero de fatias intercaladas as linhas radiais\}

LC : byte; \{numero de linhas de contorno\}

$\mathrm{NC}$ : byte; numero de camadas intercaladas as linhas de contorno\}

$I$ : byte; \{numero de ordem da linha radial ou da fatia\}

$\mathrm{J}$ : byte; \{numero de ordem da linha de contorno ou da camada\}

$\mathrm{VL}$ : real; \{maior variacao no teor de agua permitida no laco $(\mathrm{m} 3 / \mathrm{m} 3)$ \}

IC : real; \{intervalo de tempo calculado (s)\}

IT : real; \{intervalo de tempo escolhido (s)\}

TT : real: \{tempo total a simular (s)\}

TS : real; \{tempo total simulado (s)\}

TA : real: \{tempo total de presenca de agua no sulco (s)\}

ZL : real; \{coordenada $\mathrm{z}$ da superficie da lamina de agua no sulco $(\mathrm{m})$ \}

$\mathrm{TI}$ : real; \{tempo inferior no segmento para altura da lamina de agua $(\mathrm{s})\}$

LI : real; \{lamina no inicio do intervalo de tempo $(\mathrm{m})$ \}

TF : real; \{tempo superior no segmento para altura da lamina de agua (s)\}

$\mathrm{LF}$ : real; \{lamina no final do intervalo de tempo $(\mathrm{m})\}$

$\mathrm{CF}$ : real; \{coordenada $\mathrm{z}$ do fundo do sulco $(\mathrm{m})$ \}

VI : real; \{volume acumulado de agua infiltrado por metro de sulco (m3)\}

AM : real; \{area molhada por metro de sulco $(\mathrm{m} 2)$ \}

$\mathrm{KM}$ : real; \{condutividade hidraulica media entre compartimentos $(\mathrm{m} / \mathrm{s})$ \}

$\mathrm{GH}$ : real; $\{$ gradiente de potencial hidraulico $(\mathrm{m} / \mathrm{m})$ \}

NOMEARQ : string; \{nome base dos arquivos de dados\}

HO, MI, SE, CE : word:

function $\mathrm{POW}(\mathrm{X}, \mathrm{Y}$ :real):real; \{eleva um numero $\mathrm{X}$ a uma potencia $\mathrm{Y}$ \}

begin

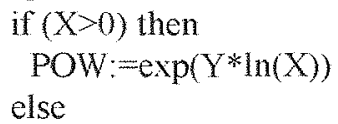




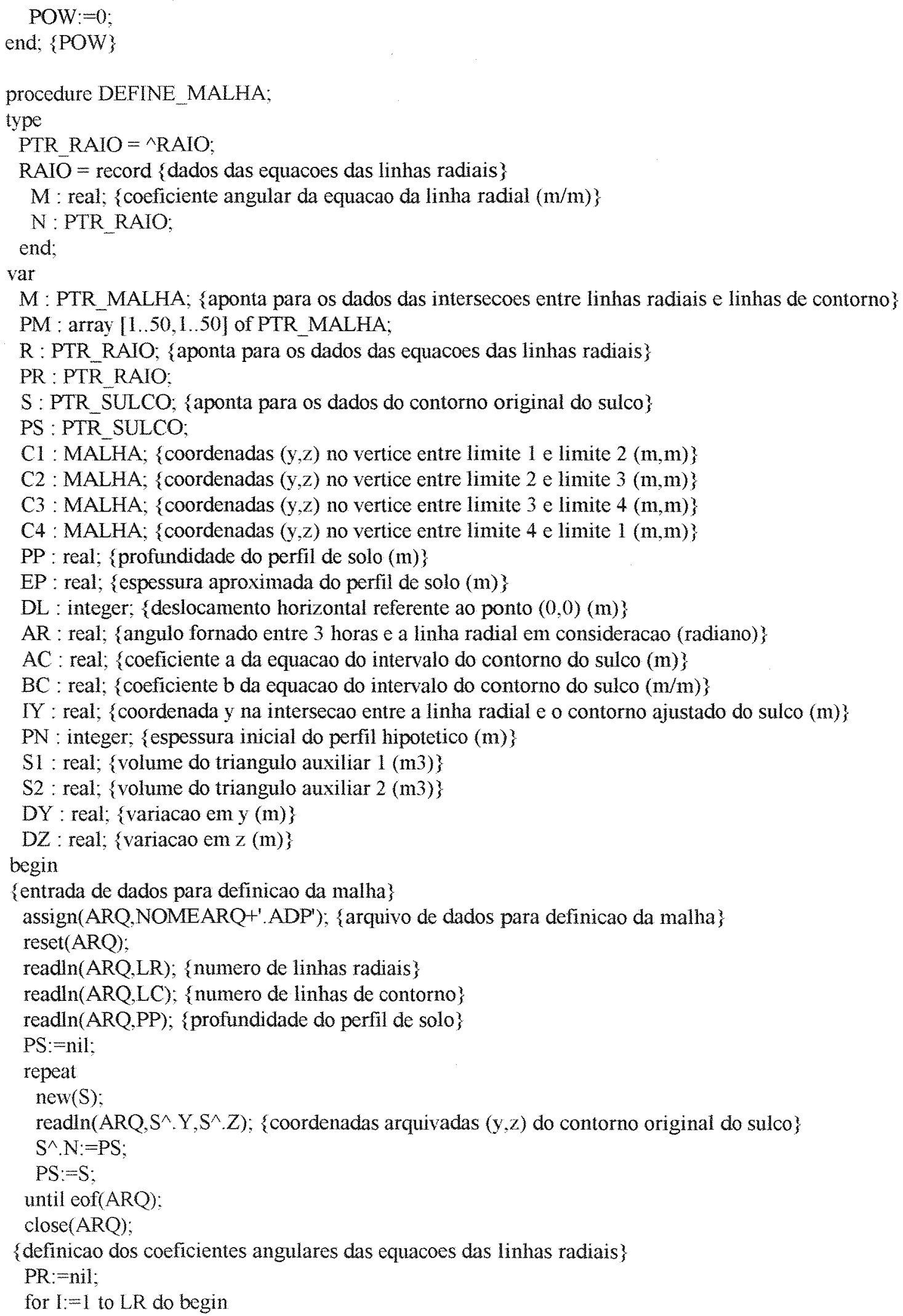


new $(\mathrm{R})$;

$\mathrm{AR}:=\mathrm{pi}^{*}(\mathrm{I}-1) /(\mathrm{LR}-1) ;$ angulo formado entre 3 horas e a linha radial\}

$\mathrm{R}^{\wedge} \cdot \mathrm{M}:=-\sin (\mathrm{AR}) / \cos (\mathrm{AR})$; coeficiente angular da equacao da linha radial 1$\}$

$\mathrm{R}^{\wedge} \cdot \mathrm{N}:=\mathrm{PR}$

$\mathrm{PR}:=\mathrm{R}$;

end:

\{coordenadas $(\mathrm{y}, \mathrm{z})$ das intersecoes entre as linhas radiais e a linha de contorno 1 (sulco)\}

$\mathrm{CF}:=0$; \{inicia valor para coordenada $\mathrm{z}$ do fundo do sulco $\}$

$\mathrm{R}:=\mathrm{PR}$;

$\mathrm{PC}:=$ nil;

for $I:=L R$ downto 1 do begin

PM[I, I]: $=$ nil;

new $(M)$;

$\mathrm{S}:=\mathrm{PS}$;

if $(I=1)$ or $(I=L R)$ then begin $\{$ linhas radiais na superficie do terreno\}

if $(I=1)$ then

$M^{\wedge} . Y:=S^{\wedge} . Y$ coordenada y da extrema direita do sulco\}

else

$\mathrm{M}^{\wedge} \mathrm{Y}:=-\mathrm{S}^{\wedge} . \mathrm{Y} ;$ \{coordenada y da extrema esquerda do sulco

$M^{\wedge} \cdot Z:=0$

$\mathrm{PM}[\mathrm{I}, \mathrm{I}]=\mathrm{M}$;

$\mathrm{R}:=\mathrm{R}^{\wedge} \cdot \mathrm{N}$;

end else repeat

$\mathrm{C} 1 . \mathrm{Y}:=\mathrm{S}^{\wedge} \mathrm{Y} ;$; coordenada $\mathrm{y}$ do primeiro ponto $\}$

$\mathrm{C} 1 . \mathrm{Z}:=\mathrm{S}^{\wedge} . \mathrm{Z} ;$; coordenada $\mathrm{Z}$ do primeiro ponto\}

$\mathrm{S}:=\mathrm{S}^{\wedge} \cdot \mathrm{N}:$

$\mathrm{C} 2 . \mathrm{Y}:=\mathrm{S}^{\wedge} . \mathrm{Y} ;$; coordenada y do segundo ponto\}

$\mathrm{C} 2 . \mathrm{Z}:=\mathrm{S}^{\wedge} . \mathrm{Z} ;$; coordenada $\mathrm{Z}$ do segundo ponto\}

$\mathrm{AC}:=(\mathrm{C} 1 . \mathrm{Z}-\mathrm{C} 2 . \mathrm{Z}) /(\mathrm{C} 1 . \mathrm{Y}-\mathrm{C} 2 . \mathrm{Y}) ;$; coeficiente a da equacao do intervalo do contorno do sulco $\}$

$\mathrm{BC}:=\mathrm{C} 1 . \mathrm{Z}-\mathrm{AC} * \mathrm{C} 1 . \mathrm{Y} ;\{$ coeficiente $\mathrm{b}$ da equacao do intervalo do contorno do sulco\}

if $\left(R^{\wedge} \cdot M<>B C\right)$ then begin

$\mathrm{IY}:=\mathrm{BC} /\left(\mathrm{R}^{\wedge}, \mathrm{M}-\mathrm{AC}\right)$; coordenada y na intersecao entre linha radial I e linha de contorno 1$\}$

if $(\mathrm{IY}<=\mathrm{C} 1 . \mathrm{Y})$ and $(\mathrm{IY}>=\mathrm{C} 2 . \mathrm{Y})$ then begin

$\mathrm{M}^{\wedge} \mathrm{Y}:=\mathrm{HY}$; coordenada y na intersecao entre linha radial $\mathrm{I}$ e linha de contorno 1 \}

$\mathrm{M}^{\wedge} . \mathrm{Z}:=\mathrm{R}^{\wedge} . \mathrm{M}^{*} \mathrm{M}^{\wedge} . \mathrm{Y} ;$; coordenada $\mathrm{z}$ na intersecao entre linha radial 1 e linha de contorno 1$\}$

$\mathrm{PM}[\mathrm{I}, 1]:=\mathrm{M}$;

$\mathrm{R}:=\mathrm{R}^{\wedge} \cdot \mathrm{N}:$

end;

end;

until (PM $[1,1]<>$ nil);

if $\left(\mathrm{M}^{\wedge}, \mathrm{Z}<\mathrm{CF}\right)$ then

$\mathrm{CF}:=\mathrm{M}^{\wedge} . \mathrm{Z} ;$ \{cota de fundo do sulco $\left.(\mathrm{m})\right\}$

new $(\mathrm{C})$;

$\mathrm{C}^{\wedge} \cdot \mathrm{Y}:=\mathrm{M}^{\wedge} \cdot \mathrm{Y}$

$C^{\wedge} \cdot Z:=M^{\wedge} \cdot Z$;

$\mathrm{C}^{\wedge} \cdot \mathrm{N}:=\mathrm{PC}$;

$\mathrm{PC}:=\mathrm{C}$ :

end:

\{coordenadas $(y, z)$ das intersecoes entre as linhas radiais e linhas de contorno 2 em diante\}

$\mathrm{NF}:=\mathrm{LR}-1 ;$ \{ numero de fatias intercaladas as linhas radiais $\}$

$\mathrm{NC}=\mathrm{LC}-1$; numero de camadas intercaladas as linhas de contorno $\}$ 
$\mathrm{PN}:=0 ;$ \{inicializando espessura do perfil hipotetico $\}$

for $\mathrm{J}:=1$ to $\mathrm{NC}$ do

$\mathrm{PN}:=\mathrm{PN}+\mathrm{J}$; \{espessura inicial do perfil hipotetico\}

$\mathrm{R}:=\mathrm{PR}$ :

$\mathrm{EP}:=\mathrm{PP}-\mathrm{abs}(\mathrm{CF}) ;$ \{espessura aproximada do perfil de solo

for $\mathrm{I}:=\mathrm{LR}$ downto 1 do begin

for $\mathrm{J}:=2$ to $\mathrm{LC}$ do begin

$\mathrm{M}:=\mathrm{PM}[\mathrm{I}, \mathrm{J}-1]$; acessa dados da malha na intersecao entre linha radial I e linha de contorno $\mathrm{J}-1$ \}

$\mathrm{Cl} . \mathrm{Y}:=\mathrm{M}^{\wedge}$.Y; $\{$ armazena coordenada y na intersecao entre limha radial 1 e linha de contorno $\mathrm{J}-1$ \} new $(\mathrm{M})$;

AR:=pi*(I-1)/(LR-1); $\{$ angulo formado entre 3 horas e a linha radial I\}

$\mathrm{M}^{\wedge} . \mathrm{Y}:=\mathrm{Cl} 1 \mathrm{Y}+\cos (\mathrm{AR})^{*}(\mathrm{~J}-1)^{*} \mathrm{EP} / \mathrm{PN} ;\{\mathrm{y}$ na intersecao entre linha radial $\mathrm{I} \mathrm{e}$ linha de contorno $\mathrm{J}\}$

$\mathrm{M}^{\wedge} . \mathrm{Z}:=\mathrm{R}^{\wedge} \cdot \mathrm{M}^{*} \mathrm{M}^{\wedge} . \mathrm{Y} ;$ \{coordenada $\mathrm{z}$ na intersecao entre linha radial I e linha de contorno $\left.\mathrm{J}\right\}$

$\mathrm{PM}[\mathrm{I}, \mathrm{J}]:=\mathrm{M}$;

end;

$\mathrm{PR}:=\mathrm{R}^{\wedge} \cdot \mathrm{N}$;

$\mathrm{R}:=\mathrm{PR}$;

end;

\{volume, baricentro, distancias e areas de contato dos compartimentos\}

assign(ARQ,NOMEARQ+'.SCR'); \{arquivo script para desenho dos compartimentos\}

rewrite(ARQ);

writeln(ARQ,'LAYER M CELULA C GREEN');

writeln(ARQ);

writeln(ARQ);

for $\mathrm{I}:=1$ to $\mathrm{NF}$ do

for $\mathrm{J}=1$ to $\mathrm{NC}$ do begin

$\mathrm{M}:=\mathrm{PM}[\mathrm{I}, \mathrm{J}]$; $\{$ acessa dados da malha na intersecao entre linha radial I e linha de contorno J\}

$\mathrm{C} 1 . \mathrm{Y}:=\mathrm{M}^{\wedge} . \mathrm{Y}$; \{coordenada y na intersecao entre linha radial I e linha de contorno $\left.\mathrm{f}\right\}$

$\mathrm{C} 1 . \mathrm{Z}:=\mathrm{M}^{\wedge} . \mathrm{Z} ;$; coordenada $\mathrm{z}$ na intersecao entre linha radial I e linha de contorno $\mathrm{J}$ \}

write(ARQ,'LINE ');

write(ARQ,C1.Y:5:3,','C1.Z:5:3,' ');

$\mathrm{M}:=\mathrm{PM}[\mathrm{I}+1, \mathrm{~J}$; $\{$ acessa dados da malha na intersecao entre linha radial $\mathrm{I}+1$ e linha de contorno $\mathrm{J}$ \}

$\mathrm{C} 2 . \mathrm{Y}:=\mathrm{M}^{\wedge} . \mathrm{Y}$; \{coordenada y na intersecao entre linha radial $\mathrm{I}+\mathrm{l}$ e linha de contorno $\left.J\right\}$

$\mathrm{C} 2 . \mathrm{Z}:=\mathrm{M}^{\wedge} . \mathrm{Z} ;$; coordenada $\mathrm{Z}$ na intersecao entre linha radial $\mathrm{I}+1$ e linha de contorno $\left.\mathrm{J}\right\}$ write(ARQ,C2.Y:5:3,",'C2.Z:5:3,"');

$\mathrm{M}:=\mathrm{PM}[\mathrm{I}+1, \mathrm{~J}+1]$; acessa dados da malha na intersecao linha radial $\mathrm{I}+1$ e linha de contorno $\mathrm{J}+1$ \}

$\mathrm{C} 3 . \mathrm{Y}:=\mathrm{M}^{\wedge} . \mathrm{Y}$; $\{$ coordenada y na intersecao linha radial $\mathrm{I}+1$ e linha de contorno $\mathrm{J}+1\}$

$\mathrm{C} 3 . \mathrm{Z}:=\mathrm{M}^{\wedge} . \mathrm{Z} ;$; coordenada $\mathrm{Z}$ na intersecao linha radial $\mathrm{I}+1$ e linha de contorno $\mathrm{J}+1$ \}

write(ARQ,C3.Y:5:3,','C3.Z:5:3,' ');

$\mathrm{M}:=\mathrm{PM}[\mathrm{I}, \mathrm{J}+1]$; $\{$ acessa dados da malha na intersecao entre linha radial I e linha de contorno $\mathrm{J}+1$ \}

$\mathrm{C} 4 . \mathrm{Y}:=\mathrm{M}^{\wedge} \mathrm{Y}$; ; coordenada y na intersecao entre linha radial I e linha de contorno $\mathrm{J}+1$ \}

$C 4 . Z:=M^{\wedge} . Z ;$; coordenada $\mathrm{Z}$ na intersecao entre linha radial I e linha de contorno $\left.\mathrm{J}+1\right\}$

write(ARQ,C4.Y:5:3,','C4.Z:5:3);

writeln(ARQ,' C');

new(G1); \{atribui dados geometricos aos compartimentos\}

\{volume dos triangulos de auxilio\}

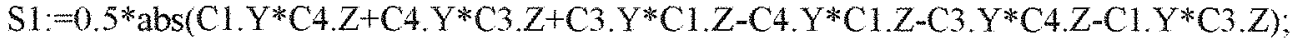

$\mathrm{S} 2:=0.5^{*} \mathrm{abs}\left(\mathrm{Cl}, \mathrm{Y} * \mathrm{C} 2 . \mathrm{Z}+\mathrm{C} 2 . \mathrm{Y}^{*} \mathrm{C} 3 . \mathrm{Z}+\mathrm{C} 3, \mathrm{Y} * \mathrm{Cl} . \mathrm{Z}-\mathrm{C} 2 . \mathrm{Y}^{*} \mathrm{C} 1 . \mathrm{Z}-\mathrm{C} 3 . \mathrm{Y}^{*} \mathrm{C} 2 . \mathrm{Z}-\mathrm{Cl}, \mathrm{Y} * \mathrm{C} 3 . \mathrm{Z}\right)$;

$\mathrm{G} 1^{\wedge} \cdot \mathrm{VC}:=\mathrm{S} 1+\mathrm{S} 2$; \{volume compartimento esquerda linha radial I e abaixo linha contorno $\left.\mathrm{I}\right\}$

\{coordenadas do baricentro do compartimento\}

$\mathrm{G} 1^{\wedge} \cdot \mathrm{BY}:=(\mathrm{S} 1 *(\mathrm{C} 1 . \mathrm{Y}+\mathrm{C} 3 . \mathrm{Y}+\mathrm{C} 4 . \mathrm{Y}) / 3+\mathrm{S} 2 *(\mathrm{C} 1 . \mathrm{Y}+\mathrm{C} 2 . \mathrm{Y}+\mathrm{C} 3, \mathrm{Y}) / 3) / \mathrm{G} 1^{\wedge} . \mathrm{VC}$ 
$\mathrm{G}^{\wedge} \cdot \mathrm{BZ}:=(\mathrm{S} 1 *(\mathrm{Cl} 1 \mathrm{Z}+\mathrm{C} 3 . \mathrm{Z}+\mathrm{C} 4 . \mathrm{Z}) / 3+\mathrm{S} 2 *(\mathrm{C} 1 . \mathrm{Z}+\mathrm{C} 2 . \mathrm{Z}+\mathrm{C} 3 . \mathrm{Z}) / 3) / \mathrm{G} 1^{\wedge} \cdot \mathrm{VC}$

$\mathrm{DY}:=\mathrm{G} 1^{\wedge} . \mathrm{BY}-(\mathrm{C} 1 . \mathrm{Y}+\mathrm{C} 2 . \mathrm{Y}) / 2 ;\{$ variacao em $\mathrm{y}\}$

$\mathrm{DZ}:=\mathrm{G} 1^{\wedge} \cdot \mathrm{BZ}-(\mathrm{C} 1 \mathrm{Z}+\mathrm{C} 2 . \mathrm{Z}) / 2$; $\{$ variacao $\mathrm{em} \mathrm{Z}$ \}

$\mathrm{G} 1^{\wedge} \cdot \mathrm{Ll}:=\mathrm{sqrt}(\mathrm{sqr}(\mathrm{DY})+\mathrm{sqr}(\mathrm{DZ})) ;$ distancia do baricentro ate limite 1$\}$

$\mathrm{DY}:=\mathrm{G} 1^{\wedge} . \mathrm{BY}-(\mathrm{C} 1 . \mathrm{Y}+\mathrm{C} 4 . \mathrm{Y}) / 2$; $\{$ variacao em $\mathrm{y}\}$

$\mathrm{DZ}:=\mathrm{Gl} 1^{\wedge} \cdot \mathrm{BZ}-(\mathrm{Cl} . \mathrm{Z}+\mathrm{C} 4 . \mathrm{Z}) / 2 ;$ variacao $\left.\mathrm{em} \mathrm{z}\right\}$

$\mathrm{G} 1^{\wedge} . \mathrm{L} 2:=\operatorname{sqrt}(\operatorname{sqr}(\mathrm{DY})+\operatorname{sqr}(\mathrm{DZ})) ;\{$ distancia do baricentro ate limite 2$\}$

$\mathrm{DY}:=\mathrm{G} 1^{\wedge} \cdot \mathrm{BY}-(\mathrm{C} 3 . \mathrm{Y}+\mathrm{C} 4 . \mathrm{Y}) / 2$; $\{$ variacao $\mathrm{em}$ y $\}$

$\mathrm{DZ}:=\mathrm{G} 1^{\wedge} \cdot \mathrm{BZ}-(\mathrm{C} 3 . \mathrm{Z}+\mathrm{C} 4 . \mathrm{Z}) / 2 ;\{$ variacao $\mathrm{em} \mathrm{z}\}$

$\mathrm{Gl}^{\wedge} . \mathrm{L} 3:=\operatorname{sqrt}(\operatorname{sqr}(\mathrm{DY})+\operatorname{sqr}(\mathrm{DZ}))$; $\{$ distancia do baricentro ate limite 3$\}$

$\mathrm{DY}:=\mathrm{G} 1^{\wedge} . \mathrm{BY}-(\mathrm{C} 2 . \mathrm{Y}+\mathrm{C} 3 . \mathrm{Y}) / 2$; (variacao em $\mathrm{y}$ \}

$\mathrm{DZ}:=\mathrm{G} 1^{\wedge} \cdot \mathrm{BZ}-(\mathrm{C} 2 . \mathrm{Z}+\mathrm{C} 3 . \mathrm{Z}) / 2 ;$ variacao $\left.\mathrm{em} \mathrm{z}\right\}$

$\mathrm{G} 1^{\wedge}, \mathrm{L} 4:=\operatorname{sqr}(\operatorname{sqr}(\mathrm{DY})+\operatorname{sqr}(\mathrm{DZ})) ;$ distancia do baricentro ate limite 4 \}

$\mathrm{G} 1^{\wedge} . \mathrm{Al}:=\operatorname{sqrt}(\operatorname{sqr}(\mathrm{C} 1 . \mathrm{Y}-\mathrm{C} 2 . \mathrm{Y})+\operatorname{sqr}(\mathrm{C} 1 . \mathrm{Z}-\mathrm{C} 2 . \mathrm{Z})) ;$; area de contato no limite 1$\}$

$\mathrm{G} 1^{\wedge} . \mathrm{A} 2:=\operatorname{sqrt}(\operatorname{sqr}(\mathrm{C} 1 . \mathrm{Y}-\mathrm{C} 4 . \mathrm{Y})+\operatorname{sqr}(\mathrm{C} 1 . \mathrm{Z}-\mathrm{C} 4 . \mathrm{Z})$ ); $\{$ area de contato no limite 2$\}$

$\mathrm{Gl}^{\wedge} . \mathrm{A} 3:=\operatorname{sqrt}(\operatorname{sqr}(\mathrm{C} 3, \mathrm{Y}-\mathrm{C} 4 . \mathrm{Y})+\operatorname{sqr}(\mathrm{C} 3 . \mathrm{Z}-\mathrm{C} 4 . \mathrm{Z}))$; \{area de contato no limite 3$\}$

$\mathrm{G} 1^{\wedge} . \mathrm{A} 4:=\operatorname{sqrt}(\mathrm{sqr}(\mathrm{C} 2 . \mathrm{Y}-\mathrm{C} 3 . \mathrm{Y})+\operatorname{sqr}(\mathrm{C} 2 . \mathrm{Z}-\mathrm{C} 3 . \mathrm{Z}))$; $\{$ area de contato no limite 4$\}$

$\mathrm{PG}[\mathrm{I}, \mathrm{J}]:=\mathrm{G} 1$;

end:

close(ARQ);

end; \{DEFINE_MALHA\}

procedure DADOS_ENSAIO;

var

PF : real; \{profundidade media da camada de solo $(\mathrm{m})$ \}

$\mathrm{EC}$ : real; \{espessura da camada de solo $(\mathrm{m})$ \}

UI : real; $\{$ teor de agua inicial na camada de solo $(\mathrm{m} 3 / \mathrm{m} 3)\}$

US : real; \{teor de agua na saturacao na camada de solo $(\mathrm{m} 3 / \mathrm{m} 3)$ \}

UR : real; \{teor de agua residual na camada de solo $(\mathrm{m} 3 / \mathrm{m} 3)\}$

CA : real; \{coeficiente alfa de van Genuchten na camada de solo $(1 / \mathrm{m})\}$

CM : real; \{coeficiente $m$ de van Genuchten na camada de solo (adimensional)\}

KS : real; \{condutividade hidraulica saturada na camada de solo $(\mathrm{m} / \mathrm{s})$ \}

UA : real; \{teor de agua adimensional\}

begin

write('. nome base dos arquivos de dados (sem extensao): ');

readin(NOMEARQ);

DEFINE MALHA;

assign(ARQ,NOMEARQ+'.ADS'); \{arquivo de dados hidraulicos do solo\}

reset(ARQ);

repeat

readin(ARQ,PF); \{profundidade media da camada de solo\}

readin(ARQ,EC); \{espessura da camada de solo\}

readin(ARQ,UI); \{teor de agua inicial na camada de solo\}

readin(ARQ,US); \{teor de agua na saturacao na camada de solo\}

readin(ARQ, UR); teor de agua residual na camada de solo\}

readin(ARQ,CA); \{coeficiente alfa de van Genuchten na camada de solo\}

readln(ARQ,CM); coeficiente $m$ de van Genuchten na camada de solo\}

readin(ARQ,KS); \{condutividade hidraulica saturada na camada de solo\}

for $I:=1$ to NF do

for $\mathrm{J}:=1$ to $\mathrm{NC}$ do begin

$\mathrm{Gl}:=\mathrm{PG}[\mathrm{I}$, , $;$; acessa dados geometricos do compartimento I,J\} 
if $\left(\mathrm{abs}\left(\mathrm{G} 1^{\wedge} \cdot \mathrm{BZ}\right)>=\mathrm{PF}-\mathrm{EC} / 2\right)$ and $\left(\mathrm{abs}\left(\mathrm{G} 1^{\wedge} \cdot \mathrm{BZ}\right)<\mathrm{PF}+\mathrm{EC} / 2\right)$ then begin new(H1); \{atribui dados hidraulicos para o compartimento

$\mathrm{H} 1^{\wedge} . \mathrm{UI}:=\mathrm{UI}$; \{teor de agua inicial no compartimento\}

H1^.UC:=UI; $\{$ teor de agua atual no compartimento\}

H1^.US:=US; \{teor de agua na saturacao no compartimento\}

$\mathrm{H} 1^{\wedge}$.UR:=UR; $\{$ teor de agua residual no compartimento\}

$\mathrm{H} 1^{\wedge} . \mathrm{CA}:=\mathrm{CA}$; coeficiente alfa de van Genuchten no compartimento\}

$\mathrm{H}^{\wedge} \mathrm{CM}:=\mathrm{CM}$; ;coeficiente $\mathrm{m}$ de van Genuchten no compartimento\}

$\mathrm{H}^{\wedge} . \mathrm{KS}:=\mathrm{KS}$; ; condutividade hidraulica saturada no compartimento

\{teor de agua calculado no potencial matricial $-150 \mathrm{~m}$ no compartimento\}

$\mathrm{H} 1^{\wedge}$. UL: $=\mathrm{H} 1^{\wedge} . \mathrm{UR}+\left(\mathrm{H} 1^{\wedge} . \mathrm{US}-\mathrm{H} 1^{\wedge}\right.$. UR $) / \mathrm{POW}\left(1+\mathrm{POW}\left(\mathrm{H} 1^{\wedge} . \mathrm{CA}^{*} \mathrm{PML}, 1 /\left(1-\mathrm{H} 1^{\wedge} . \mathrm{CM}\right)\right), \mathrm{H}^{\wedge} . \mathrm{CM}\right)$;

if $\left(\mathrm{Hl^{ \wedge }} . \mathrm{UC}<\mathrm{Hl^{ \wedge }}\right.$. UL) then begin

$\mathrm{H} 1^{\wedge} . \mathrm{PM}:=(\mathrm{PML}-\mathrm{PMS})^{*} \mathrm{H} 1^{\wedge} . \mathrm{UC} / \mathrm{H} 1^{\wedge} . \mathrm{UL}+\mathrm{PMS} ;$ \{potencial matricial atual no compartimento

$\mathrm{H}^{\wedge} . \mathrm{CH}:=0$; condutividade hidraulica atual no compartimento

end else begin

$\mathrm{UA}:=\left(\mathrm{H} 1^{\wedge} . \mathrm{UC}-\mathrm{H} 1^{\wedge} . \mathrm{UR}\right) /\left(\mathrm{H} 1^{\wedge}\right.$. US-H $\left.1^{\wedge} . \mathrm{UR}\right) ;$ teor de agua adimensional $\}$

\{potencial matricial atual no compartimento\}

$\mathrm{H} 1^{\wedge} . \mathrm{PM}:=\mathrm{POW}\left(\mathrm{POW}\left(1 / \mathrm{UA}, \mathrm{I} / \mathrm{H} 1^{\wedge} . \mathrm{CM}\right)-1,1-\mathrm{H} 1^{\wedge} . \mathrm{CM}\right) / \mathrm{H} 1^{\wedge} . \mathrm{CA}$;

\{condutividade hidraulica atual no compartimento\}

$\mathrm{H} 1^{\wedge} \cdot \mathrm{CH}:=\mathrm{H} 1^{\wedge} \cdot \mathrm{KS}^{*} \operatorname{sqt}(\mathrm{UA}) * \operatorname{sqr}\left(1-\mathrm{POW}\left(1-\mathrm{POW}\left(\mathrm{UA}, 1 / \mathrm{H} 1^{\wedge}, \mathrm{CM}\right), \mathrm{H} 1^{\wedge}, \mathrm{CM}\right)\right)$;

end:

$\mathrm{PH}[\mathrm{I}, \mathrm{J}]:=\mathrm{H} 1$;

end;

end:

until eof(ARQ):

close(ARQ);

\{entrada de dados do comportamento da lamina de agua sobre o sulco\}

assign(ARQ,NOMEARQ+'.ADL'); \{arquivo de dados da lamina de agua sobre o sulco\}

reset(ARQ);

readln(ARQ,TA); \{tempo total de presenca de agua no sulco\}

repeat

new $(L)$ :

readln( $\left.A R Q, L^{\wedge} \cdot T, L^{\wedge} . L\right) ;$; tempo e altura da lamina de agua $\}$

$\mathrm{L}^{\wedge} . \mathrm{N}:=\mathrm{PL}$;

PL: $=\mathrm{L}$ :

until eof(ARQ);

close(ARQ);

assign(ARQ,NOMEARQ+',ADC'); \{arquivo de dados de controle da simulacao\}

reset(ARQ);

readin(ARQ,TT); \{tempo total a simular\}

readin(ARQ, VL); \{ maior variacao no teor de agua permitida no laco\}

end; $\{$ DADOS_ENSAIO $\}$

function TV(A, V:real):real;

var

DU : real; \{variacao do teor de agua na unidade de tempo $(\mathrm{m} 3 / \mathrm{m} 3)$ \}

begin

$\mathrm{DU}:=\mathrm{KM}^{*} \mathrm{GH} * \mathrm{~A} /$; $\{$ variacao do teor de agua no tempo $\}$

if $(\operatorname{abs}(\mathrm{DU} * \mathrm{IC})>\mathrm{VL})$ then

$I C:=a b s(V L / D U) ;\{$ define valor para intervalo de tempo calculado $\}$

TV:=DU; \{taxa de variacao do teor de agua $\}$ 
end; \{TV\}

procedure LIMITE_ 1;

begin

$\mathrm{H1}:=\mathrm{PH}[\mathrm{I}, \mathrm{J}$; $\{$ acessa dados hidraulicos do compartimento $\mathrm{I}, \mathrm{J}\}$

$\mathrm{G} 1:=\mathrm{PG}[\mathrm{I}, \mathrm{J}]$; $\{$ acessa dados geometricos do compartimento $\mathrm{I}, \mathrm{J}\}$

if $(\mathrm{I}<\mathrm{NF})$ then begin

$\mathrm{H} 2:=\mathrm{PH}[\mathrm{I}+1, \mathrm{~J}] ;$ acessa dados hidraulicos do compartimento da esquerda $\}$

$\mathrm{G} 2:=\mathrm{PG}[\mathrm{H}+1, \mathrm{~J} ;$; acessa dados geometricos do compartimento da esquerda\}

$\mathrm{KM}:=\left(\mathrm{H} 1^{\wedge} \cdot \mathrm{CH}^{*} \mathrm{Gl}^{\wedge} \cdot \mathrm{L} 4+\mathrm{H} 2^{\wedge} \cdot \mathrm{CH}^{*} \mathrm{G} 2^{\wedge} \cdot \mathrm{L} 2\right) /\left(\mathrm{G} 1^{\wedge} \cdot \mathrm{L} 4+\mathrm{G} 2^{\wedge} \cdot \mathrm{L} 2\right)$; \{condutividade hidraulica media

$\mathrm{GH}:=\left(\left(\mathrm{H} 1^{\wedge} \cdot \mathrm{PM}+\mathrm{G} 1^{\wedge} \cdot \mathrm{BZ}\right)-\left(\mathrm{H} 2^{\wedge} \cdot \mathrm{PM}+\mathrm{G} 2^{\wedge} \cdot \mathrm{BZ}\right)\right) /\left(\mathrm{G} 1^{\wedge} \cdot \mathrm{L} 4+\mathrm{G} 2^{\wedge} \cdot \mathrm{L} 2\right)$; ; gradiente de potencial total\}

$\mathrm{H} 2^{\wedge} \cdot \mathrm{UC}:=\mathrm{H} 2^{\wedge} \cdot \mathrm{UC}+\mathrm{TV}\left(\mathrm{G} 2^{\wedge} \cdot \mathrm{A} 2, \mathrm{G} 2^{\wedge} \cdot \mathrm{VC}\right)^{*} \mathrm{TT}$; \{novo teor de agua no compartimento da esquerda\}

$\mathrm{H} 1^{\wedge} . \mathrm{UC}:=\mathrm{H} 1^{\wedge} . \mathrm{UC}-\mathrm{TV}\left(\mathrm{Gl}^{\wedge} . \mathrm{A} 4, \mathrm{G} 1^{\wedge} . \mathrm{VC}\right)^{*} \mathrm{IT}$; $\{$ novo teor de agua no compartimento considerado

end;

if $(\mathrm{J}<\mathrm{NC})$ then begin

$\mathrm{H} 2:=\mathrm{PH}[\mathrm{I}, \mathrm{J}+1]$; $\{$ acessa dados hidraulicos do compartimento inferior

$\mathrm{G} 2:=\mathrm{PG}[\mathrm{I}, \mathrm{J}+1\}$; \{acessa dados geometricos do compartimento inferior

$\mathrm{KM}:=\left(\mathrm{H} 1^{\wedge} \cdot \mathrm{CH} \mathrm{G}^{*} 1^{\wedge} \cdot \mathrm{L} 3+\mathrm{H} 2^{\wedge} \cdot \mathrm{CH} \mathrm{G}^{*} 2^{\wedge} \cdot \mathrm{L} 1\right) /\left(\mathrm{G} 1^{\wedge} \cdot \mathrm{L} 3+\mathrm{G} 2^{\wedge}, \mathrm{L} 1\right) ;$ condutividade hidraulica media $\}$

$\mathrm{GH}:=\left(\left(\mathrm{H} 1^{\wedge} \cdot \mathrm{PM}+\mathrm{G} 1^{\wedge} \cdot \mathrm{BZ}\right)-\left(\mathrm{H} 2^{\wedge} \cdot \mathrm{PM}+\mathrm{G} 2^{\wedge} \cdot \mathrm{BZ}\right)\right) /\left(\mathrm{G} 1^{\wedge} \cdot \mathrm{L} 3+\mathrm{G} 2^{\wedge} \cdot \mathrm{L} 1\right)$; gradiente de potencial total

$\mathrm{H} 2^{\wedge} . \mathrm{UC}:=\mathrm{H} 2^{\wedge} . \mathrm{UC}+\mathrm{TV}\left(\mathrm{G} 2^{\wedge} \cdot \mathrm{A} 1, \mathrm{G} 2^{\wedge} \cdot \mathrm{VC}\right)^{*} \mathrm{TT}$; \{ novo teor de agua no compartimento inferior

$\mathrm{H} 1^{\wedge} . \mathrm{UC}:=\mathrm{H} 1^{\wedge} . \mathrm{UC}-\mathrm{TV}\left(\mathrm{Gl}^{\wedge} . \mathrm{A} 3, \mathrm{G} 1^{\wedge} . \mathrm{VC}\right) * \mathrm{IT} ;$; novo teor de agua no compartimento considerado end:

end; \{LIMITE_1\}

procedure LIMITE_2;

var

$Z M$ : real; \{coordenada $\mathrm{z}$ no ponto medio de contato da agua com o compartimento (m)\}

YM : real; \{coordenada y no ponto medio de contato da agua com o compartimento $(\mathrm{m})$ \}

A1 : real; \{area de contato do compartimento com a agua por metro de sulco $(\mathrm{m} 2)\}$

DY : real: $\{$ variacao em y $(m)\}$

$\mathrm{DZ}$ : real; $\{$ variacao em $\mathrm{z}(\mathrm{m})\}$

$A C$ : real; \{coeficiente a da equacao do intervalo do contorno ajustado do sulco $(\mathrm{m})\}$

$\mathrm{BC}$ : real; \{coeficiente $\mathrm{b}$ da equacao do intervalo do contorno ajustado do sulco $(\mathrm{m} / \mathrm{m})$ \}

NA : real; \{maior altura do nivel de agua no sulco $(\mathrm{m})$ \}

AA : real; \{altura da lamina de agua no sulco no ponto considerado $(\mathrm{m})$ \}

Cl : MALHA;

begin

if (TS $>=$ TF) then begin

$\mathrm{TI}:=\mathrm{TF} ;$ \{tempo inferior no segmento para altura da lamina de agua no sulco\}

$\mathrm{LI}:=\mathrm{LF}$; \{lamina no inicio do intervalo de tempo

$L:=L^{\wedge} \cdot N$

$T F:=L^{\wedge} . T ;$ tempo superior no segmento para altura da lamina de agua no sulco\}

$\mathrm{LF}:=\mathrm{L}^{\wedge} . \mathrm{L} ;$; lamina no final do intervalo de tempo\}

end:

$\mathrm{NA}:=\mathrm{LI}+(\mathrm{LF}-\mathrm{LI})^{*}(\mathrm{TS}-\mathrm{TI}) /(\mathrm{TF}-\mathrm{TI})$; $\{$ maior altura do nivel de agua no sulco $\}$

$\mathrm{ZL}:=\mathrm{CF}+\mathrm{NA}+0.001 ;$ (coordenada $\mathrm{z}$ da superficie da lamina de agua no sulco\}

Cl. $\mathrm{Y}:=\mathrm{C}^{\wedge} . \mathrm{Y}$; coordenada y do vertice em contato com o sulco mais a direita\}

$C 1 . Z:=C^{\wedge} . Z ;$ \{coordenada $\mathrm{z}$ do vertice em contato com o sulco mais a direita\}

$\mathrm{C}:=\mathrm{C}^{\wedge} \cdot \mathrm{N} ;$ \{acessa coordenadas $(\mathrm{y}, \mathrm{Z})$ do proximo vertice em contato com o sulco mais a esquerda\}

if $(\mathrm{ZL}>=\mathrm{C} 1 . \mathrm{Z})$ and $\left(\mathrm{ZL}>=\mathrm{C}^{\wedge} . \mathrm{Z}\right)$ then begin compartimento totalmente molhado\}

$\mathrm{HI}:=\mathrm{PH}[1,1] ;$ \{acessa dados hidraulicos do compartimento junto ao sulco $\}$ 
$\mathrm{Gl}:=\mathrm{PG}[1,1] ;$ \{acessa dados geometricos do compartimento junto ao sulco\}

if $\left(\mathrm{H}^{\wedge} . \mathrm{UC}<\mathrm{H} 1^{\wedge}\right.$. US $)$ then begin

$\mathrm{ZM}:=\left(\mathrm{Cl} . \mathrm{Z}+\mathrm{C}^{\wedge} . \mathrm{Z}\right) / 2 ;$ \{coordenada $\mathrm{z}$ no ponto medio de contato da agua com o compartimento\}

$\mathrm{AA}:=\mathrm{ZL}-\mathrm{ZM}$; $\{$ altura da lamina de agua sobre o ponto medio de contato

$\mathrm{KM}:=\left(\mathrm{H} 1^{\wedge} \cdot \mathrm{CH}^{*} \mathrm{Gl}^{\wedge} \cdot \mathrm{L} 1+\mathrm{H}^{\wedge} \cdot \mathrm{KS}^{*} 0.001\right) /\left(\mathrm{G} 1^{\wedge} \cdot \mathrm{L} 1+0.001\right) ;$ condutividade hidraulica media\}

$\mathrm{GH}:=\left(\left(\mathrm{H} 1^{\wedge} \cdot \mathrm{PM}+\mathrm{G} 1^{\wedge} \cdot \mathrm{BZ}\right)-(\mathrm{AA}+\mathrm{ZM})\right) / \mathrm{G} 1^{\wedge} \cdot \mathrm{LI}$; \{gradiente de potencial total\}

$\mathrm{H} 1^{\wedge}, \mathrm{UC}:=\mathrm{H} 1^{\wedge} . \mathrm{UC}-\mathrm{TV}\left(\mathrm{G} 1^{\wedge}, \mathrm{Al}, \mathrm{G} 1^{\wedge} . \mathrm{VC}\right)^{*} \mathrm{IT} ;$; novo teor de agua no compartimento considerado

$\mathrm{VI}:=\mathrm{VI}-\mathrm{KM}^{*} \mathrm{GH}^{*} \mathrm{Gl}^{\wedge} . \mathrm{A} 1^{*} \mathrm{IT}$; \{volume acumulado de agua infiltrado por metro de sulco

$\mathrm{AM}:=\mathrm{AM}+\mathrm{Gl} \wedge . \mathrm{Al}$; \{acumula area molhada por metro de sulco\}

end;

end else if $(Z L>C 1 . Z)$ or $\left(Z L>C^{\wedge} . Z\right)$ then begin \{compartimento parcialmente molhado\}

\{coordenada y do ponto medio de contato da agua com o compartimento\}

$\mathrm{AC}:=\mathrm{C} 1 . \mathrm{Z}-\mathrm{Cl} 1 . \mathrm{Y}^{*}\left(\mathrm{C}^{\wedge} \cdot \mathrm{Z}-\mathrm{C} 1 . \mathrm{Z}\right) /\left(\mathrm{C}^{\wedge} \cdot \mathrm{Y}-\mathrm{Cl} . \mathrm{Y}\right)$;

$\mathrm{BC}:=\left(\mathrm{C}^{\wedge} . \mathrm{Z}-\mathrm{C} 1 . \mathrm{Z}\right) /\left(\mathrm{C}^{\wedge} \cdot \mathrm{Y}-\mathrm{Cl} \cdot \mathrm{Y}\right)$;

if $(Z \mathrm{~L}>\mathrm{C} 1 \mathrm{Z})$ then begin \{compartimentos mais a esquerda\}

$Z M:=(Z L+C 1 . Z) / 2 ;$ coordenada $\mathrm{Z}$ no ponto medio de contato da agua com o compartimento $\}$

$\mathrm{DZ}:=\mathrm{ZL}-\mathrm{Cl} . \mathrm{Z} ;\{$ variacao em $\mathrm{Z}\}$

$\mathrm{DY}:=(\mathrm{ZL}-\mathrm{AC}) / \mathrm{BC}-\mathrm{C} 1 \mathrm{Y} ;$ variacao em $\mathrm{y}\}$

end else begin \{compartimentos mais a direita\}

$\mathrm{ZM}:=\left(Z \mathrm{~L}+\mathrm{C}^{\wedge} \mathrm{Z}\right) / 2 ;$ coordenada $\mathrm{z}$ no ponto medio de contato da agua com o compartimento $\}$

$\mathrm{DZ}:=\mathrm{ZL}-\mathrm{C}^{\wedge} \cdot \mathrm{Z} ;$; variacao em $\left.\mathrm{Z}\right\}$

$\mathrm{DY}:=(\mathrm{ZL}-\mathrm{AC}) / \mathrm{BC}-\mathrm{C}^{\wedge} . \mathrm{Y} ;\{$ variacao em $\mathrm{y}\}$

end:

$\mathrm{YM}:=(\mathrm{ZM}-\mathrm{AC}) / \mathrm{BC}$; $\{$ coordenada y no ponto medio de contato da agua com o compartimento $\}$

$\mathrm{AA}:=\mathrm{ZL}-Z \mathrm{M}$; \{altura da lamina de agua sobre o ponto medio de contato\}

$\mathrm{Al}:=\mathrm{sqrt}(\mathrm{sqr}(\mathrm{DY})+\operatorname{sqr}(\mathrm{DZ})) ;\{$ area de contato do compartimento com a agua por metro de sulco $\}$

$\mathrm{H1}:=\mathrm{PH}[1,1]$; \{acessa dados hidraulicos do compartimento junto ao sulco

G1:=PG[1,1]; \{acessa dados geometricos do compartimento junto ao sulco\}

$\mathrm{KM}:=\left(\mathrm{H} 1^{\wedge} \cdot \mathrm{CH}^{*} \mathrm{G} 1^{\wedge} \cdot \mathrm{L} 1+\mathrm{H} 1^{\wedge} \cdot \mathrm{KS}^{*} 0.001\right) /\left(\mathrm{G} 1^{\wedge} \cdot \mathrm{L} 1+0.001\right)$; condutividade hidraulica media\}

$\mathrm{DY}:=\mathrm{G} \mathrm{I}^{\wedge} \mathrm{BY}-\mathrm{YM} ;\{$ variacao em $\mathrm{y}\}$

$\mathrm{DZ}:=\mathrm{G} 1^{\wedge} \cdot \mathrm{BZ}-\mathrm{ZM} ;\{$ variacao em $\mathrm{Z}\}$

$\mathrm{GH}:=\left(\left(\mathrm{H} 1^{\wedge} \cdot \mathrm{PM}+\mathrm{G} l^{\wedge} \cdot \mathrm{BZ}\right)-(\mathrm{AA}+\mathrm{ZM})\right) / \mathrm{sqrt}(\operatorname{sqr}(\mathrm{DY})+\operatorname{sqr}(\mathrm{DZ})) ;$ \{gradiente de potencial total\}

$\mathrm{H} 1^{\wedge} . \mathrm{UC}:=\mathrm{H} 1^{\wedge} . \mathrm{UC}-\mathrm{TV}\left(\mathrm{A} 1, \mathrm{G} 1^{\wedge} . \mathrm{VC}\right)^{*} \mathrm{IT} ;$;novo teor de agua no compartimento considerado\}

$\mathrm{VI}:=\mathrm{VI}-\mathrm{KM}^{*} \mathrm{GH} * \mathrm{Al} * \mathrm{IT}$; $\{$ volume acumulado de agua infiltrado por metro de sulco $\}$

$\mathrm{AM}:=\mathrm{AM}+\mathrm{Al} ;\{$ acumula area molhada por metro de sulco $\}$

end;

end; \{LIMITE_2\}

procedure SIMULA_TESTE;

var

CL : byte; numero de ordem do contorno limite\}

$\mathrm{CP}$ : byte; \{numero de ordem do contorno limite provisorio\}

$\mathrm{SU}$ : real; \{sobra de teor de agua no compartimento $(\mathrm{m} 3 / \mathrm{m} 3)$ \}

UA : real; \{teor de agua adimensional\}

VU : real; \{volume de agua transmitido em excesso $(\mathrm{m} 3)$ \}

NL : byte; \{numero de lacos\}

W : PTR_INFILTRA; \{aponta para dados de infiltracao de agua\}

PW : PTR_INFILTRA;

begin

IT: $=0 ;\{$ inicia com intervalo de tempo igual a $0 \mathrm{~s}\}$

TS: $=0$; zera tempo total simulado $\}$ 
$\mathrm{NL}:=0$; zera numero de lacos\}

$\mathrm{VI}:=0 ;\{$ zera volume acumulado de agua infiltrado por metro de sulco $\}$

$\mathrm{AM}:=0$; $\{$ zera area molhada por metro de sulco\}

$\mathrm{CP}:=2 ;$ inicia com contorno limite provisorio em 2$\}$

$\mathrm{CL}:=\mathrm{CP} ;\{$ assume contorno limite igual ao provisorio

$\mathrm{Tl}:=\mathrm{L}^{\wedge} \mathrm{T} ;\{$ tempo inferior no segmento para altura da lamina de agua no sulco $\}$

$\mathrm{LI}:=\mathrm{L}^{\wedge} . \mathrm{L} ;$; lamina no inicio do intervalo de tempo\}

$\mathrm{L}:=\mathrm{L}^{\wedge} \cdot \mathrm{N}$;

$\mathrm{TF}:=\mathrm{L}^{\wedge} \mathrm{T}$; $\{$ tempo superior no segmento para altura da lamina de agua no sulco\}

$\mathrm{LF}:=\mathrm{L}^{\wedge} . \mathrm{L} ;$ \{lamina no final do intervalo de tempo\}

PW: $=$ nil;

repeat

$\mathrm{C}:=\mathrm{PC}$ :

$\mathrm{IC}:=60 * 4 ;$ \{limita intervalo de tempo em 60 segundos\}

if (TS $<$ TA) then begin \{presenca de agua no sulco\}

$\operatorname{inc}(\mathrm{NL})$; $\{$ incrementa em 1 o numero de lacos\}

for $\mathrm{I}:=1$ to NF do

LIMITE_2; \{limite entre compartimentos e o sulco\}

if $(\mathrm{NL}=100)$ then begin

new $(W)$;

$\mathrm{W}^{\wedge} \cdot \mathrm{T}:=\mathrm{TS}+\mathrm{IT}$; guarda valor de tempo total simulado

$W^{\wedge} . A:=A M / 100$; guarda valor de area molhada media por metro de sulco em 100 lacos\}

$\mathrm{W}^{\wedge} . \mathrm{V}:=\mathrm{VI}$; $\{$ guarda volume acumulado de agua infiltrado por metro de sulco\}

$W^{\wedge} \cdot \mathrm{N}:=\mathrm{PW}$;

$\mathrm{PW}:=\mathrm{W}$;

$\mathrm{NL}:=0 ;$ zera numero de lacos\}

$\mathrm{AM}:=0 ;$ zera area molhada por metro de sulco $\}$ end;

end:

for $I:=1$ to NF do

for $J:=1$ to $C L$ do

LIMITE 1; \{limite entre compartimentos interiores\}

$\mathrm{TS}:=\mathrm{TS}+\mathrm{IT}$; $\{$ acumula tempo total simulado $\}$

IT: $=\mathrm{IC} / 4$; assume $1 / 4$ do valor de intervalo de tempo calculado para intervalo de tempo\}

for $\mathrm{I}:=1$ to $\mathrm{NF}$ do

for $J:=1$ to $C L$ do begin

G1:=PGII,J]; \{acessa dados geometricos do compartimento I, $J$ \}

$\mathrm{H1}:=\mathrm{PHII,J;}\{$ acessa dados hidraulicos do compartimento I,J\}

if $\left(\mathrm{H} 1^{\wedge}\right.$.UC $>\mathrm{H} 1^{\wedge}$.US) then begin \{teor de agua no compartimento I, $\mathrm{I}$ alem da saturacao\}

if $(\mathrm{J}<\mathrm{NC})$ then begin

$\mathrm{VU}:=\left(\mathrm{HI}^{\wedge} . \mathrm{UC}-\mathrm{HI}^{\wedge} . \mathrm{US}\right)^{*} \mathrm{GI}^{\wedge}, \mathrm{VC} ;\{$ volume de agua transmitida em excesso $\}$

$\mathrm{G} 2:=\mathrm{PG}[1, \mathrm{~J}+1\}$; \{acessa dados geometricos do compartimento posterior\}

$\mathrm{H} 2:=\mathrm{PH}[1, \mathrm{~J}+1]$; acessa dados hidraulicos do compartimento posterior

$\mathrm{H} 2^{\wedge} . \mathrm{UC}^{\prime}=\mathrm{H} 2^{\wedge} . \mathrm{UC}+\mathrm{VU} / \mathrm{G}^{\wedge} . \mathrm{VC}$; \{transfere excesso de agua para o compartimento posterior\} end:

$\mathrm{H} 1^{\wedge} . \mathrm{UC}:=\mathrm{H} 1^{\wedge}$.US; \{compartimento $\mathrm{I}, \mathrm{J}$ com teor de agua na saturacao

end;

\{novo potencial matricial e condutividade hidraulica no compartimento $1, J$ \}

if $\left(\mathrm{H} 1^{\wedge}\right.$. UC $<\mathrm{H} 1^{\wedge}$. UL $)$ then begin

$\mathrm{H} 1^{\wedge} . \mathrm{PM}:=(\mathrm{PML}-\mathrm{PMS})^{*} \mathrm{HI}^{\wedge} . \mathrm{UC} / \mathrm{HI}^{\wedge} . \mathrm{UL}+\mathrm{PMS} ;$ potencial matricial atual no compartimento $\left.\mathrm{IJ}\right\}$

$\mathrm{H} 1^{\wedge} . \mathrm{CH}:=0$; condutividade hidraulica atual no compartimento $\left.I, J\right\}$ 
end else begin

$\mathrm{UA}:=\left(\mathrm{H} 1^{\wedge} . \mathrm{UC}-\mathrm{H} 1^{\wedge} . \mathrm{UR}\right) /\left(\mathrm{H} 1^{\wedge}, \mathrm{US}-\mathrm{H} 1^{\wedge}\right.$.UR $) ;$ \{teor de agua adimensional $\}$

\{potencial matricial atual no compartimento $I, I\}$

$\mathrm{H} 1^{\wedge} . \mathrm{PM}:=\mathrm{POW}\left(\mathrm{POW}\left(1 / \mathrm{UA}, 1 / \mathrm{H} 1^{\wedge} . \mathrm{CM}\right)-1,1-\mathrm{H} 1^{\wedge} . \mathrm{CM}\right) / \mathrm{H} 1^{\wedge} . \mathrm{CA}$;

\{condutividade hidraulica atual no compartimento $I, J\}$

$\mathrm{H}^{\wedge} . \mathrm{CH}:=\mathrm{H1}^{\wedge} \cdot \mathrm{KS}^{*} \operatorname{sqrt}(\mathrm{UA}){ }^{*} \operatorname{sqr}\left(1-\mathrm{POW}\left(1-\mathrm{POW}\left(\mathrm{UA}, 1 / \mathrm{H} 1^{\wedge} . \mathrm{CM}\right), \mathrm{H} 1^{\wedge} . \mathrm{CM}\right)\right.$ );

end:

if $(\mathrm{J}=\mathrm{CL})$ and $\left(\mathrm{H1^{ \wedge }} \cdot \mathrm{UC}-\mathrm{H} 1^{\wedge} . \mathrm{UI}>=0.01\right)$ then

$\mathrm{CP}:=\mathrm{CL}+1$; \{abaixa contorno limite provisorio

end;

if $(\mathrm{CP}>\mathrm{CL})$ and $(\mathrm{CL}<\mathrm{NC})$ then

$\mathrm{CL}:=\mathrm{CP} ;$ contorno limite atualizado $\}$

gotoxy $(1,21)$;

write('TS $=$ ', TS: 10:3);

until (keypressed) or (TS $>$ TT); ; condicao de fim de simulacao

assign(ARQ,NOMEARQ+'. INF'); \{arquivo para dados de infiltracao\}

rewrite(ARQ);

writeln(ARQ,'tempo simulado (s), area molhada $(\mathrm{m} 2 / \mathrm{m})$ e volume de agua infiltrado $(\mathrm{m} 3 / \mathrm{m})$ ');

$\mathrm{W}:=\mathrm{PW}$ :

while $(\mathrm{W}<>$ nil) do begin

$\mathrm{PW}:=\mathrm{W}^{\wedge} \cdot \mathrm{N}$;

\{grava tempo simulado, area molhada media e volume acumulado de agua infiltrada por metro\}

writeln(ARQ, $\left.W^{\wedge} . T,{ }^{\prime}, W^{\wedge} . A,,^{\prime}, W^{\wedge} . V\right)$;

$\mathrm{W}:=\mathrm{PW}$;

end;

close(ARQ):

assign(ARQ,NOMEARQ+'.SCR'); \{arquivo script para desenho do perfil\}

append(ARQ);

writeln(ARQ,'LAYER M TEORAGUA C RED');

writeln(ARQ):

writeln(ARQ):

for $\mathrm{I}:=1$ to $\mathrm{NF}$ do

for $\mathrm{J}:=1$ to $\mathrm{NC}$ do begin

$\mathrm{G1}:=\mathrm{PG}[\mathrm{I}, \mathrm{J} ;$; acessa dados geometricos do compartimento $\mathrm{IJ}\}$

$\mathrm{HI}:=\mathrm{PH}[\mathrm{I}, \mathrm{J}]$; $\{$ acessa dados hidraulicos do compartimento $\mathrm{I}, \mathrm{J}\}$

write(ARQ,'POINT ');

\{grava coordenada $(\mathrm{y}, \mathrm{z})$ do baricentro e respectivo teor de agua do compartimento $I, J$ \}

writeln(ARQ,GI^.BY:5:3,',',G1^.BZ:5:3,','H1^.UC:6:4);

end:

writeln(ARQ,'ZOOM E');

close(ARQ);

end; \{SIMULA_TESTE\}

begin

clrscr;

DADOS_ENSAIO;

gettime(HO,MI,SE,CE);

SIMULA TESTE:

assign(ARQ,NOMEARQ+'.RES'); \{arquivo para dados resumo\}

rewrite(ARQ);

writeln(ARQ,'identificacao do teste: ',NOMEARQ); 
writeln(ARQ,'numero de linhas radiais: ',LR);

writeln(ARQ,'numero de linhas de contorno: ',LC);

writeln(ARQ,'variacao permitida no teor de agua no laco: ',VL:6:4);

writeln(ARQ,'tempo total simulado: ', TS:6:0);

writeln(ARQ,'volume total de agua infiltrado (m3/m): ',VI:6:4);

writeln(ARQ, 'horario ao inicio da simulacao: ',HO,':, MI,',', SE, ', CE);

gettime(HO,MI,SE,CE);

writeln(ARQ, 'horario ao final da simulacao: ',HO, ',',MI,:', SE, ', CE); close(ARQ):

end. 
Anexo 2. Exemplo de arquivo de entrada de dados de perfil (extensão ADP).

10

10

1.00

$-0.170 .000$

$-0.16-0.021$

$-0.15-0.030$

$-0.14-0.037$

$-0.13-0.043$

$-0.12-0.053$

$-0.11-0.061$

$-0.10-0.071$

$-0.09-0.081$

$-0.08-0.090$

$-0.07-0.099$

$-0.06-0.106$

$-0.05-0.111$

$-0.04-0.114$

$-0.03-0.118$

$-0.02-0.120$

$-0.01-0.122$

$0.00-0.123$

$0.01-0.123$

$0.02-0.122$

$0.03-0.119$

$0.04-0.113$

$0.05-0.108$

$0.06-0.102$

$0.07-0.096$

$0.08-0.090$

$0.09-0.085$

$0.10-0.081$

$0.11-0.075$

$0.12-0.065$

$0.13-0.049$

$0.14-0.033$

$0.15-0.016$

$0.16-0.006$

0.170 .000
* numero de linhas radiais

* numero de linhas de contorno

* profundidade do perfil de solo $(\mathrm{m})$

* posicao horizontal da esquerda para direita vista de jusante para montante e respectiva profundidade do sulco 
Anexo 3. Exemplo de arquivo de dados de entrada de solo (extensão ADS).

0.10

0.20

0.2515

0.5847

0.2976

$-2.9484$

0.3398

$2.04 \mathrm{E}-5$

0.30

0.20

0.3267

0.5394

0.3020

$-2.5962$

0.3282

2.10E-5

0.50

0.20

0.3280

0.5521

0.3238

$-7.6387$

0.3113

3.23E-5

0.70

0.20

0.3158

0.5309

0.3114

$-3.5955$

0.3209

3. $03 \mathrm{E}-5$

0.90

0.20

0.2987

0.5318

0.2776

$-5.5825$

0.3762

4.94E-5
* profundidade media na camada (m)

* espessura da camada (m)

* teor de agua inicial no solo da camada $(\mathrm{m} 3 / \mathrm{m} 3)$

* teor de agua na saturacao da camada $(\mathrm{m} 3 / \mathrm{m} 3)$

* teor de agua residual na camada $(\mathrm{m} 3 / \mathrm{m} 3)$

* coeficiente alfa da camada $(1 / \mathrm{m})$

* coeficiente m da camada (adimensional)

* condutividade hidraulica saturada da camada $(\mathrm{m} / \mathrm{s})$

* profundidade media na camada (m)

* espessura da camada (m)

* teor de agua inicial no solo da camada $(\mathrm{m} 3 / \mathrm{m} 3)$

* teor de agua na saturacao da camada $(\mathrm{m} 3 / \mathrm{m} 3)$

* teor de agua residual na camada $(\mathrm{m} 3 / \mathrm{m} 3)$

* coeficiente alfa da camada $(1 / \mathrm{m})$

* coeficiente $m$ da camada (adimensional)

* condutividade hidraulica saturada da camada $(\mathrm{m} / \mathrm{s})$

* profundidade media na camada (m)

* espessura da camada (m)

* teor de agua inicial no solo da camada (m3/m3)

* teor de agua na saturacao da camada $(\mathrm{m} 3 / \mathrm{m} 3)$

* teor de agua residual na camada $(\mathrm{m} 3 / \mathrm{m} 3)$

* coeficiente alfa da camada $(1 / \mathrm{m})$

* coeficiente $m$ da camada (adimensional)

* condutividade hidraulica saturada da camada $(\mathrm{m} / \mathrm{s})$

* profundidade media na camada $(\mathrm{m})$

* espessura da camada (m)

* teor de agua inicial no solo da camada $(\mathrm{m} 3 / \mathrm{m} 3)$

* teor de agua na saturacao da camada $(\mathrm{m} 3 / \mathrm{m} 3)$

* teor de agua residual na camada $(\mathrm{m} 3 / \mathrm{m} 3)$

* coeficiente alfa da camada $(1 / \mathrm{m})$

* coeficiente $\mathrm{m}$ da camada (adimensional)

* condutividade hidraulica saturada da camada $(\mathrm{m} / \mathrm{s})$

* profundidade media na camada $(\mathrm{m})$

* espessura da camada (m)

* teor de agua inicial no solo da camada $(\mathrm{m} 3 / \mathrm{m} 3)$

* teor de agua na saturacao da camada $(\mathrm{m} 3 / \mathrm{m} 3)$

* teor de agua residual na camada $(\mathrm{m} 3 / \mathrm{m} 3)$

* coeficiente alfa da camada $(1 / \mathrm{m})$

* coeficiente $\mathrm{m}$ da camada (adimensional)

* condutividade hidraulica saturada da camada $(\mathrm{m} / \mathrm{s})$ 
Anexo 4. Exemplo de arquivo de dados de entrada de lâmina (extensão ADL).

2640

26400.000

26100.006

25800.010

25500.013

25200.015

24900.018

24600.020

24300.022

24000.025

23700.027

23400.031

23100.034

22800.036

22500.039

22200.042

21900.046

21600.048

21300.050

21000.053

20700.054

20400.057

20100.059

19800.061

19500.065

19200.068

18900.070

18600.072

18300.074

18000.078

17700.080

17400.083

17100.084

16800.087

16500.091

16200.093

15900.094

15600.096

15300.095

15000.095

14700.095

14400.095

14100.095
* tempo total de presenca de agua no sulco (s)

* tempo (s) e altura da lamina de agua (m) instantaneos (final da aplicacao para o inicio) 
13800.095

13500.093

13200.093

12900.091

12600.090

12300.090

12000.090

11700.090

11400.090

11100.090

10800.089

10500.089

10200.089

9900.090

9600.090

9300.092

9000.092

8700.093

8400.094

8100.095

7800.095

7500.095

7200.095

6900.094

6600.092

6300.090

6000.089

5700.089

5400.089

5100.088

4800,085

$450 \quad 0.082$

4200.081

3900.078

3600.075

3300.072

3000.069

2700.065

2400.062

2100.057

1800.051

1500.047

1200.040

900.035

600.031 
300.025

00.000

Anexo 5. Exemplo de arquivo de dados de entrada de controle (extensão ADC).

86400

0.001

* tempo total a simular (s)

* maior variacao no teor de agua permitida no laco $(\mathrm{m} 3 / \mathrm{m} 3)$

Anexo 6. Exemplo de arquivo de dados de saida de compartimentos e teor de água (extensão SCR).

\section{LAYER M CELULA C GREEN}

LINE $0.170,0.0000 .131,-0.0480 .149,-0.0540 .190,0.000 \mathrm{C}$ LINE $0.190,0.0000 .149,-0.0540 .186,-0.0680 .229,0.000 \mathrm{C}$ LINE $0.229,0.000 \quad 0.186,-0.068 \quad 0.241,-0.0880 .287,0.000 \mathrm{C}$ LINE $0.287,0.0000 .241,-0.0880 .314,-0.1140 .365,0.000 \mathrm{C}$ LINE $0.365,0.000 \quad 0.314,-0.1140 .406,-0.1480 .463,0.000 \mathrm{C}$

LINE $-0.402,-0.146-0.463,-0.000-0.580,-0.000-0.512,-0.186 \mathrm{C}$ LINE $-0.512,-0.186-0.580,-0.000-0.717,-0.000-0.640,-0.233 \mathrm{C}$ LINE $-0.640,-0.233-0.717,-0.000-0.873,-0.000-0.787,-0.287 \mathrm{C}$ LINE $-0.787,-0.287-0.873,-0.000-1.048,-0.000-0.952,-0.347 \mathrm{C}$ LAYER M TEORAGUA C RED

POINT $0.159,-0.026,0.4235$

POINT $-0.234,-0.039,0.4203$

POINT $-0.301,-0.051,0.4129$

POINT $-0.387,-0.066,0.3929$

POINT $-0.491,-0.085,0.3542$

POINT $-0.614,-0.106,0.3135$

POINT $-0.756,-0.131,0.2554$

POINT $-0.918,-0.160,0.2515$ ZOOM E 
Anexo 7. Exemplo de arquivo de dados de saida de infiltração (extensão INF).

tempo simulado (s), area molhada $(\mathrm{m} 2 / \mathrm{m})$ e volume de agua infiltrado $(\mathrm{m} 3 / \mathrm{m})$ $2.63637768301740 \mathrm{E}+0003 \quad 5.49097090505484 \mathrm{E}-0002 \quad 7.07040430355619 \mathrm{E}-0002$ $2.61971543754265 \mathrm{E}+0003 \quad 7.13911640829110 \mathrm{E}-0002 \quad 7.06767125781198 \mathrm{E}-0002$ $2.60367719771340 \mathrm{E}+0003 \quad 7.49003520893439 \mathrm{E}-0002 \quad 7.06417197932296 \mathrm{E}-0002$ $2.58868977094069 \mathrm{E}+0003 \quad 7.69115407538266 \mathrm{E}-0002 \quad 7.06042508069231 \mathrm{E}-0002$ $2.57334966516495 \mathrm{E}+0003 \quad 8.03670684849749 \mathrm{E}-0002 \quad 7.05614628431022 \mathrm{E}-0002$ $2.55722821073979 \mathrm{E}+0003 \quad 8.80776208285852 \mathrm{E}-0002 \quad 7.05112975207385 \mathrm{E}-0002$ $2.54224072135985 \mathrm{E}+0003 \quad 9.33408958622977 \mathrm{E}-0002 \quad 7.04596941982345 \mathrm{E}-0002$ $2.52818918436393 \mathrm{E}+0003 \quad 9.81492966661790 \mathrm{E}-0002 \quad 7.04084184461635 \mathrm{E}-0002$ $2.51490648372099 \mathrm{E}+0003 \quad 1.00107132320886 \mathrm{E}-0001 \quad 7.03573902059134 \mathrm{E}-0002$ $2.50240301582217 \mathrm{E}+0003 \quad 9.91624158364175 \mathrm{E}-0002 \quad 7.03067570433404 \mathrm{E}-0002$ $2.49068970168009 \mathrm{E}+0003 \quad 9.35146463244791 \mathrm{E}-0002 \quad 7.02572315764201 \mathrm{E}-0002$ $2.47942372363433 \mathrm{E}+0003 \quad 9.28527116660689 \mathrm{E}-0002 \quad 7.02099820756530 \mathrm{E}-0002$ $2.46848706064001 \mathrm{E}+0003 \quad 9.37827299596847 \mathrm{E}-0002 \quad 7.01635792112256 \mathrm{E}-0002$ $2.45757170319557 \mathrm{E}+0003 \quad 7.74719769868852 \mathrm{E}-0002 \quad 7.01165129023593 \mathrm{E}-0002$ $2.44307054044306 \mathrm{E}+0003 \quad 8.10690308229596 \mathrm{E}-0002 \quad 7.00484632898224 \mathrm{E}-0002$ $2.42821310705692 \mathrm{E}+0003 \quad 8.58652777683346 \mathrm{E}-0002 \quad 6.99737560510130 \mathrm{E}-0002$ $2.41314516685158 \mathrm{E}+0003 \quad 9.13438823870365 \mathrm{E}-0002 \quad 6.98915859352383 \mathrm{E}-0002$ $2.39823419095948 \mathrm{E}+0003 \quad 9.56714591922037 \mathrm{E}-0002 \quad 6.98034762451698 \mathrm{E}-0002$

$1.44839260893496 \mathrm{E}+0001 \quad 1.01839567888874 \mathrm{E}-0001 \quad 7.24364364099728 \mathrm{E}-0004$ $1.31367534072633 \mathrm{E}+0001 \quad 9.57294369156898 \mathrm{E}-0002 \quad 6.72606951222399 \mathrm{E}-0004$ $1.16297181630798 \mathrm{E}+0001 \quad 8.87506497808772 \mathrm{E}-0002 \quad 6.17692580467732 \mathrm{E}-0004$ $9.87929731096665 \mathrm{E}+0000 \quad 8.12973130789487 \mathrm{E}-0002 \quad 5.56819315038481 \mathrm{E}-0004$ $8.25986996707798 \mathrm{E}+0000 \quad 7.49296926435363 \mathrm{E}-0002 \quad 5.01490889912581 \mathrm{E}-0004$ $6.88711634457286 \mathrm{E}+0000 \quad 6.93614450619862 \mathrm{E}-0002 \quad 4.54652538383282 \mathrm{E}-0004$ $5.65574702689628 \mathrm{E}+0000 \quad 6.42846295584150 \mathrm{E}-0002 \quad 4.12018862291585 \mathrm{E}-0004$ $4.51771644625114 \mathrm{E}+0000 \quad 5.95487234929237 \mathrm{E}-0002 \quad 3.71373580457579 \mathrm{E}-0004$ $3.44785355010754 \mathrm{E}+0000 \quad 5.50776246681153 \mathrm{E}-0002 \quad 3.31385946557905 \mathrm{E}-0004$ $2.43623983164434 \mathrm{E}+0000 \quad 5.08983667826897 \mathrm{E}-0002 \quad 2.91138957523085 \mathrm{E}-0004$ $1.51480714872014 \mathrm{E}+0000 \quad 4.78199618530653 \mathrm{E}-0002 \quad 2.50543777098766 \mathrm{E}-0004$ $1.13034151115062 \mathrm{E}+0000 \quad 4.71408748164777 \mathrm{E}-0002 \quad 2.17870410015530 \mathrm{E}-0004$ $1.04301808474156 \mathrm{E}+0000 \quad 4.55843711199009 \mathrm{E}-0002 \quad 1.92226257356154 \mathrm{E}-0004$ $7.09476090506541 \mathrm{E}-0001 \quad 3.58811719110577 \mathrm{E}-0002 \quad 1.63081719817271 \mathrm{E}-0004$ $2.42966381201086 \mathrm{E}-0001 \quad 2.83129742387302 \mathrm{E}-0002 \quad 1.34233124514660 \mathrm{E}-0004$ $2.87877533607457 \mathrm{E}-0002 \quad 2.63210737304291 \mathrm{E}-0002 \quad 1.04277690863186 \mathrm{E}-0004$ $8.55242326797168 \mathrm{E}-0003 \quad 2.60623729633096 \mathrm{E}-0002 \quad 7.75452876379257 \mathrm{E}-0005$ $1.46979132239800 \mathrm{E}-0003 \quad 2.59883823274265 \mathrm{E}-0002 \quad 4.87328557320366 \mathrm{E}-0005$ $4.41576415372680 \mathrm{E}-0004 \quad 2.59743104903691 \mathrm{E}-0002 \quad 2.33571186359360 \mathrm{E}-0005$ 
Anexo 8. Exemplo de arquivo de dados de saida resumo (extensão RES).

identificacao do teste: ENSAIO1

numero de linhas radiais: 10

numero de linhas de contorno: 10

variacao permitida no teor de agua no laco: 0.0010

tempo total simulado: 86419

volume total de agua infiltrado $(\mathrm{m} 3 / \mathrm{m}): 0.0707$

horario ao inicio da simulacao: $23: 19: 5.37$

horario ao final da simulacao: $23: 28: 48.74$ 